\title{
ASSESSMENT OF FLAGELLATE DIVERSITY AT DEEP-SEA HYDROTHERMAL VENTS USING THE COMBINED APPROACH OF CULTURE-DEPENDENT AND CULTURE-INDEPENDENT METHODS
}

By

Michael S. Atkins

B.A., University of California, Santa Cruz, 1993

Submitted in partial fulfillment of the requirements for the degree of

Doctor of Philosophy

at the

MASSACHUSETTS INSTITUTE OF TECHNOLOGY

and the

WOODS HOLE OCEANOGRAPHIC INSTITUTION

May 2000

(C) 2000 Michael S. Atkins

All rights reserved.

The author hereby grants to MIT and WHOI permission to reproduce paper and electronic copies of this thesis in whole or in part and to distribute them publicly.

Signature of

Author

Joint Program in Biological Oceanography

Massachusetts Institute of Technology

and Woods Hole Oceanographic Institution

May 2000

Certified by

Craig B. Taylor

Thesis Co-supervisor
Andreas P. Teske

Thesis Co-supervisor

Accepted

by

Mark E. Hahn

Chair, Joint Committee for Biological Oceanography.

Woods Hole Oceanographic Institution 


\section{Table of Contents}

$\begin{array}{ll}\text { Abstract } & 9\end{array}$

Chapter 1 General Introduction $\quad 11$

Description of Deep-Sea Hydrothermal Vents 16

$\begin{array}{ll}\text { Outline of the Dissertation } & 17\end{array}$

Part I Culturing and Molecular Analysis 25

Chapter $2 \quad$ A survey of flagellate diversity at four deep-sea hydrothermal . 27

vents in the Eastern Pacific Ocean using structural and molecular

approaches

Chapter 3 Ancyromonadida: a new phylogenetic lineage among the proto-

63 zoa closely related to the common ancestor of Metazoans, Fungi, and Choanoflagellates (Opisthokonta)

Chapter 4 Detection and distribution patterns of kinetoplastid flagellates at deep-sea hydrothermal vents as determined by culturing and denaturing gradient gel electrophoresis

Part II Physiological Experiments

Chapter $5 \quad$ Effect of hydrostatic pressure on the growth rates and encystment of flagellated protozoa isolated from a deep-sea hydrothermal vent and a deep shelf region

Chapter 6 Tolerance of flagellated protozoa to extreme environmental conditions potentially encountered at deep-sea hydrothermal vents:

I. High sulfide; II. High concentrations of $\mathrm{Cu}, \mathrm{Fe}, \mathrm{Mn}$, and $\mathrm{Zn}$

$\begin{array}{lll}\text { Chapter } 7 & \text { General Conclusions } & 207\end{array}$

Abbreviations and Acronyms 218

Contributions to publications presented in this dissertation 221

Acknowledgements 222 
For Mom and Dad 
Mon âme éternelle, Observe ton voeu,

Malgré le nuit seule

My eternal soul,

Et le jour en feu.

Redeem your promise,

In spite of the night alone And the day on fire.

A. Rimbaud 


\title{
ASSESSMENT OF FLAGELLATE DIVERSITY AT DEEP-SEA HYDROTHERMAL VENTS USING THE COMBINED APPROACH OF CULTURE-DEPENDENT AND CULTURE-INDEPENDENT METHODS
}

\author{
By \\ Michael S. Atkins \\ Submitted in partial fulfillment of the requirements for the degree of \\ Doctor of Philosophy
}

\begin{abstract}
Eighteen strains of flagellated protists representing 9 species were isolated and cultured from four deep-sea hydrothermal vents in the Eastern Pacific Ocean: Juan de Fuca Ridge, Guaymas Basin, and both $21^{\circ} \mathrm{N}$ and $9^{\circ} \mathrm{N}$ on the East Pacific Rise (EPR). The hydrothermal vent flagellates belonged to six different taxonomic orders: the Ancyromonadida, Bicosoecida, Cercomonadida, Choanoflagellida, Chrysomonadida, and Kinetoplastida. Molecular and ultrastructural evidence point to one of the isolates, Ancyromonas, as a plausible candidate for the closest relative to the common ancestor of Metazoans, Fungi, and Choanoflagellates (the Opisthokonta). Using 18S rDNA sequences from most of the major eukaryotic lineages, maximum likelihood, minimum evolution and maximum parsimony analyses yielded congruent phylogenies supporting this hypothesis.

Deep-sea vent samples were both cultured to select for kinetoplastid flagellates and analyzed without culturing by denaturing gradient gel electrophoresis (DGGE) using PCR primers specific to the kinetoplastid clade. By comparing these two different methods of analysis, my goal was to decrease the biases and/or errors inherent in either method alone and to improve our ability to assess flagellate diversity and distribution in samples from remote vent environments. PCR and DGGE were used to specifically isolate and amplify target DNA's from all cultured kinetoplastid species in matching vent samples, thus corroborating the findings of culturing. Molecular methods had the additional ability to detect species presence where culturing did not, thereby providing a better indication of the distribution of these species.

Many of the vent isolates were ubiquitous members of marine, freshwater, and terrestrial ecosystems worldwide, suggesting a global distribution of these flagellate species. This discovery advanced the hypothesis that ubiquity in distribution patterns among heterotrophic flagellates implies high tolerance and/or adaptability to a wide range of environmental conditions. Experiments under vent conditions of high pressure and high concentrations of metals and sulfide showed that some of these species are very tolerant to extreme environmental conditions.
\end{abstract}


Chapter 1

General introduction 
Culture-Dependent and Culture-Independent Methods of Assessing Diversity. One of the greatest challenges facing ecologists today is identification and quantification of the enormous number of species inhabiting the global ecosystem. Estimates of global biodiversity range from 10 to 100 million species yet only a fraction of these - 1 to 2 million - have actually been identified (Colwell 1994; Wilson 1988). Microbial organisms are expected to make up the vast majority of these estimated numbers. The number of parasitic/symbiotic microorganisms alone that are associated with fewer numbers of host species underscores this expectation. Microorganisms remain the most difficult organisms to identify and quantify because they typically have had to be cultured to be studied. However, the vast majority of microorganisms are not amenable to laboratory cultivation and so have gone unrecognized. This is due in part to the metabolic diversity and range of environmental requirements needed to culture every microorganism; Nature cultures everything, but we are unable to imitate Nature's complexity. To address this limitation, contemporary microbiologists complement culturing with molecular biological techniques to improve our understanding of microbial species richness, abundance and distribution in addition to classical culturedependent studies of behavior and physiology. This two-pronged approach to probing microbial diversity has successfully been applied to the study of prokaryotic organisms encompassing a wide range of phyla from a diversity of environments (Brinkhoff and Muyzer 1997; DeLong 1991; DeLong et al. 1989; Muyzer et al. 1996; Muyzer and Smalla 1998; Teske et al. 1996a; Teske et al. 1996b).

In this research, I have used a similar approach to assess the diversity and ecological role of flagellated protozoa in a complex, extreme environment: the deep-sea hydrothermal vent. Prior to this work essentially nothing was known about the diversity, distribution, abundance and activity of flagellates at vents. The combined use of microbiological and molecular biological techniques to examine these ecological parameters at vent sites represents a new area of research in the field of protozoology, namely assessment of flagellate 
diversity in extreme and very remote environments. Flagellates were chosen for this study because of their importance in microbial and biogeochemical processes. Protozoa in general constitute a very large and diverse group of microorganisms, second only to bacteria in abundance and cytological diversity (Patterson 1999). Like bacteria, they have important ecological roles in the decomposition of matter and in the process of nutrient recycling. Protozoan organisms also are capable of consuming other, smaller organisms, such as bacteria, making the energy and nutrients incorporated by these prey available to larger consumers. This pivotal role in the 'microbial food web' has made the study of protozoan diversity and physiology very important and the lack of knowledge about protists from vent environments makes the information obtained by vent research more important still.

Culture-dependent techniques - enrichment, isolation and culturing - were used to isolate and identify several species of vent flagellates. These isolates later were used in physiological experiments to measure the effects of extreme physical and chemical conditions on growth and survival. Physiological experiments allow researchers to see how organisms function in their environmental niche and tolerate such extreme conditions. From cultured flagellates and related species in molecular databases, clade-specific primers were developed to target sites encompassing a 400 base-pair portion of the $18 \mathrm{~S}$ small subunit ribosomal RNA gene. These DNA fragments were then PCR-amplified from uncultured environmental samples and analyzed using Denaturing Gradient Gel Electrophoresis (DGGE) technology. Molecular analysis of well-preserved environmental samples allows researchers to search for specific, uncultured phylotypes and compare diversity and distribution results with those isolates obtained by culturing. In this way, the combined approach of culturedependent and culture-independent methods provides an improvement in diversity assessment over either method used individually. 
Flagellated Protozoa. The term protozoa cannot easily be defined because protists are diverse and are often only distantly related to each other. Although the domain has been expanded to include life-history stages of macroalgae, protozoa are best described as unicellular or microbial eukaryotes. Some distinguish protozoans as heterotrophic, yet this is an inadequate description because a large number of protists are mixotrophic, capable of both heterotrophy and photosynthesis. Protozoan communities typically are comprised of a diversity of flagellates, ciliates, and amoebae capable of heterotrophic nutrition, whether or not they contain chloroplasts. Some heterotrophic protists evolved prior to the emergence of photosynthesis; others evolved from photosynthetic protists by loss of their chloroplasts. The protozoan state has been achieved independently in many different lines of evolution. To suggest that protozoan evolution is simply paraphyletic is an understatement; measured in molecular terms, two protozoa may have less in common than do a plant and an animal. Therefore, it is difficult to make generalizations about this large and diverse group of organisms.

This work focuses on one specific subgroup within the protozoa, the flagellates. There have been described over 70 lineages of protozoa, with 40 lineages of flagellates (Patterson 1999). Flagellates therefore dominate the high level diversity of eukaryotes. Flagellates typically occur at concentrations of about $10^{2}-10^{5}$ cells $/ \mathrm{ml}$. Flagellate communities are dynamic with numbers of cells changing rapidly by cell division, encystment and excystment. Changes in cell numbers result from community responses to changing physical and chemical characteristics of the environment, suggesting that the diversity and occurrence patterns of particular species may be used as indicators of specific or changing environmental conditions. Flagellate communities typically contain dominant species with competitive advantage under particular conditions and frequently-occurring or cosmopolitan species have been described from many diverse environments around the globe. 
Description of Deep-Sea Hydrothermal Vents. The discovery of abundant life at deep-sea hydrothermal vents (Lonsdale 1977) launched a substantial amount of research into the physical, chemical and biological features of vents which permit these complex and diverse ecosystems to thrive at such extremes. In subsequent years, it was determined that hydrothermal vents are comprised of some of the most extreme environments on Earth. Not only are there physical extremes of high pressure and temperature and the total absence of light, deep-sea vents also are characterized by very steep chemical and temperature gradients between vent fluids and seawater. Cold seawater seeps through the permeable seafloor and deeper subsurface dikes where it undergoes a series of chemical reactions with subsurface rocks at very high temperatures (Delaney et al. 1998). This process creates hot hydrothermal fluid that is vented back up through the seafloor where it mixes with normal seawater surrounding the vent field. These hydrothermal fluids contain very high concentrations of transition metals like copper, iron, manganese, and zinc and dissolved gases such as hydrogen, methane, and hydrogen sulfide. As a result, vent fluids are hotter, more acidic and enriched with metals and dissolved gasses than the surrounding seawater; end-member vent fluid concentrations of transition metal species are enriched several orders of magnitude relative to average seawater and hydrogen sulfide concentrations may reach several millimolar (Campbell et al. 1988; Seyfried and Mottl 1995; Von Damm 1990).

Regional conditions contribute to other features of interest in this research. For example, some vents are located under biologically productive surface waters, resulting in sedimentation, whereas other vents lack sediment cover. Sedimentation can contribute significantly to the extreme conditions encountered at vents. In this research, samples were obtained from stations at four vent sites in the Eastern Pacific Ocean: the Endeavour segment of the Juan de Fuca Ridge System and Guaymas Basin (Gulf of California), and the $21{ }^{\circ} \mathrm{N}$ and $9^{\circ} \mathrm{N}$ vent sites on the East Pacific Rise (EPR). Three of the vents - Juan de Fuca (JDF), $21^{\circ} \mathrm{N}$ and $9{ }^{\circ} \mathrm{N}$ EPR - are hard-substrate (basaltic) sites with bivalve and tube worm beds 
providing a patchy mosaic of organic-rich habitats. These vents are characterized by rapid spreading and low sedimentation rates, as opposed to Guaymas Basin, which has an unusually high sedimentation rate (1-2 mm/yr) due to high biological productivity in surface waters and a large terrigenous input (Calvert 1966; Schrader 1982). Guaymas Basin is covered with up to $500 \mathrm{~m}$ of sediments, which contain large quantities of petroleum and other organic compounds formed via pyrolysis (Bazylinski et al. 1988; Peter et al. 1991), making it a very different environment than the other three.

A question raised by these environmental extremes and addressed in this research was how some organisms, particularly cosmopolitan species, are able to tolerate and survive vent conditions. This question was especially relevant for microorganisms like the flagellated protists that arrive in the deep sea in large numbers on sinking particulate matter (Bak et al. 1995; Caron 1991; Patterson and Fenchel 1990; Patterson et al. 1993; Silver and Alldredge 1981; Silver et al. 1984) and have been shown to be members of deep-sea environments (Burnett 1977; Small and Gross 1985; Turley et al. 1988).

Outline of the Dissertation. To assess the diversity and distribution patterns of flagellates at vents and to determine their tolerance limits to extreme environmental conditions, a program of sampling, experimentation and analysis was undertaken, resulting in this thesis. This work is presented here in two parts comprised of 5 chapters, with 2 additional chapters dedicated to a general introduction and conclusion, respectively. In Part I, I present the results of culturing and molecular analysis of samples obtained from the four vent sites. In Part II, I present the results of physiological experiments measuring tolerance limits. The final chapter is dedicated to general conclusions summarizing the results of the work as a whole.

In Chapter 2, culturing of vent samples from four sites in the Eastern Pacific Ocean yielded the first glimpse of flagellate diversity and distribution at deep-sea hydrothermal vents. My initial hypothesis was that extreme conditions at vents would select for novel spe- 
cies of flagellates previously unknown to science. Microscopical identification and phylogenetic analysis of $18 \mathrm{~S}$ small subunit ribosomal genes obtained from cultured isolates revealed a different story that helped to redefine the approach used later in physiological experimentation.

In Chapter 3, an intriguing result found in the phylogenetic analysis of Chapter 2 was explored in more detail. One of the vent isolates was found to be phylogenetically important since it formed a lineage just basal to the common node of all animals and fungi, implying that it is descended directly from the earliest common ancestor of this multicellular group. Intensive computational analyses were used to determine the strength of our result which later helped us construct an evolutionary history congruent with molecular and ultrastructural evidence.

Finally, in Chapter 4, the comparison between culturing and Denaturing Gradient Gel Electrophoresis (DGGE) of vent samples is presented. For DGGE, I chose to focus on a specific group of flagellates among the ones obtained by culturing. This group, the Kinetoplastida, is considered to be one of the oldest flagellate groups known. Its members include several clinically well-known and -studied parasites (the trypanosomes), but little work, especially at the molecular level, has been done on its free-living species. Furthermore, the group is monophyletic, which makes finding clade-specific primer sites easier. Therefore, the Kinetoplastida seemed like an appropriate group among the flagellates to begin the development of this methodology.

In the first chapter of Part II (Chapter 5), I examined the effect of pressure on isolates' growth rates. As pressure is perhaps the most conspicuous extreme condition at vents, its inclusion in this thesis seemed necessary. Although sampling conditions may have precluded the discovery of truly barophilic species, the observation of reversible encystment in barotolerant species exposed to high pressures hinted at a process with the potential for significant ecological implications regarding benthic/pelagic coupling in the open ocean. 
In Chapter 6, I present the results of additional physiological experimentation with extreme chemistry relevant to vent environments. Since nearly all of the flagellates isolated from my vent samples were found to be well-known, cosmopolitan species, I hypothesized that ubiquity in occurrence patterns implied high tolerance or adaptability to a wide range of environmental conditions. The results presented in Chapter 6, using very high concentrations of metals and sulfide, suggest that this hypothesis is true with respect to the flagellate isolates tested here. 


\section{References}

Bak, R. P. M., F. C. van Duyl, and G. Nieuwland. 1995. Organic sedimentation and macrofauna as forcing factors in marine benthic nanoflagellate communities. Microb. Ecol., 29(2):173-182.

Bazylinski, D. A., J. W. Farrington, and H. W. Jannasch. 1988. Hydrocarbons in surface sediments from a Guaymas Basin hydrothermal vent site. Org. Geochem., 12(6):547558.

Brinkhoff, T., and G. Muyzer. 1997. Increased species diversity and extended habitat range of sulfur-oxidizing Thiomicrospira spp. Appl. Environ. Microbiol., 63:3789-3796.

Burnett, B. R. 1977. Quantitative sampling of microbiota of the deep-sea benthos - I. Sampling techniques and some data from the abyssal central North Pacific. Deep-Sea Res., 24:781-789.

Calvert, S. E. 1966. Origin of diatom-rich varved sediments from the Gulf of California. $J$. Geol., 76:546-565.

Campbell, A. C., T. S. Bowers, C. I. Measures, K. K. Falkner, M. Khadem, and J. M. Edmond. 1988. A time-series of vent fluid compositions from $21^{\circ} \mathrm{N}$, East Pacific Rise $(1979,1981,1985)$ and the Guaymas Basin, Gulf of California $(1982,1985)$. J. Geophys. Res., 93:4537-4549.

Caron, D. A. 1991. Heterotrophic flagellates associated with sedimenting detritus. In: Patterson, D. J. and J. Larsen (ed.), The Biology of Free-Living Heterotrophic Flagellates, Special Volume 45. Clarendon Press, Oxford. pp. 77-92.

Colwell, R. R. 1994. Presented at the International Symposium on Microbial Diversity in Time and Space, Tokyo, Japan.

Delaney, J. R., D. S. Kelley, M. D. Lilley, D. A. Butterfield, J. A. Baross, W. S. D. Wilcock, R. W. Embley, and M. Summit. 1998. The Quantum Event of Oceanic Crustal Accretion: Impacts of Diking at Mid-Ocean Ridges. Science, 281(5374):222-230.

DeLong, E. F. 1991. Molecular systematics, microbial ecology and single cell analysis. In: Demers, S. (ed.), Particle Analysis in Oceanography, 1991 ed, vol. G 27. SpringerVerlag, pp. 237-257.

DeLong, E. F., F. S. Wickham, and N. R. Pace. 1989. Phylogenetic stains: ribosomal RNAbased probes for the identification of single cells. Science, 243:1360-1363.

Lonsdale, P. 1977. Clustering of suspension-feeding macrobenthos near abyssal hydrothermal vents at oceanic spreading centers. Deep-Sea Res., 24:857-863. 
Muyzer, G., S. Hottenträger, A. Teske, and C. Wawer. 1996. Denaturing gradient gel electrophoresis of PCR-amplified 16S rDNA - a new molecular approach to analyze the genetic diversity of mixed microbial communities. In: Akkermans, A. D. L., J. D. Van Elsas, and F. J. de Bruijn (ed.), Molecular Microbial Ecology Manual, 2nd ed., Kluwer Academic Publishers, Dordrecht, The Netherlands.

Muyzer, G., and K. Smalla. 1998. Application of denaturing gradient gel electrophoresis (DGGE) and temperature gradient gel electrophoresis (TGGE) in microbial ecology. Antonie van Leeuwenhoek, 73:127-141.

Patterson, D. J. 1999. The diversity of Eukaryotes. Am. Nat., 154 (supplement):S96-S124.

Patterson, D. J., and T. Fenchel. 1990. Massisteria marina Larsen \& Patterson 1990, a widespread and abundant bacterivorous protist associated with marine detritus. Mar. Ecol. Prog. Ser., 62:11-19.

Patterson, D. J., K. Nygaard, G. Steinberg, and C. M. Turley. 1993. Heterotrophic flagellates and other protists associated with oceanic detritus throughout the water column in the mid North Atlantic. J. Mar. Biol. Assoc. U.K., 73:67-95.

Peter, J. M., P. Peltonen, and S. D. Scott. $1991 .{ }^{14} \mathrm{C}$ ages of hydrothermal petroleum and carbonate in Guaymas Basin, Gulf of California: Implications for oil generation, expulsion, and migration. Geology, 19:253-256.

Schrader, H. 1982. Diatom biostratigraphy and laminated diatomaceous sediments from the Gulf of California, Deep Sea Drilling Project Leg 64. In: Curray, J. R. (ed.), Initial Reports of the Deep Sea Drilling Project, 64. U. S. Government Printing Office, Washington, D. C. pp. 973-981.

Seyfried, W. E., Jr., and M. J. Mottl. 1995. Geological Setting and Chemistry of Deep-Sea Hydrothermal Vents. In: Karl, D. M. (ed.), The Microbiology of Deep-Sea Hydrothermal Vents, CRC Press, New York. pp. 1-34.

Silver, M. W., and A. L. Alldredge. 1981. Bathypelagic marine snow: deep-sea algal and detrital community. J. Mar. Res., 39:501-530.

Silver, M. W., M. M. Gowing, D. C. Brownlee, and J. O. Corliss. 1984. Ciliated protozoa associated with oceanic sinking detritus. Nature, 309:246-248.

Small, E. B., and M. E. Gross. 1985. Preliminary observations of protistan organisms, especially ciliates, from the $21^{\circ} \mathrm{N}$ hydrothermal vent site. Biol. Soc. Wash. Bull., 6:401410.

Teske, A., P. Sigalevich, Y. Cohen, and G. Muyzer. 1996a. Molecular identification of bacteria from a coculture by denaturing gradient gel electrophoresis of $16 \mathrm{~S}$ ribosomal DNA 
fragments as a tool for isolation in pure cultures. Appl. Environ. Microbiol., 62(11):4210-4215.

Teske, A., C. Wawer, G. Muyzer, and N. B. Ramsing. 1996b. Distribution of sulfatereducing bacteria in a stratified fjord (Mariager Fjord, Denmark) as evaluated by mostprobable-number counts and denaturing gradient gel electrophoresis of PCR-amplified ribosomal DNA fragments. Appl. Environ. Microbiol., 62(4):1405-1415.

Turley, C. M., K. Lochte, and D. J. Patterson. 1988. A barophilic flagellate isolated from $4500 \mathrm{~m}$ in the mid-North Atlantic. Deep-Sea Res., 35(7):1079-1092.

Von Damm, K. L. 1990. Seafloor hydrothermal activity: black smoker chemistry and chimneys. Annu. Rev. Earth Planet. Sci., 18:173-204.

Wilson, E. O. (ed.). 1988. Biodiversity, National Academy Press, Washington D. C. 


\section{Part I}

Culturing and Molecular Analysis 


\title{
Chapter 2
}

\section{A survey of flagellate diversity at four deep-sea hydrothermal vents in the Eastern Pacific Ocean using structural and molecular approaches}

\author{
Michael S. Atkins, Andreas P. Teske, and O. Roger Anderson
}

Journal of Eukaryotic Microbiology, 47(4): In Press, 2000 


\begin{abstract}
Eighteen strains of flagellated protists representing 9 species were isolated and cultured from four deep-sea hydrothermal vents: Juan de Fuca Ridge (2200 m), Guaymas Basin $(2000 \mathrm{~m}), 21^{\circ} \mathrm{N}(2550 \mathrm{~m})$ and $9^{\circ} \mathrm{N}(2000 \mathrm{~m})$. Light and electron microscopy were used to identify flagellates to genus and, when possible, species. The small subunit ribosomal RNA genes of each vent species and related strains from shallow-waters and the American Type Culture Collection were sequenced then used for comparative analysis with database sequences to place taxa in an rDNA tree. The hydrothermal vent flagellates belonged to six different taxonomic orders: the Ancyromonadida, Bicosoecida, Cercomonadida, Choanoflagellida, Chrysomonadida, and Kinetoplastida. Comparative analysis of vent isolate and database sequences resolved systematic placement of some well-known species with previously uncertain taxonomic affinities, such as Ancyromonas sigmoides, Caecitellus parvulus, and Massisteria marina. Many of these vent isolates are ubiquitous members of marine, freshwater, and terrestrial ecosystems worldwide, suggesting a global distribution of these flagellate species.
\end{abstract}

\footnotetext{
Key Words: Ancyromonadida - Bicosoecida - Cercomonadida - Choanoflagellida • Chrysomonadida • small subunit ribosomal DNA • extreme environment • flagellates • hydrothermal vents $\bullet$ Kinetoplastida
} 
Protozoa constitute a very large group of microorganisms. They are second only to bacteria in abundance and cytological (if not species) diversity (Patterson 1999). Like bacteria, they have important ecological roles in the decomposition of matter and in the processes of nutrient recycling. Protozoa also are capable of consuming other, smaller organisms, such as bacteria, making the energy and nutrients incorporated by these prey available to larger consumers. This pivotal role in the microbial food web has made the study of protozoa both ecologically and economically important. For example, protists that can control the rate of bacterial activity in processes such as fermentation and the breakdown of industrial or organic wastes currently are being sought and studied for use in microbial biotechnologies. This search has extended into new - and in some cases extreme - environments where there is hope to find protists capable of surviving and thriving under conditions of high pressure, high or low temperature, and even high concentrations of many toxic compounds. Thus, knowledge of the ecology and physiology of protozoa living in extreme environments is of great interest not only for basic research, but also for applied research.

At present, little is known about protozoa in extreme environments. Few studies have examined the diversity of protists at deep-sea hydrothermal vents and only a few research articles have addressed this issue in the deep-sea at large (Burnett 1977; Burnett 1979; Burnett 1981; Cunningham and Ustach 1992; Svavarsson et al. 1993; Turley et al. 1988). Deep-sea vents are considered extreme environments due to their potential for creating harsh living conditions that exclude most organisms. Deep-sea vents have extremes of temperature, $\mathrm{pH}$ and high concentrations of toxic chemicals such as hydrogen sulfide and metal oxides. While these physical and chemical barriers may select for an endemic fauna adapted to severe conditions, there is a continuous rain of sinking particles known to deliver cosmopolitan flagellate species to vent sites (Bak et al. 1995; Caron 1991; Patterson and Fenchel 1990; Patterson et al. 1993; Silver and Alldredge 1981; Silver et al. 1984). 
Only one effort was undertaken to observe protistan diversity, of mostly ciliates, at deep-sea vents (Small and Gross 1985). Therefore, a sampling program was started to assess the diversity of flagellated protozoa at deep-sea vents using the combined approaches of morphological and molecular identification of cultured isolates. Flagellates were enriched from vent samples and isolated into pure culture. They were subsequently identified both by light and electron microscopy and by sequence analysis of small-subunit ribosomal RNA genes. The sequence database will allow the design of clade-specific primers and probes for future screening of environmental samples. This paper presents a survey of flagellated protozoa isolated and cultured from four deep-sea hydrothermal vents. This paper also looks at the species cultured in an ecological context and discusses their presence from a biogeographical perspective.

\section{Materials and Methods}

Culturing and Identification. Samples were obtained from stations at four vent sites in the Eastern Pacific Ocean: the Endeavour segment of the Juan de Fuca Ridge System and Guaymas Basin (Gulf of California), and the $21^{\circ} \mathrm{N}$ and $9{ }^{\circ} \mathrm{N}$ vent sites on the East Pacific Rise (Table 2.1 and Figure 2.1). Three of the vents - Juan de Fuca (JDF), $21^{\circ} \mathrm{N}$ and $9{ }^{\circ} \mathrm{N}$ are hard-substrate (basaltic) sites with bivalve and worm beds providing a patchy mosaic of organic-rich habitats. These vents are characterized by rapid spreading and low sedimentation rates, as opposed to Guaymas Basin (GBB), which has an unusually high sedimentation rate (1-2 mm/yr) due to high biological productivity in surface waters and a large terrigenous input (Calvert 1966; Schrader 1982). The vent site at GBB is covered with up to $500 \mathrm{~m}$ of sediments, which release vast quantities of petroleum and other organic compounds via pyrolysis (Bazylinski et al. 1988; Peter et al. 1991), making it a very different environment from the other three. 
Figure 2.1. Map showing locations and geological features of four deep-sea hydrothermal vents sampled for the present study (adapted from Heezen and Tharp 1977). Flagellate species and strain names are listed by collection location. Additional detail regarding this flagellate collection is provided in Table 2.1 . 


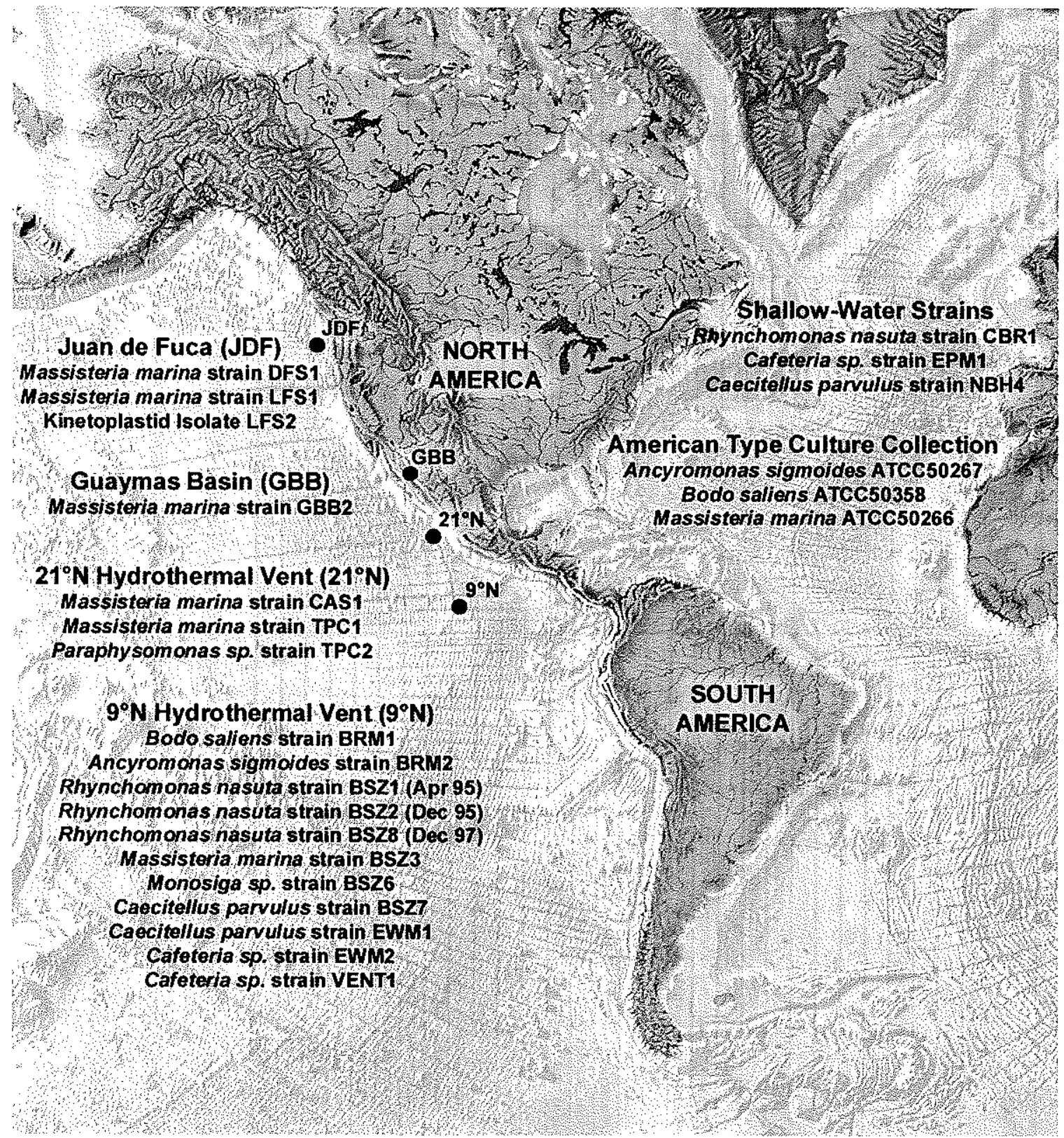




\begin{tabular}{|c|c|c|c|c|c|c|c|c|c|}
\hline & Classification & Species & Strain & Collection Location & \begin{tabular}{|l|} 
Vent \\
Site \\
\end{tabular} & $\begin{array}{l}\text { Collection } \\
\text { Depth (m) }\end{array}$ & $\begin{array}{c}\text { Coilection } \\
\text { Date }\end{array}$ & $\begin{array}{c}\text { GenBank Accession } \\
\text { Number }\end{array}$ & \\
\hline & \multicolumn{9}{|c|}{ Ancyromonadida, Cavalier-Smith, 1998} \\
\hline \multirow[t]{3}{*}{$\cdot 1$} & & Ancyromonas sigmoides, Kent, 1880 & 50267 & American Type Culture Collection & & & & AF174363 & 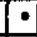 \\
\hline & & Ancyromonas sigmoides, Kent, 1880 & BRM2 & Biovent Riftia and Mussels Bed & $9^{\circ} \mathrm{N}$ & 2500 & Dec-95 & & \\
\hline & \multicolumn{9}{|c|}{ Bicosoecida, Grassé and Deflandre, 1952} \\
\hline$\cdot 1$ & & Cafeteria sp. & VENT1 & $9^{\circ} \mathrm{N}$ vent water $-\mathrm{H}_{2} \mathrm{~S}$ reactors & $9^{\circ} \mathrm{N}$ & 2500 & Dec-97 & AFl74364 & - \\
\hline$\cdot 1$ & & Cafeteria sp. & EWM2 & East Wall Mussels Bed & $9^{\circ} \mathrm{N}$ & 2500 & Dec-96 & $\mathrm{AF} 174365$ & $\bullet$ \\
\hline \multirow[t]{2}{*}{$\cdot$} & & Cafeteria sp. & EPM1 & Eel Pond Marsh $-\mathrm{H}_{2} \mathrm{~S}$ reactors & & surface & Oct-98 & $\mathrm{AF174366}$ & $\bullet$ \\
\hline & & Caecitellus parvulus, (Griessman, 1913) Patterson et al., 1993 & BSZ7 & Biovent Serpulid Zone & $9^{\circ} \mathrm{N}$ & 2500 & Dec-95 & & \\
\hline$\cdot 1$ & & Caecitellus parvulus, (Griessman, 1913) Patterson et al., 1993 & EWMI & East Wall Mussels Bed & $9^{\circ} \mathrm{N}$ & 2500 & Dec-95 & AF174367 & $\cdot$ \\
\hline \multirow[t]{2}{*}{-} & & Caecitellus parvulus, (Griessman, 1913) Patterson et al., 1993 & NBH4 & New Bedford Harbor, MA & & 3 & Aug-96 & AFI74368 & 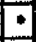 \\
\hline & \multicolumn{9}{|c|}{ Cercomonadida, Vickerman, 1983} \\
\hline \multirow[t]{2}{*}{-} & & Massisteria marina, Larsen and Patterson, 1990 & 50266 & American Type Culture Collection & & & & AF174369 & $\bullet$ \\
\hline & & Massisteria marina, Larsen and Patterson, 1990 & BSZ3 & Biovent Serpulid Zone & $9^{\circ} \mathrm{N}$ & 2500 & Dec-95 & & \\
\hline -1 & & Massisteria marina, Larsen and Patterson, 1990 & GBB2 & Guaymas Basin Beggiotoa Mat & GBB & 2000 & Apr 98 & AFi74370 & $\cdot$ \\
\hline 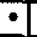 & & Massisteria marina, Larsen and Patterson, 1990 & DFS1 & Dante Flange Substrates & JDF & 2200 & Jun-98 & AF174371 & 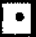 \\
\hline$\cdot$ & & Massisteria marina, Larsen and Patterson, 1990 & LFS1 & Lobo Flange Substrates & JDF & 2200 & Jun-98 & AF174372 & $\bullet$ \\
\hline$\cdot 1$ & & Massisteria marina, Larsen and Patterson, 1990 & CAS1 & Clam Acres Spire & $21^{\circ} \mathrm{N}$ & 2550 & May-98 & AF174373 & - \\
\hline \multirow[t]{2}{*}{$\bullet$} & & Massisteria marina, Larsen and Patterson, 1990 & TPC1 & Twin Peaks Chimney & $21^{\circ} \mathrm{N}$ & 2550 & May-98 & AF174374 & -1 \\
\hline & \multicolumn{9}{|c|}{ Choanofiagellida, Kent, 1880} \\
\hline \multirow[t]{2}{*}{ 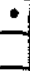 } & & Monosiga sp. & BSZ6 & Biovent Serpulid Zone & $9^{\circ} \mathrm{N}$ & 2500 & Dec-95 & AF174375 & • \\
\hline & Chrysomonad & ida, Engler, 1898 & & & & & & & \\
\hline$\cdot+$ & & Paraphysomonas sp. & TPC2 & Twin Peaks Chimney & $21^{\circ} \mathrm{N}$ & 2550 & May-98 & AF174376 & -1 \\
\hline & Kinetoplastido & a, Honigberg, 1963 & & & & & & & \\
\hline$\cdot 1$ & & Rhynchomonas nasuta, Klebs, 1892 & CBR1 & Chesapeake Bay, MD & & 1 & N/A & AF174377 & $\cdot$ \\
\hline \multirow[t]{3}{*}{$\cdot$} & & Rhynchomonas nasuta, Klebs, 1892 & BSZ1 & Biovent Serpulid Zone & $9^{\circ} \mathrm{N}$ & 2500 & Apr-95 & AF 174378 & $\cdot$ \\
\hline & & Rhynchomonas nasuta, Klebs, 1892 & BSZ2 & Biovent Serpulid Zone & $9^{\circ} \mathrm{N}$ & 2500 & Dec-95 & & \\
\hline & & Rhynchomonas nasuta, Klebs, 1892 & BSZ8 & Biovent Serpulid Zone & $9^{\circ} \mathrm{N}$ & 2500 & Dec-97 & & \\
\hline \multirow[t]{2}{*}{$\cdot$} & & Bodo saliens, Larsen and Patterson, 1990 & 50358 & American Type Culture Collection & & & & $\mathrm{AF} 174379$ & $\cdot$ \\
\hline & & Bodo saliens, Larsen and Patterson, 1990 & BRM1 & Biovent Riftia and Mussels Bed & $9^{\circ} \mathrm{N}$ & 2500 & Dec-95 & & \\
\hline$\cdot 1$ & & Unidentified & LFS2 & Lobo Flange Substrates & JDF & 2200 & Jun-98 & AF174380 & $\cdot 1$ \\
\hline
\end{tabular}

Table 2.1. Pure culture isolates obtained from the American Type Culture Collection (ATCC), shallow, coastal waters (Chesapeake Bay, MD (CBR),

Eel Pond, MA (EPM) and New Bedford Harbor, MA (NBH)) and four deep-sea hydrothermal vents in the Eastern Pacific Ocean (Juan De Fuca (JDF),

Guaymas Basin $(\mathrm{GBB}), 21^{\circ} \mathrm{N}$ and $9^{\circ} \mathrm{N}$ ). Shown are taxonomic classification, species and strain names, specific collection locations, vent sites, depths and dates (see Figure 2.1). All cultures were grown at atmospheric pressure. GenBank accession numbers are provided for those isolates sequenced in this study: $(\bullet)$ strains sequenced. 
All samples were collected from deep-sea vent sites (see Table 2.1 for specific collection information) at stations where temperatures ranged between $1.9^{\circ} \mathrm{C}$ and $30^{\circ} \mathrm{C}$. Samples were collected into sterilized seawater-filled containers to minimize the possibility of contamination. Flagellates collected from these vent sites were enriched, isolated and cultured as described by Atkins et al. (1998). Once cells were isolated in pure culture they were identified to the genus or species level using light or electron microscopy. Microscopical observations were compared to the Biogeochemical Ocean Flux Study Protist Video Database (University of Bristol, UK) and to several guides and keys containing heterotrophic marine flagellates (Cavalier-Smith 1993; Cavalier-Smith 1997; Corliss 1984; Lee et al. 1985; Levine et al. 1980; Margulis et al. 1990; Patterson 1993; Patterson 1999; Patterson and Larsen 1991; Sleigh et al. 1984). Different strains of species or genera isolated at vents were purchased from the American Type Culture Collection (ATCC) to obtain sequence information for comparison with some vent isolates.

Scanning and transmission electron microscopy. For SEM, cultures were fixed at $5{ }^{\circ} \mathrm{C}$ in $2 \%(\mathrm{w} / \mathrm{v}$ ) electron microscopic grade glutaraldehyde (Ladd Research Industries, Burlington, VT) prepared in $0.05 \mathrm{M}$ cacodylate buffer ( $\mathrm{pH} \mathrm{7.8).} \mathrm{The} \mathrm{flagellate} \mathrm{sus-}$ pension was gently centrifuged, the supernatant aspirated off, and the pellet was washed by resuspension in distilled water. This washing step was repeated and the final suspension collected by gentle pressure on a teflon micropore filter $(0.20 \mu \mathrm{m}$ pore size $)$, dehydrated in a graded ethanol series, infiltrated with liquid carbon dioxide and critical point dried (Tousimis SamDri-780A). Dried filters were affixed to scanning electron microscope stubs, plated with gold/palladium (Tousimis SamSputter-2A) and observed with a Cambridge Stereoscan 250 Mk 2 electron microscope. Preparations for transmission microscopy (TEM) used standard methods for fixation and embedding (e.g., Anderson 1992) and were observed with a Philips 201 transmission microscope operated at $60 \mathrm{kV}$. 
DNA isolation, PCR and sequencing. The following protocol generated high quality, consistent results from a wide diversity of protist taxa. Pure-cultured isolates were grown to high density $\left(\geq 10^{6} \mathrm{cell} / \mathrm{s} / \mathrm{ml}\right)$ then filtered over Millipore $2.0 \mu \mathrm{m}$ TTTP Isopore Membrane Filters (cat no. TTTP04700) to remove bacteria and PCR-inhibiting substances. Nucleic acids were isolated by hot phenol extraction: cells bound on individual filters were incubated in $500 \mu \mathrm{L}$ Lysis Buffer ( $10 \mathrm{~g}$ sucrose, $2 \mathrm{ml} 1 \mathrm{M}$ Tris $\mathrm{pH} 8.0$, brought up to $40 \mathrm{ml}$ with $\left.\mathrm{MQH}_{2} \mathrm{O}\right), 75 \mu \mathrm{L} 10 \%$ SDS and $25 \mu \mathrm{L}$ Proteinase $\mathrm{K}(20 \mathrm{mg} / \mathrm{ml})$ for 1 hour at $65^{\circ} \mathrm{C}$; then, $600 \mu \mathrm{L}$ hot $\left(65^{\circ} \mathrm{C}\right)$ phenol:chloroform:isoamyl alcohol (25:24:1) (Tris equilibrated to $\mathrm{pH}$ 8.0) was added and incubation proceeded at $65^{\circ} \mathrm{C}$ for an additional 5-10 min. Continued phenol extraction and precipitation of genomic DNA was performed as described by Treco (1987).

Amplification of small subunit ribosomal DNA (ssrDNA) from DNA extracts was performed for each organism using standard polymerase chain reaction (PCR) protocols and general PCR primers A and B (Medlin et al. 1988). The standard protocol included a hot start at $95^{\circ} \mathrm{C}$ for $5 \mathrm{~min}$, and continued with 35 cycles of denaturation at $94{ }^{\circ} \mathrm{C}$ for $1 \mathrm{~min}$, annealing at $55^{\circ} \mathrm{C}$ for $45 \mathrm{sec}$ and extension at $72{ }^{\circ} \mathrm{C}$ for $2 \mathrm{~min}$, concluded by a final extension at $72{ }^{\circ} \mathrm{C}$ for $10 \mathrm{~min}$. Primers A (forward) and B (reverse) did not work well with euglenozoan DNA due to sequence mismatches in the primer target sites (Table 2.2). Therefore, later PCR amplifications were performed using modifications of primers A and B, and the internal primers $\mathrm{C}$ (forward) and $\mathrm{D}$ (reverse) (Table 2.2). Primer $\mathrm{C}$ overlaps in eight positions with primer A; primer D anneals four nucleotides from the 3 '-end of primer B. It should be noted that further modification of primer $\mathrm{A}$ to include mixed cytosine and thymine nucleotides at position 3 , in addition to the one modified at position 13 , as well as concomitant modifications to primer B (shown) would improve the efficiency of this primer combination in targeting a wider range of flagellate taxa. 


\begin{tabular}{|c|c|c|c|c|c|}
\hline Primer & A & $\mathbf{B}$ & c & & D \\
\hline $\begin{array}{l}\text { Unmodiffed primer } \\
\text { Modified Primer }\end{array}$ & $\begin{array}{l}\text { AACCTGGTTGATCCTGCCAGT } \\
\text { ARCTGGTTGATYCTGCCAG }\end{array}$ & $\begin{array}{r}\text { CATCCACTTGGACGTCTTCCTAG } \\
\text { CACTMGGACGRCMWCCTAGT }\end{array}$ & CTGCCAGYAGTCATATGCTT & & TTCGTTT \\
\hline Euglena gracilis & AATCTGGTTGATCCTGCCAGC $2 / 0$ & GTAGGTGAACCTGCAGCAGGATCA $1 / 0$ & CTGCCAGCAGTCATATGCTT. & & AAGCAAAAGTCGTAACAAGGT \\
\hline Bodo caudatus & AATCTGGTTGATICTGCCAGT $2 / 0$ & 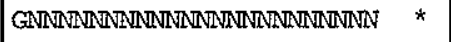 & CTGCCAGTAGTCATATGCTT & 0 & AAGCAAAAGTCGTAACAAGGT \\
\hline Leishmania donovani & GATCTGGTTGATTCTGCCAGT $2 / 0$ & GTAGGTGAACCIGCAGCTGGATCA $2 / 0$ & CTGCCAGTAGTCATAIGCII & 0 & AAGCAAAAGTCGTAACAAGGT \\
\hline Cafeteria roenbergensis & AACCTGGTTGATCCTGCCAGT $0 / 1$ & GTAGGTGAACCTGCAGAAGGATCA $0 / 0$ & CTGCCAGMAGTCATACGCTT & 1 & AAGGTGAAGICGTAACAAGGT \\
\hline Caecitellus parvulus & AACCTGGTTGATCCTGCCAGT $0 / 1$ & GTAGGTGAACCTGCAGAAGGATCA $0 / 0$ & CTGCCAGTAGTCATACGCTT & 1 & AAGGTGAAGTCGTAACAAGGT \\
\hline Mallomonas papillosa & AACCTGGTTGATCCTGCCAGT $0 / 1$ & GTAGGTGAACCTGCAGAAGGATCA $0 / 0$ & CTGCCAGTAG-CATACGCTT & 1 & AAGGTGAAGTCGTAACAAGGT \\
\hline Apusomonas proboscidea & AACCTGGTTGATCCTGCCAGT $0 / 1$ & GTAGGTGAACCTGCAGAAGGATCN $0 / *$ & CTGCCAGTAGTCATATGCTT & 0 & AAGTAAAAGTCGTAACAAGGT \\
\hline Dermocystidium sp. & AACCTGGTTGATCCTGCCAGT $0 / 1$ & GTAGGTGAACCTGCAGAAGGATCT $0 / 1$ & CTGCCAGTAGTCATATGCTT & 0 & AAGTAAAAGTCGTAACAAGGT \\
\hline Monosiga brevicollis & AACCTGGTTGATCCTGCCAGT $0 / 1$ & GTAGGTGAACCTGCAGAAGGATCA $0 / 0$ & CTGCCAGTAGTCATATGCTT & o & AAGTAAAAGTCGTAACAAGGT \\
\hline
\end{tabular}

Table 2.2. PCR primer and small subunit ribosomal DNA (ssrDNA) target sequences for selected flagellates. Forward primers (A and $\mathrm{C}$ ) shown in 5 prime to 3 prime direction; reverse primers (B and $\mathrm{D}$ ) shown in 3 prime to 5 prime direction. All ssrDNA target sequences shown in 5 prime to 3 prime direction. Primers A and B were modified as shown and primers $\mathrm{C}$ and $\mathrm{D}$ were initially designed to selectively amplify euglenozoan flagellates represented by Euglena gracilis, Bodo caudatus and Leishmania donovani. Numbers and underscoring indicate mismatches between target sequences and primers (For A and B: first number = mismatches with unmodified primer; second number $=$ mismatches with modified primer). Asterisks indicate nucleotide ambiguity $(\mathrm{N})$ in primer target site $(\mathrm{s})$, therefore the exact number of mismatches could not be determined. 
PCR products were column-purified using Wizard PCR Preps (Promega, Madison, Wisconsin) following manufacturer's protocols and sequenced directly on an ABI 377 Automated Sequencer using fluorescence-labeled sequencing dideoxyoligonucleotides. Internal sequencing primers (primer 514F: 5'-GTG CCA GCA SCC GCG G-3'; primer 920F: 5'-GAA ACT TAA AGR AAT TG-3'; primer 690R: 3'-S TCT CCA CTT TAA GAA-5'; and primer 1055R: 3'-CC ACC ACG TAC CGG CRA-5') and the primers A and $\mathrm{B}$ or $\mathrm{C}$ and $\mathrm{D}$ were used to generate overlapping sequence contigs that covered the length of the ssrDNA gene both in 3 - and 5'- directions. Overlapping sequence contigs were aligned and assembled using the AssemblyLIGN application within the MacVector Sequence Analysis Program (v 6.5, Oxford Molecular Limited). In all, 15 deep-sea vent strains, and 3 shallow-water strains of Caecitellus parvulus, Cafeteria sp. and Rhynchomonas nasuta, were sequenced. GenBank accession numbers for all 18 sequences are listed in Table 2.1.

Database search and phylogenetic analysis. Sequences closely related to or otherwise phylogenetically relevant for the newly sequenced organisms were obtained from Genbank using BLAST searches (Altschul et al. 1990). Literature references of the Genbank entries and other relevant sources were consulted regarding the general phylogenetic relationships of the eukaryotic branches to which the isolates were affiliated. This was done to place vent flagellates among other closely related taxa in the rDNA tree. Initial alignments obtained with ClustalW (Thompson et al. 1994) were edited manually based on eukaryotic secondary structure consensus (Van de Peer et al. 1997). In the final analysis, regions that did not allow an unambiguous sequence alignment were excluded. These were helices whose length differed considerably between sequences from different phyla (e.g., Helices 10, E10-1, 11, 17, all E23 helices except E23-6 and E23-7, and helices 29, 30, 43, 45, 46, 49) or incompletely sequenced terminal regions of the ssrRNA gene (Helices $1-4,50$ ) (Van de Peer et al. 1997). After masking these regions, the remaining sequence alignment containing ca. 1200 nucleotide positions was analyzed with PAUP 4.0b2 (Swofford 1999). The 
rDNA tree was inferred using minimum evolution as optimality criterion and the distance measure set to maximum likelihood. The settings corresponded to a general-time-reversible model (Swofford et al. 1996) with rate heterogeneity and optimized parameters for base frequencies, mutation frequencies, gamma shape, and proportion of fixed sites. Bootstrap runs of 1,000 replicates each were performed with these distance settings and also with maximum parsimony. The alignment and model parameters used in these analyses are available upon request.

\section{Results}

Structural identification of flagellate collection. Eighteen strains of flagellates representing 9 distinct species were isolated and cultured from the four vent sites; in addition, 3 species were obtained from shallow waters and 3 from ATCC (Table 2.1 and Figure 2.1). Microscopical identifications were based mostly on circumscriptive and in some cases ultrastructural definitions. These definitions have limitations in that they 'may describe taxa but can fail to distinguish taxa' (Patterson 1999). However, circumscriptive and ultrastructural definitions are still widely accepted and used and guides employing several different approaches to defining taxa (e.g., circumscription, ultrastructure, synapomorphy and composition) were consulted to help with the following identifications. 
Figure 2.2. (A) Cafeteria sp. strain VENT 1 showing mastigonemes on anterior flagellum; (B) Cafeteria sp. strain EPM 1; (C) light micrograph of Caecitellus parvulus trophs with characteristic gliding morphology; (D) Caecitellus parvulus strain NBH 4 (arrow, acronematic flagellar tip); (E) light micrograph of Rhynchomonas nasuta strain BSZ 1 trophonts with characteristic proboscis; (F) Rhynchomonas nasuta strain BSZ 1; (G) light micrograph of Rhynchomonas nasuta strain CBR 1 trophonts with characteristic proboscis; (H) Rhynchomonas nasuta strain CBR 1 showing long posterior and short anterior flagella and proboscis emerging from groove at the base of the snout; (I) unidentified kinetoplastid flagellate LFS 2 showing two heterokont flagella; $(\mathrm{J}, \mathrm{K})$ thin-section TEM images of Monosiga sp. strain BSZ 6 showing corona of microvilli; (L) light micrograph of Monosiga sp. strain BSZ 6 showing collar and apical flagellum; (M) apical flagellum of Monosiga sp. strain BSZ 6; (N) mastigoneme-covered anterior flagellum of Paraphysomonas sp. strain TPC 2; (O,P) Ancyromonas sigmoides strains ATCC 50267 and BRM 2, respectively; (Q) detail of papillate projections from the latero-ventral groove of Ancyromonas sigmoides strain BRM 2. All markers $=1.0 \mu \mathrm{m}$. 


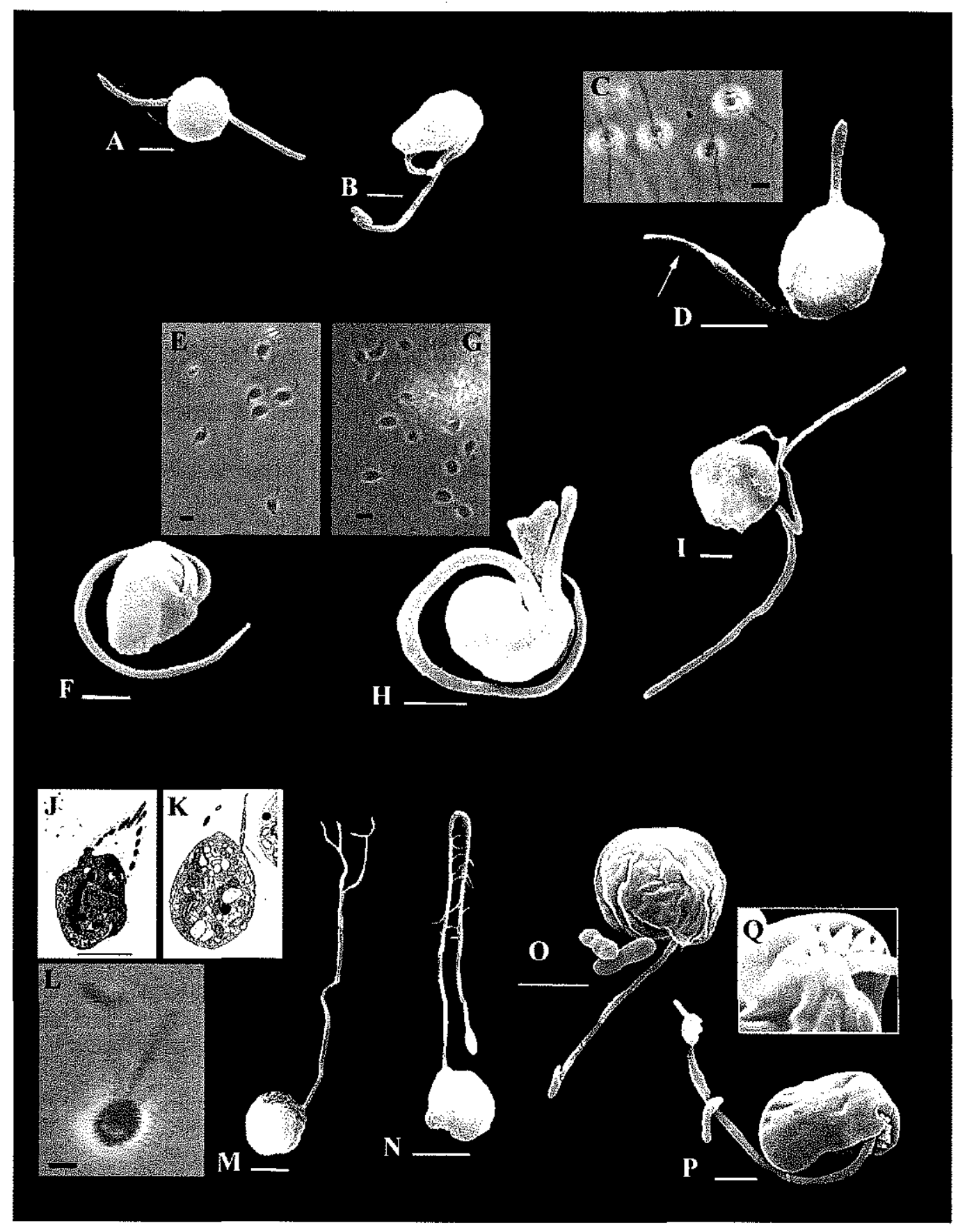




\section{Order Ancyromonadida Cavalier-Smith, 1998}

\section{Ancyromonas sigmoides Kent, 1880 (Figure $2.2 \mathrm{O}-\mathrm{Q}$ )}

Heterotrophic, surface-associated or gliding flagellates, roughly kidney-bean shaped (dorso-ventrally flattened); 3-7 $\mu \mathrm{m}$ long. One trailing, acronematic flagellum (ca. $2 \times$ body length) was observed emerging from a latero-ventral groove as described by Patterson and Simpson (1996); no secondary flagella were observed. Latero-ventral groove contains papillate projections evident in Mylnikov's (1990) description of this species (under the name Heteromita sp.). Ancyromonas sigmoides was observed in motion in which the flagellate appears to sway back and forth along the substratum. This species is distinguished from the two other species of the genus, Ancyromonas melba, based on the presence of an acronematic posterior flagellum and lack of a prominent anterior flagellum and Ancyromonas contorta based on lack of a contorted body shape.

\section{Order Bicosoecida Grassé and Deflandre, 1952}

Caecitellus parvulus (Griessman, 1913), Patterson et al., 1993 (Figure 2.2 C, D)

Heterotrophic, biflagellated, gliding cells; 3-10 $\mu \mathrm{m}$. Long, trailing flagellum (3-4 x body length) with shorter ( $1 \mathrm{x}$ body length) anterior flagellum; no mastigonemes were observed. Cells glide along on posterior flagellum while sweeping, forward-directed anterior flagellum is used for locomotion and to dislodge attached bacterial prey. Direct observations were consistent with descriptions by Griessman (1913) and Patterson et al. (1993). May belong to an as yet undefined sister taxon of the Bicosoecids, due to lack of mastigonemes and other defining characteristics for that group (see O'Kelly and Nerad 1998).

\section{Cafeteria sp. (Figure $2.2 \mathrm{~A}, \mathrm{~B}$ )}

Heterotrophic, biflagellated cells; 3-5 $\mu \mathrm{m}$. Anterior and posterior flagella of approximately similar size (1-2 $\mathrm{x}$ body length) with mastigonemes evident on anterior flagel- 
lum (Figure 2.2 A). Attaches to substrate by tip of posterior flagellum when feeding, with anterior flagellum undulating to create feeding currents. When swimming, anterior flagellum is directed forward. Appearance is consistent with descriptions for species of Cafeteria in (Fenchel and Patterson 1988; Patterson and Simpson 1996); some strains may be Cafeteria roenbergensis Fenchel and Patterson (1988).

\section{Order Cercomonadida Vickerman, 1983}

Massisteria marina Larsen and Patterson, 1990

No satisfactory pictures could be obtained for this organism. The following description refers therefore to direct observations. Heterotrophic flagellates with two distinct states: a flagellated, swimming form (3-7 $\mu \mathrm{m})$ and a sessile, feeding form with retracted flagella and extended pseudopodia (up to $15 \mu \mathrm{m}$ ). Flagellated cells swim quickly in forwarddirected motion and may be observed gliding in a decreasing spiral (usually in clockwise direction) until they settle on a suitable substrate. Once settled, flagella (ca. $2 \mathrm{x}$ body length) are quickly resorbed and pseudopodia (5-10 $\mathrm{x}$ body length) extended for feeding. Pseudopodia have granulated appearance similar to those described by Patterson and Fenchel (1990). When disturbed or triggered by other cues, sessile cells resorb pseudopodia while simultaneously extending flagella and swimming resumes.

\section{Order Choanoflagellida Kent, 1880}

Monosiga sp. (Figure 2.2 J-M)

Heterotrophic cells with one apically-inserted flagellum surrounded by fine cytoplasmic tentacles (collar); $3-7 \mu \mathrm{m}$. The single flagellum (ca. $5 \mathrm{x}$ body length) beats sinusoidally, drawing a water current through the collar in filter-feeding. Cells mostly observed swimming and feeding, although some cells may have been attached; no apparent stalk or lorica. 


\section{Order Chrysomonadida Engler, 1898}

Paraphysomonas sp. (Figure 2.2 N)

Heterotrophic cells (10-15 $\mu \mathrm{m})$ with two unequal flagella (not observed in Figure 2.2 N), one directed anteriorly with mastigonemes (shown, ca. $10 \mathrm{x}$ body length) and the other trailing and smooth ( $<1-1 \mathrm{x}$ body length). The long flagellum beats quickly in a sinusoidal wave and is directed forward during swimming. Chloroplasts absent. Scales not observed; therefore, identification to species not possible.

\section{Order Kinetoplastida Honigberg, 1963}

Bodo saliens Larsen and Patterson, 1990

From direct observation only: Heterotrophic, biflagellated cells, lanceolate in shape; 3-7 $\mu \mathrm{m}$. Anterior flagellum directed forward with a slight curve at the distal end $(\leq 1 \times$ body length), posterior flagellum directed straight back (1-2 $\mathrm{x}$ body length). Swimming cells rotate around their longitudinal axis, while moving along straight paths. Appearance consistent with descriptions by Larsen and Patterson (1990) and Patterson and Simpson (1996).

\section{Rhynchomonas nasuta Klebs, 1892 (Figure $2.2 \mathrm{E}-\mathrm{H}$ )}

Heterotrophic, gliding cells with two heterokont flagella and a characteristic proboscis; 5-7 $\mu \mathrm{m}$. One posterior trailing flagellum (ca. $2 \mathrm{x}$ body length) and one anterior flagellum ( $<1 \mathrm{x}$ body length) associated with an anterior snout (about half the body length) broadened at its distal end, all emerging from an anterior groove (clearly evident in Figure 2 H). Cells observed swimming - rapidly tumbling and rolling - and gliding with a swaying motion as the proboscis sweeps side to side, dislodging attached bacterial prey. Easily distinguished from other gliding flagellates by the flexible and bulbous snout. 
Unidentified kinetoplastid flagellate (Figure 2.2 I)

Heterotrophic, biflagellated cells with heterokont flagella; 8-10 $\mu \mathrm{m}$. Cells may swim rapidly in a darting manner or glide with anterior flagellum directed forward (1-2 $\mathrm{x}$ body length) and posterior flagellum trailing behind (3-4 x body length). This flagellate was placed among the Kinetoplastida by ssrDNA analysis.

Occurrence patterns. The most frequently obtained flagellates, not counting the ATCC reference strains, were six isolates of the cercomonad $M$. marina from diverse vent sites; six bicosoecids from vent and shallow water sites, half of them Cafeteria and the other half $C$. parvulus isolates; and six kinetoplastids from vent sites and Chesapeake Bay (Table 2.1). In addition, Monosiga sp., Paraphysomonas sp. and A. sigmoides were obtained a single time each. Collection locations and dates are provided to show spatial and temporal uniformity among sampling efforts with regard to different strains of a unique species. For example, $M$. marina was isolated from two distinct vent localities at both Juan de Fuca Ridge (Dante and Lobo flange) and $21^{\circ} \mathrm{N}$ EPR (Clam Acre Spire and Twin Peaks Chimney), indicating small-scale spatial homogeneity at these vents. On the other hand, $R$. nasuta was isolated from the same $9^{\circ} \mathrm{N}$ EPR site (Biovent Serpulid Zone) at three different times over three years, indicating a stable population of Rhynchomonas at this site.

Sequencing and molecular analysis. Sequencing and comparative analysis of ssrDNA corroborated microscopical identifications. In general, molecular and morphological identifications were congruent. The orders Ancyromonadida Cavalier-Smith, 1998, Bicosoecida Grassé and Deflandre, 1952, Cercomonadida Vickerman, 1983, Choanoflagellida Kent, 1880, Chrysomonadida Engler, 1898, and Kinetoplastida Honigberg, 1963 (Table 2.1) correspond to distinct clades in the ssrDNA tree, supported by bootstrap values > $50 \%$ (Figure 2.3). 
Figure 2.3. Distance tree of hydrothermal vent flagellates based on analysis of nearcomplete small subunit ribosomal DNA sequences using euglenozoan flagellates as the outgroup. The evolutionary distance between two organisms is obtained by the summation of the length of the connecting branches along the horizontal axis, using the scale at the bottom. Numbers at nodes show percent bootstrap support with distance (minimum evolution) followed by maximum parsimony (1,000 replicates each). Organisms sequenced in this study are in larger, bold font. Accession numbers for database sequences (top to bottom) are: Choanoflagellates AF100941, AF100940, L10823, L10824; DRIP's U21337, L29455, AF118851, U43712, U33180, AF070445; Fungi M59758, M59761, M59759, D88318, X04971, Z75577, D31648; Apusomonads L37037; Cercomonads U42448, U42447, U42446; Chrysophyceae M32704, M55285, M87336, AF109325, Z38025; Pelagophyceae U40257; Phaeophyceae AB011423, L43062; Bolidophyceae AF123595; Bacillariophyceae X85396, M87325; Oomycetes X80344, X54265; Bicosoecids L27633, (Adriamonas - C. J. O'Kelly, pers. comm), AF072883; Blastocystida U51151, U51152; Labyrinthulida L27634, U21338, L34054; Kinetoplastids AJ009142, L35076, U01015, X53911, M84225, L29266, L29264, L14840, AF080226, X53910, X76494, AJ130868, U67183; Diplonemids AF119811, AF119812; Euglenids U84731, M12677, U84732, AF061338. 


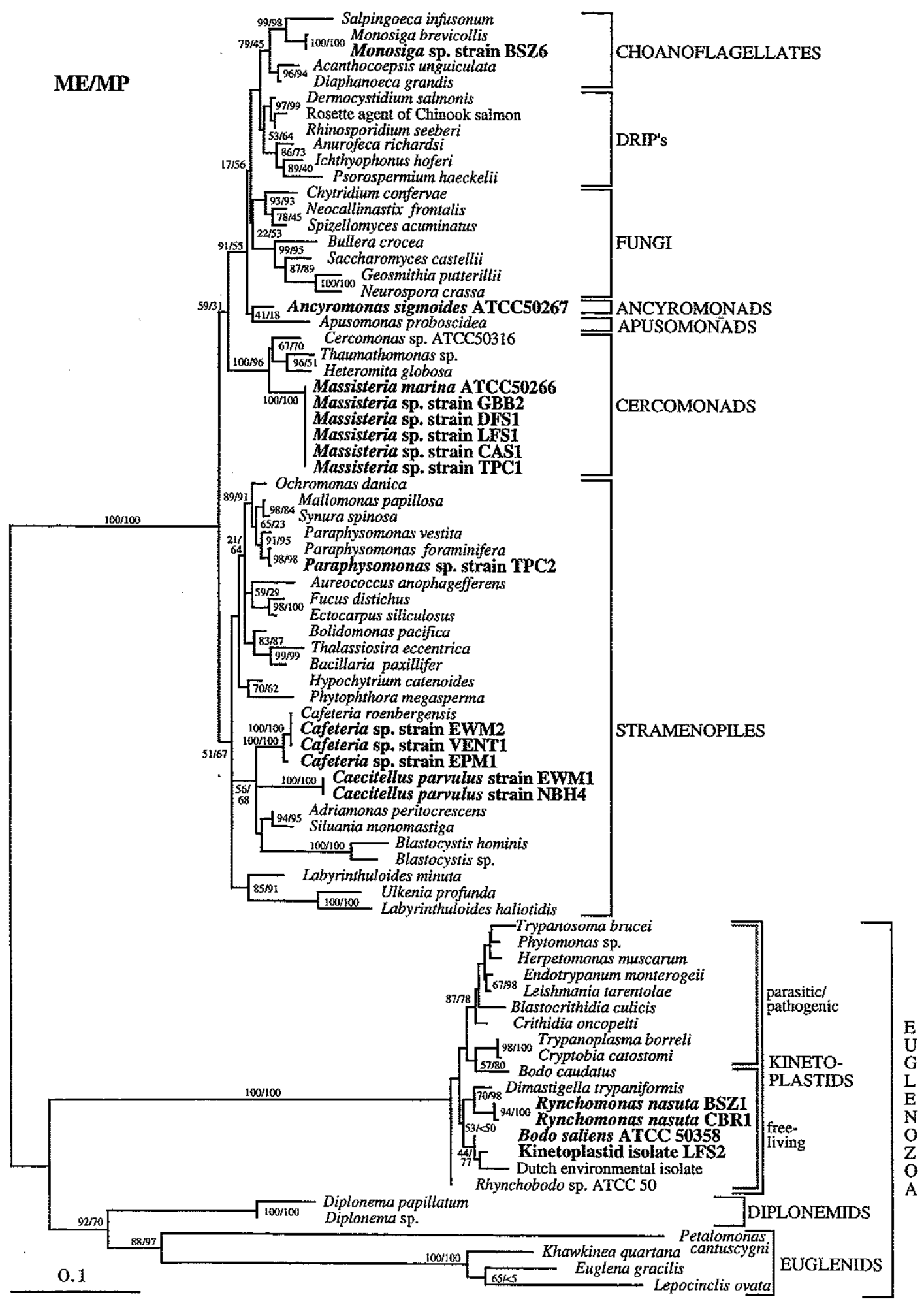


The hydrothermal vent flagellates belonged to six different phylogenetic groups within two major subdivisions of the eukaryotes (Figure 2.3). Most isolates were placed into lineages forming the highly diversified evolutionary radiation that currently includes the majority of the phylogenetically-characterized eukaryotes. The term "crown group" is frequently used for this cluster referring to its distal position in the ssrRNA-based eukaryotic tree, and to contrast it to the more widely-spaced, deeply-branching lineages represented by fewer sequenced organisms (Sogin 1997). A distinct group of flagellate isolates belonged to one of these deep branches, the Kinetoplastida (Figure 2.3), which together with euglenid, diplonemid, and Postgaardi flagellates constitute the eukaryotic taxon Euglenozoa (Linton et al. 1999; Simpson 1997). The diversity represented by these cultured flagellates is therefore comparable to different bacterial or archaeal phyla; the general morphological designation of the isolates as "flagellates" does not mirror the phylogenetic depth separating these superficially similar organisms.

The kinetoplastid flagellates from hydrothermal vents were related to different freeliving kinetoplastid species. Two isolates of $R$. nasuta (strains BSZ1 and CBR1) formed a monophyletic group with Dimastigella trypaniformis, a deep-branching, free-living kinetoplastid (Berchtold et al. 1994) (Figure 2.3). The isolate LFS2 could not be assigned to any known kinetoplastid species by morphological criteria. Its closest relative was an environmental isolate obtained from detritus-enriched lake water in the Netherlands (van Hannen et al. 1999) and to the free-living kinetoplastid Bodo saliens. Interestingly, Bodo saliens and Bodo caudatus do not form a monophyletic lineage.

The most frequently occurring flagellates, the six $M$. marina isolates with almost identical sequences, formed a monophyletic clade with other cercomonads - Cercomonas sp., Heteromita globosa and Thaumatomonas sp. - supported by nearly $100 \%$ bootstrap support (Figure 2.3). All Massisteria isolates, regardless of their diverse origin (Table 2.1), and the ATCC strain of M. marina showed at least $99 \%$ similarity over the complete length 
of the ssrDNA sequence. This new cluster could not be subsumed under another phylogenetic lineage within the eukaryotic crown group, but appears to be a distinct phylogenetic lineage on its own.

Five bicosoecid flagellates from the $9^{\circ} \mathrm{N}$ EPR vent site and a coastal marsh in Woods Hole constituted a second major phylogenetic cluster of isolates. Three Cafeteria strains were found; two of them (VENT1 and EWM2) showed more than $99.5 \%$ similarity to the type species Cafeteria roenbergensis (Fenchel and Patterson 1988) over the full length of the sequence, while the local salt marsh isolate EPM1 differed by 3.3\%. The two C. parvulus strains NBH4 and EWM2 had identical ssrDNA sequences. Together with the bicosoecid Siluania monomastiga (Karpov et al. 1998) and the pseudodendromonad Adriamonas peritocrescens (Verhagen et al. 1994), the Cafeteria and Caecitellus isolates form a clade with bootstrap support near $60 \%$. The situation is complicated by the erratic placement of the parasite Blastocystis. The best minimum evolution tree places Blastocystis into this clade with good bootstrap support (Figure 2.3). However, there is no significant difference in bootstrap support between the best minimum evolution tree and trees that exclude Blastocystis sp. from the shared basal node of Cafeteria, Caecitellus, Adriamonas and Siluania, and place it outside this group. Given the ambiguity of this sequence data, we do not view Blastocystis as a sister taxon of the bicosoecids and pseudodendromonads.

In contrast to the numerous kinetoplastids, Massisteria, and bicosoecid strains, some isolates were obtained a single time. Two of them were very closely related or identical to previously sequenced organisms. The Paraphysomonas sp. strain TPC2 showed $99.6 \%$ sequence similarity to the published sequence of Paraphysomonas foraminifera, placed into the well-supported Chrysomonadida group (Figure 2.3). Monosiga sp. strain BSZ6 was identical in all sequence positions to the published sequence of Monosiga brevicollis, a member of the Choanoflagellida (Figure 2.3). 
Ancyromonas sigmoides was one of the most unusual organisms in the vent flagellate collection. The sequence data disproved the previous provisional placements of Ancyromonas into the Opalozoa (Cavalier-Smith 1993; Mylnikov 1990) and the Euglenozoa (Larsen and Patterson 1990). It is therefore necessary to reorganize the Neomonada and Cercozoa sensu stricto (Cavalier-Smith 1997; Cavalier-Smith 1999). Based on its ssrDNA sequence, $A$. sigmoides is placed at the base of the clade that includes all choanoflagellates and DRIPs (Ragan et al. 1994) and thus forms a parallel branch to Apusomonas proboscidea (Cavalier-Smith and Chao 1995). Bootstrap support ties Ancyromonas and Apusomonas into a common clade with choanoflagellates, DRIP's and fungi (Figure 2.3).

\section{Discussion}

Occurrence patterns and ecology. An interesting observation regarding this particular group of vent flagellates is that many of them are ubiquitous members of marine, freshwater, and terrestrial ecosystems worldwide (Larsen and Patterson 1990; Lee and Patterson 1998; Patterson 1990; Patterson and Fenchel 1990; Patterson and Hedley 1992; Patterson and Larsen 1991; Patterson et al. 1993; Vørs 1992; Vørs 1993a; Vørs 1993b). Ancyromonas sigmoides, B. saliens, C. parvulus, Cafeteria sp., M. marina, and $R$. nasuta have been described as a naturally-occurring assemblage from environments as diverse as terrestrial garden soils (Ekelund and Patterson 1997), hypersaline habitats (Patterson and Simpson 1996), and highly contaminated marine sediments (New Bedford Harbor, Massachusetts; MSA., pers. observ.). Choanoflagellates, such as Diaphanoeca grandis, and chrysomonads, such as $P$. imperforata, have been observed, albeit with less frequency, cooccurring among the larger assemblage described above. The occurrence of $M$. marina at each of the vent sites suggests that its distribution in the deep sea is widespread and well established. 
While specific enrichment and culturing conditions may selectively favor growth of this group to the exclusion of numerically dominant species (see Lim et al. 1999), many of these flagellates are known to be tolerant and/or highly adaptable to a very wide range of environmental conditions (Patterson 1993; Patterson and Simpson 1996). This trait could account for the ubiquity of these flagellates in diverse and extreme habitats. Physiological experiments have measured the tolerance of $C$. parvulus, Cafeteria sp. and $R$. nasuta strains to some extreme conditions likely to be encountered at deep-sea vents. These organisms are highly tolerant and capable of surviving very harsh conditions, in some cases exceeding extreme vent conditions (Atkins et al. 1998; Atkins et al. submitted).

One important aspect of high tolerance and adaptability to a wide range of conditions was pointed out by Patterson (1993), namely the elimination of barriers that might stimulate speciation. It is remarkable that ssrDNA sequences from strains of $C$. parvulus (EWM1; NBH4), from strains of $R$. nasuta (BSZ1; CBR1), and from the two Cafeteria strains, C. roenbergensis (ATCC strain) and Cafeteria sp. (VENT1), separated by significant geographic barriers (both continental and oceanic), are virtually identical. As well, high sequence similarity between $M$. marina isolates from each of the vent sites along the Eastern Pacific (oceanic barrier) suggests that gene flow can, and perhaps does, occur through and around these large-scale barriers, thereby preventing speciation in selective niches. At least with respect to vent microorganisms, this evidence contradicts suggestions by Gage and Tyler (1991) that vents be considered as 'ephemeral, biogeographic islands to their endemic faunas' that result in restricted gene flow. Rather it appears that flagellates and other protists (Finlay et al. 1999) as well as prokaryotic organisms (Wirsen et al. 1998) have a global distribution unaffected by these large-scale barriers.

Lee and Patterson (1998) analyzed the distribution patterns of ca. 350 species of heterotrophic flagellates from 31 communities around the world and suggested that most communities are comprised of relatively few species of free-living flagellates and that most 
of these have a cosmopolitan distribution. They found that A. sigmoides, B. saliens, $C$. roenbergensis, $R$. nasuta and to a lesser degree $M$. marina and $P$. imperforata occur very widely (Lee and Patterson 1998). Now, similar results have been obtained from deep-sea vents in support of their conclusions.

Molecular analysis. The placement of the hydrothermal vent flagellates according to ssrDNA sequence analysis solves several systematic problems, while raising some new ones. The case of Caecitellus shows how sequence data can complement careful morphological study. Patterson et al. (1993) pointed out that Griessman (1913) previously assigned C. parvulus to the genus Bodo, but ultrastructural analysis revealed 1) mitochondria with tubular cristae, 2) lack of paraxial rods, 3) a mouth supported by a horseshoe-shaped arc of microtubules, 4) the microtubules are associated with massive electron-dense material, and 5) there is no kinetoplast. They concluded that these observations contradict assignment to the genus Bodo and assigned it to the new genus Caecitellus of uncertain taxonomic affinity. Subsequently, C. parvulus was placed as a sister group to Cafeteria within the Bicosoecida, based on kinetid architecture (O'Kelly and Nerad 1998). This placement is now supported by the sequence data reported here. Yet, other problems remain; while Caecitellus, pseudodendromonads, and bicosoecids sensu stricto (i.e. Bicosoeca, Cafeteria, and Pseudobodo) form a clade based on the presence of a U-shaped microtubular root, Caecitellus and pseudodendromonads do not possess mastigonemes whereas bicosoecids do. Therefore, placement of Caecitellus and pseudodendromonads as sister taxa within the Bicosoecida is not entirely correct. Based on the structural work of Patterson et al. (1993) and O'Kelly and Nerad (1998), and the current molecular analysis (Figure 2.3), a new taxon appears to be required for $[($ Caecitellus + Pseudodendromonads $)+($ bicosoecids $)]$ that takes these distinctions into account rather than simply making one group a subset of the other.

The placement of Blastocystis sp. among the bicosoecid/Caecitellus/pseudodendromonad lineages represents an unresolved polytomy in the minimum evolution tree: 
almost equal bootstrap support is available for inclusion as well as exclusion of Blastocystis sp. in the bicosoecid/Caecitellus/pseudodendromonad branch. Apparently, the highly divergent ssrRNA sequence of Blastocystis sp. and the unusual length of this branch interfere with a consistent phylogenetic placement. A previous phylogenetic study of Blastocystis placed it within the stramenopiles, but not as a sister taxon to $C$. roenbergensis (Silberman et al. 1996).

The inclusion of Thaumatomonas within the cercomonad clade is interesting because the best synapomorphy for the cercomonads is the paranuclear body, not present in thaumatomonads, although both groups have tubular mitochondrial cristae (Patterson 1999). Bootstrap support for this inclusion is consistently very high (always $>95 \%$ ). This area of flagellate phylogeny needs further investigation.

The problematic placements of Ancyromonas within the Opalozoa (Cavalier-Smith 1993; Mylnikov 1990) and Euglenozoa (Larsen and Patterson 1990) were based on morphological and ultrastructural criteria whose taxonomic ambiguity has been well documented (Ekelund and Patterson 1997; Patterson and Simpson 1996). Our results indicate that Ancyromonas, similar to Apusomonas, represents a new phylogenetic lineage basal to the opisthokont clade $[($ metazoa + choanoflagellates + DRIP's $)+($ fungi + chytrids $)]$ as suggested by Cavalier-Smith and Chao (1995). Although Ancyromonas and Apusomonas share a common basal node in the minimum evolution tree, this node has only very low bootstrap support (41\% distance/18\% parsimony, Figure 2.3 ) and is also not validated by ultrastructure; Ancyromonas has flattened mitochondrial cristae whereas apusomonads are tubulocristate. Additional taxon sampling within these groups is required to resolve this phylogeny. When Apusomonas is excluded from the analysis, bootstrap support for the opisthokont node increases significantly (from 17/56 to 97/62) suggesting a closer relationship between Ancyromonas and the platycristate opisthokonts. 
A question underlying the present study is how reliably ssrRNA sequences identify protists, in comparison to morphological and ultrastructural data. Current concerns regarding the limitations of ssrRNA data focus especially on its ability to resolve relative branching order, particularly in deeply-branching lineages. These were until recently regarded as ancestral, "amitochondriate" eukaryotes that preceded the later radiation of mitochondriate, modern eukaryotes in the "crown group" near the tip of the tree (Embley and Hirt 1998; Philippe and Laurent 1998; Roger 1999). The discovery of mitochondrial genes in "amitochondriate" taxa (Roger et al. 1996), as well as critical refinement in phylogenetic assessments (Philippe and Laurent 1998) are calling for a more restrained interpretation of deep branching patterns in ssrRNA phylogenies. Although questions of deep phylogeny remain to be resolved, ssrRNA analysis meanwhile emerges as a framework for protist identifications whose usefulness will strongly depend on sufficient detail and mutual correspondence of morphological and molecular data. Clearly delineated and mutually exclusive branches in the ssrRNA tree, for example the alveolates and the stramenopiles, correspond to protist clades defined by ultrastructural criteria; and in this regard, eukaryotic branches defined by rRNA phylogeny must make biological sense (Taylor 1999). However, the groundwork for assessing correspondences between morphological/ultrastructural and sequence data is far from being finished; for example, no precedent existed for the ssrRNA placement of Ancyromonas or Massisteria. Wherever phylogenetic precedents existed, as with the genera Cafeteria, Paraphysomonas and Monosiga, the genus-level morphological identifications were consistent with the sequence-based placements of the isolates, although in these specific cases the identification could not be carried further to the species level without speciesspecific morphological features.

Cosmopolitan flagellate species from a diversity of taxa inhabit deep-sea vent environments and may be key players in the microbial food webs there. Flagellate communities at deep-sea vents are comprised of highly adaptable, cosmopolitan species whose tolerance 
to a wide range of environmental conditions may be the selection criteria permitting them to exist in these extreme environments. Future work will address questions of abundance and tolerance of these organisms in their unique habitat. The combined approach of culturedependent and -independent methods of analysis should enable microbial ecologists to more fully and more accurately assess the diversity of microorganisms in complex environmental samples where uncultivable species often go unaccounted.

\section{Acknowledgments}

The authors would like to thank Drs. Lauren Mullineaux, Cindy Van Dover, John Rummel, Craig Taylor and Carl Wirsen for their collection efforts; Dr. Rolf Nimzyk and his staff at Genom Analytik in Bremen, Germany for the very high quality of their DNA sequencing and editing; and Drs. Kenneth Halanych, Andrew McArthur and Jeffrey Silberman for their helpful suggestions with the phylogenetic analyses. This work was supported by a National Science Foundation Graduate Research Fellowship, a National Science Foundation Coastal Research Traineeship, the Rhinehart Coastal Research Center and the Ocean Ventures Fund of the Woods Hole Oceanographic Institution and a grant from the PADI Foundation. Sampling at the $9^{\circ} \mathrm{N}$ EPR vents was made possible by NSF grant OCE-9019575 to Dr. Lauren S. Mullineaux. Sampling at the Guaymas Basin and $21^{\circ} \mathrm{N}$ EPR vents was made possible by LEXEN grant OCE-9714195 to Andreas Teske and Holger W. Jannasch. This is Woods Hole Oceanographic Institution contribution number 10159 and Lamont-Doherty Earth Observatory contribution number 6055. 


\section{References}

Altschul, S. F., W. Gish, W. Miller, E. W. Myers, and D. J. Lipman. 1990. Basic local alignment search tool. J. Mol. Biol., 215:403-410.

Anderson, O. R. 1992. Cytochemical localization of acid phosphatase (Lysosomal and digestive enzyme activity). In: Lee, J. J. and A. T. Soldo (ed.), Protocols in Protozoology, Allen Press, Kansas. pp. C22.21-C22.27.

Atkins, M. S., O. R. Anderson, and C. O. Wirsen. 1998. Effect of hydrostatic pressure on the growth rates and encystment of flagellated protozoa isolated from a deep-sea hydrothermal vent and a deep shelf region. Mar. Ecol. Prog. Ser., 171:85-95.

Atkins, M. S., M. A. Hanna, E. A. Kupetsky, M. A. Saito, C. D. Taylor, and C. O. Wirsen. submitted. Tolerance of flagellated protozoa to extreme environmental conditions potentially encountered at deep-sea hydrothermal vents: I. High sulfide; II. High concentrations of $\mathrm{Cu}, \mathrm{Fe}, \mathrm{Mn}$ and $\mathrm{Zn}$. Limnol. Oceanogr.

Bak, R. P. M., F. C. van Duyl, and G. Nieuwland. 1995. Organic sedimentation and macrofauna as forcing factors in marine benthic nanoflagellate communities. Microb. Ecol., 29(2): 173-182.

Bazylinski, D. A., J. W. Farrington, and H. W. Jannasch. 1988. Hydrocarbons in surface sediments from a Guaymas Basin hydrothermal vent site. Org. Geochem., 12(6):547558.

Berchtold, M., H. Philippe, A. Breunig, G. Brugerolle, and H. König. 1994. The phylogenetic position of Dimastigella trypaniformis within the parasitic kinetoplastids. Parasitol. Res., 80:672-679.

Burnett, B. R. 1977. Quantitative sampling of microbiota of the deep-sea benthos - I. Sampling techniques and some data from the abyssal central North Pacific. Deep-Sea Res., 24:781-789.

Burnett, B. R. 1979. Quantitative sampling of microbiota of the deep-sea benthos II. Evaluation of technique and introduction to the biota of the San Diego Trough. Trans. Am. Microsc. Soc., 98:233-242.

Burnett, B. R. 1981. Quantitative sampling of microbiota of the deep-sea benthos - III. The bathyal San Diego Trough. Deep-Sea Res., 28A:649-663.

Calvert, S. E. 1966. Origin of diatom-rich varved sediments from the Gulf of California. $J$. Geol., 76:546-565. 
Caron, D. A. 1991. Heterotrophic flagellates associated with sedimenting detritus. In: Patterson, D. J. and J. Larsen (ed.), The Biology of Free-Living Heterotrophic Flagellates, Special Volume 45. Clarendon Press, Oxford. pp. 77-92.

Cavalier-Smith, T. 1993. The protozoan phylum Opalozoa. J. Euk. Microbiol., 40:609-615.

Cavalier-Smith, T. 1997. Amoeboflagellates and mitochondrial cristae in eukaryote evolution: megasystematics of the new protozoan subkingdoms Eozoa and Neozoa. Archiv. Protistenkd, 147:237-258.

Cavalier-Smith, T. 1999. Zooflagellate Phylogeny and the Systematics of Protozoa. Biol. Bull., 196:393-396.

Cavalier-Smith, T., and E. E. Chao. 1995. The opalozoan Apusomonas is related to the common ancestor of animals, fungi and choanoflagellates. Proceedings of the Royal Society of London B, Biological Sciences, 261:1-6.

Corliss, J. O. 1984. The kingdom Protista and its 45 phyla. BioSys., 14:461-481.

Cunningham, J. R., and J. F. Ustach. 1992. Protozoan numbers and biomass in the sediments of the Blake Outer Ridge. Deep-Sea Res., 39:789-794.

Ekelund, F., and D. J. Patterson. 1997. Some heterotrophic flagellates from a cultivated garden soil in Australia. Arch. Protistenkd., 148:461-478.

Embley, T. M., and R. P. Hirt. 1998. Early branching eukaryotes? Curr. Opin. Genet. Dev., 8:624-629.

Fenchel, T., and D. J. Patterson. 1988. Cafeteria roenbergensis nov. gen., nov. sp., a heterotrophic microflagellate from marine plankton. Mar. Microb. Food Webs, 3:9-19.

Finlay, B. J., G. F. Esteban, J. L. Olmo, and P. A. Tyler. 1999. Global distribution of freeliving microbial species. Ecography, 22:138-144.

Gage, J. D., and P. A. Tyler. 1991. Deep-Sea Biology: A Natural History of Organisms at the Deep-Sea Floor, University Press, Cambridge. 504 pp.

Griessmann, K. 1913. Über marine Flagellaten. Arch. Protistenkd., 32(1914):1-78.

Heezen, B. C., and M. Tharp. 1977. World Ocean Floor. United States Navy, Office of Naval Research, Washington, D. C.

Karpov, S. A., R. Kersanach, and D. M. Williams. 1998. Ultrastructure and 18S rRNA gene sequence of a small heterotrophic flagellate Siluania monomastiga gen et sp. nov. (Bicosoecida). Europ. J. Protistol., 34:415-425.

Larsen, J., and D. J. Patterson. 1990. Some flagellates (Protista) from tropical marine sediments. J. Nat. His., 24:801-937. 
Lee, J. J., S. H. Hutner, and E. C. Bovee (ed.). 1985. An illustrated guide to the protozoa, Society of Protozoologists, Lawrence, Kansas.

Lee, W. J., and D. J. Patterson. 1998. Diversity and geographic distribution of free-living heterotrophic flagellates - analysis by PRIMER. Protist, 149:229-244.

Levine, N. D., J. O. Corliss, F. E. G. Cox, G. Deroux, J. Grain, B. M. Honigberg, G. F. Leedale, A. R. Loeblich, III, J. Lom, D. Lynn, E. G. Merinfeld, F. C. Page, G. Poljansky, V. Sprague, J. Vavra, and F. G. Wallace. 1980. A newly revised classification of the Protozoa. J. Protozool., 27:37-58.

Lim, E. L., M. R. Dennett, and D. A. Caron. 1999. The ecology of Paraphysomonas imperforata based on studies employing oligonucleotide probe identification in coastal water samples and enrichment cultures. Limnol. Oceanogr., 44(1):37-51.

Linton, E. W., D. Hittner, C. Lewandowski, T. Auld, and R. E. Triemer. 1999. A molecular study of euglenoid phylogeny using small subunit rDNA. J. Euk. Microbiol., 46:217223.

Margulis, L., J. O. Corliss, M. Melkonian, and D. J. Chapman (ed.). 1990. Handbook of Protoctista: The Structure, Cultivation, Habitats and Life Histories of the Eukaryotic Microorganisms and Their Descendants Exclusive of Animals, Plants and Fungi, 2nd ed., Jones and Bartlett,

Medlin, L., H. J. Elwood, S. Stickel, and M. L. Sogin. 1988. The characterization of enzymatically amplified eukaryotic 16S-like rRNA-coding regions. Gene, 71:491-499.

Mylnikov, A. P. 1990. Characteristic features of the ultrastructure of the colourless flagellate Heteromita sp. Tsitologiya, 32:567-571.

O'Kelly, C. J., and T. A. Nerad. 1998. Kinetid architecture and Bicosoecid affinities of the marine heterotrophic nanoflagellate Caecitellus parvulus (Griesmann, 1913) Patterson et al., 1993. Europ. J. Protistol., 34:369-375.

Patterson, D. J. 1990. Jakoba libera (Ruinen, 1938), a heterotrophic flagellate from deep oceanic sediments. J. Mar. Biol. Assoc. U.K., 70:381-393.

Patterson, D. J. 1993. The current status of the free-living heterotrophic flagellates. $J . E u k$. Microbiol., 40:606-609.

Patterson, D. J. 1999. The diversity of Eukaryotes. Am. Nat., 154 (supplement):S96-S124.

Patterson, D. J., and T. Fenchel. 1990. Massisteria marina Larsen \& Patterson 1990, a widespread and abundant bacterivorous protist associated with marine detritus. Mar. Ecol. Prog. Ser., 62:11-19. 
Patterson, D. J., and S. Hedley. 1992. Free-Living Freshwater Protozoa: A Color Guide, CRC Press, Boca Raton.

Patterson, D. J., and J. Larsen (ed.). 1991. The biology of free-living heterotrophic flagellates, Clarendon Press, Oxford.

Patterson, D. J., K. Nygaard, G. Steinberg, and C. M. Turley. 1993. Heterotrophic flagellates and other protists associated with oceanic detritus throughout the water column in the mid North Atlantic. J. Mar. Biol. Assoc. U.K., 73:67-95.

Patterson, D. J., and A. G. B. Simpson. 1996. Heterotrophic flagellates from coastal marine and hypersaline sediments in Western Australia. Europ. J. Protistol., 32:423-448.

Peter, J. M., P. Peltonen, and S. D. Scott. $1991 .{ }^{14} \mathrm{C}$ ages of hydrothermal petroleum and carbonate in Guaymas Basin, Gulf of California: Implications for oil generation, expulsion, and migration. Geology, 19:253-256.

Philippe, H., and J. Laurent. 1998. How good are deep phylogenetic trees? Curr. Opin. Genet. Dev., 8:616-623.

Ragan, M. A., C. L. Goggins, R. J. Cawthorn, L. Cerenius, A. V. C. Jamieson, S. M. Plourde, T. G. Rand, K. Söderhall, and R. R. Gutell. 1994. A novel clade of protistan parasites near the animal-fungal divergence. Proc. Nat. Acad. Sci. USA, 93:1190711912.

Roger, A. J. 1999. Reconstructing early events in eukaryotic evolution. Am. Nat., 154 (supplement):S146-S163.

Roger, A. J., C. G. Clark, and W. F. Doolittle. 1996. A possible mitochondrial gene in the early-branching amitochondriate protist Trichomonas vaginalis. Proc. Nat. Acad. Sci. USA, 93:14618-14622.

Schrader, H. 1982. Diatom biostratigraphy and laminated diatomaceous sediments from the Gulf of California, Deep Sea Drilling Project Leg 64. In: Curray, J. R. (ed.), Initial Reports of the Deep Sea Drilling Project, 64. U. S. Government Printing Office, Washington, D. C. pp. 973-981.

Silberman; J. D., M. L. Sogin, D. D. Leipe, and C. G. Clark. 1996. Human parasite finds taxonomic home. Nature, 380:398.

Silver, M. W., and A. L. Alldredge. 1981. Bathypelagic marine snow: deep-sea algal and detrital community. J. Mar. Res., 39:501-530.

Silver, M. W., M. M. Gowing, D. C. Brownlee, and J. O. Corliss. 1984. Ciliated protozoa associated with oceanic sinking detritus. Nature, 309:246-248. 
Simpson, A. G. B. 1997. The identity and composition of the Euglenozoa. Arch. Protistenkd., 148:318-328.

Sleigh, M. A., J. D. Dodge, and D. J. Patterson. 1984. Kingdom Protista. In: Barnes, R. S. K. (ed.), A Synoptic Classification of Living Organisms, Blackwell Scientific Publications, Oxford. pp. 25-88.

Small, E. B., and M. E. Gross. 1985. Preliminary observations of protistan organisms, especially ciliates, from the $21^{\circ} \mathrm{N}$ hydrothermal vent site. Biol. Soc. Wash. Bull., 6:401410.

Sogin, M. L. 1997. History assignment: when was the mitochondrion founded? Curr. Opin. Genet. Dev., 7:792-799.

Svavarsson, J., G. Gudmundsson, and T. Brattegard. 1993. Feeding by asellote isopods (Crustacea) on foraminifers (Protozoa) in the deep sea. Deep-Sea Res., 40(6):12251239.

Swofford, D. K., G. J. Olsen, P. J. Waddell, and D. M. Hillis. 1996. Phylogenetic inference. In: Hillis, D. M., C. Moritz, and B. K. Mable (ed.), Molecular Systematics, 2nd ed., Sinauer Associates, Sunderland, MA. pp. 407-514.

Swofford, D. L. 1999. PAUP*. Phylogenetic Analysis Using Parsimony (*and Other Methods). Sinauer Associates, Sunderland, Massachusetts.

Taylor, F. J. R. 1999. Ultrastructure as a control for protistan molecular phylogeny. Am. Nat., 154 (supplement):S125-S136.

Thompson, J. D., D. G. Higgins, and T. J. Gibson. 1994. CLUSTAL W: improving the sensitivity of progressive multiple sequence alignment through sequence weighting, positions-specific gap penalties and weight matrix choice. Nucleic Acids Res., 22:46734680.

Treco, D. A. 1987. Preparation of genomic DNA. In: Ausubel, F. M., R. Brent, R. E. Kingston, D. D. Moore, J. G. Seidman, J. A. Smith, and K. Struhl (ed.), Current Protocols in Molecular Biology, 1. John Wiley and Sons, Inc., New York. pp. 2.1.1-2.1.3.

Turley, C. M., K. Lochte, and D. J. Patterson. 1988. A barophilic flagellate isolated from $4500 \mathrm{~m}$ in the mid-North Atlantic. Deep-Sea Res., 35(7):1079-1092.

Van de Peer, Y., J. Jensen, P. De Rijk, and R. De Wachter. 1997. Database on the structure of small ribosomal subunit RNA. Nucleic Acids Res., 25:111-116.

van Hannen, E. J., W. Mooij, M. P. van Agterveld, H. J. Gons, and H. J. Laanbroek. 1999. Detritus-dependent development of the microbial community in an experimental system: 
qualitative analysis by denaturing gradient gel electrophoresis. Appl. Environ. Microbiol., 65:2478-2484.

Verhagen, F. J. M., M. Zölffel, G. Brugerolle, and D. J. Patterson. 1994. Adriamonas peritocrescens gen. nov., sp. nov., a new free-living soil flagellate (Protista, Pseudodendromonadidae incertae sedis). Europ. J. Protistol, 30:285-308.

Vørs, N. 1992. Heterotrophic amoebae, flagellates and heliozoa from the Tvärminne area, Gulf of Finland, in 1988-1990. Ophelia, 36(1):1-109.

Vørs, N. 1993a. Heterotrophic amoebae, flagellates and heliozoa from Arctic marine waters (North West Territories, Canada and West Greenland). Polar Biol., 13:113-126.

Vørs, N. 1993b. Marine heterotrophic amoebae, flagellates and heliozoa from Belize (Central America) and Tenerife (Canary Islands), with descriptions of new species, Luffisphaera bulbochaete n. sp., L. longihasti n. sp., L. turriformis n. sp., and Paulinella intermedia n. sp. J. Euk. Microbiol., 40(3):272-287.

Wirsen, C. O., T. Brinkhoff, J. Kuever, G. Muyzer, S. Molyneaux, and H. W. Jannasch. 1998. Comparison of a new Thiomicrospira strain from the Mid-Atlantic Ridge with known hydrothermal vent isolates. Appl. Environ. Microbiol., 64(10):4057-4059. 


\section{Chapter 3}

Ancyromonadida: a new phylogenetic lineage among the protozoa closely related to the common ancestor of Metazoans, Fungi, and Choanoflagellates (Opisthokonta)

Michael S. Atkins, Andrew G. McArthur, and Andreas P. Teske

Journal of Molecular Evolution, Submitted 
Abstract: Molecular and morphological evidence point to the ancyromonad Ancyromonas as a plausible candidate for the closest known relative to the common ancestor of Metazoans, Fungi, and Choanoflagellates (the Opisthokonta). Using 18S rDNA sequences from most of the major eukaryotic lineages, maximum likelihood, minimum evolution and maximum parsimony analyses yielded congruent phylogenies supporting this hypothesis. Combined with ultrastructural similarities between Ancyromonas and opisthokonts, the evidence presented here suggests that Ancyromonas may form an independent lineage, the Ancyromonadida Cavalier-Smith 1997, closer in its relationship to the opisthokonts than is its nearest protist relatives, the Apusomonadida. However, very low bootstrap support for deep nodes and hypothesis testing indicate that the resolving power of $18 \mathrm{~S}$ rDNA sequences is limited for examining this aspect of eukaryotic phylogeny. Alternate branching positions for the Ancyromonas lineage cannot be robustly rejected, revealing the importance of ultrastructure when examining the origins of multicellularity. The future use of a multi-gene approach may additionally be needed to resolve this aspect of eukaryotic phylogeny.

Key Words: Protozoa - Flagellate - Ancyromonas - Apusomonas - Opisthokont $・ 18 \mathrm{~S}$ small subunit ribosomal DNA • phylogeny 
Animals and true fungi, along with their protist relatives, the choanoflagellates and chytrids, comprise the largest major eukaryotic lineage with over 1 million species (Patterson 1999). Together, and exclusive of green plants, this group was hypothesized to form a single clade, the Opisthokonta, based on shared ultrastructural characteristics (Cavalier-Smith and Chao 1995). These characteristics include the presence of a unicellular motile stage (sperm in the case of animals) bearing a single posterior flagellum, similarities in flagellar root structure between choanoflagellates and chytrids (Cavalier-Smith 1987), and flattened mitochondrial cristae (Cavalier-Smith and Chao 1995). This hypothesis has found strong support from molecular research with the discovery of an insertion in the amino acid sequence of protein synthesis elongation factor $1 \alpha(\mathrm{EF}-1 \alpha)$, shared exclusively by animals and fungi (Baldauf and Palmer 1993), and in the molecular phylogenies of ribosomal RNA's (Van de Peer and De Wachter 1997; Wainright et al. 1993), actin, $\alpha$-tubulin, B-tubulin and EF-1 $\alpha$ proteins (Baldauf 1999), and other protein phylogenies (Nikoh et al. 1994). Recent molecular evidence also suggests that the Opisthokonta should include the Myxospora (previously considered a group of protozoa) as a subgroup within the Cnidaria (Smothers et al. 1994) and the Microspora as close relatives to the fungi (Hirt et al. 1999; Roger 1999).

While all opisthokonts have origins among the protozoa, it is uncertain whether these origins are mono- or polyphyletic. Some have argued for independent evolution of specific taxa, especially among the metazoa (Harbison 1985; Wilmer 1990), but many lines of evidence appear to favor monophyletic origins for opisthokonts (Baldauf 1999; Van de Peer and De Wachter 1997). One intriguing hypothesis posits that mitochondrial cristal morphology delineates large groups of organisms (Cavalier-Smith 1997; Taylor 1976; Taylor 1978), including the opisthokonts, of which all are platycristate (Cavalier-Smith and Chao 1995; Patterson 1999). With rare exceptions (e.g., among trypanosome life-history stages which alternate between discoid and tubular and in the mitochondria of mammalian 
adrenal cortex cells which are tubulo- rather than platycristate), cristal morphology appears to be highly conservative among and strikingly characteristic of groups of eukaryotic taxa. This may have resulted from polyphyletic origins of mitochondria (Stewart and Mattox 1984), pleiotropic effects following inchoative cell surface changes (Cavalier-Smith 1997) or other early evolutionary pathways. Based on this hypothesis, Wainright et al. (1993) predicted that the hypothetical protist representing the most recent common ancestor to the opisthokonts would have flattened mitochondrial cristae and other taxon-defining ultrastructural characteristics. A recent molecular analysis of 18S rDNA sequences from several species of flagellates isolated from deep-sea hydrothermal vents revealed that Ancyromonas, a flagellate with platycristate mitochondria, is related to the common ancestor of the opisthokonts (Atkins et al. in press). The current paper presents the phylogenetic position of Ancyromonas sigmoides based on maximum likelihood, minimum evolution, and maximum parsimony analyses of $18 \mathrm{~S}$ rDNA sequences from the major crown group lineages.

\section{Materials and Methods}

DNA isolation, PCR and sequencing. Ancyromonas sigmoides Kent strain ATCC50267 was grown to high density $\left(\geq 10^{6}\right.$ cells $/ \mathrm{ml}$ ) in seawater media (sterilized Vineyard Sound Seawater, $0.01 \%$ yeast extract, Halomonas halodurens bacteria as prey) then filtered over Millipore $2.0 \mu \mathrm{m}$ TTTP Isopore Membrane Filters (cat no. TTTP04700) to remove bacteria and PCR-inhibiting substances. Nucleic acids were isolated by hot phenol extraction: cells bound on individual filters were incubated in $500 \mu \mathrm{L}$ Lysis Buffer $(10 \mathrm{~g}$ sucrose, $2 \mathrm{ml} 1 \mathrm{M}$ Tris pH 8.0, brought up to $40 \mathrm{ml}$ with $\mathrm{MQH}_{2} \mathrm{O}$ ), $75 \mu \mathrm{L} 10 \%$ SDS and $25 \mu \mathrm{L}$ Proteinase $\mathrm{K}(20 \mathrm{mg} / \mathrm{ml})$ for 1 hour at $65^{\circ} \mathrm{C}$; then, $600 \mu \mathrm{L}$ hot $\left(65^{\circ} \mathrm{C}\right)$ phe- 
nol:chloroform:isoamyl alcohol (25:24:1) (Tris equilibrated to $\mathrm{pH} 8.0$ ) was added and incubation proceeded at $65^{\circ} \mathrm{C}$ for an additional 5-10 min. Continued phenol extraction and precipitation of genomic DNA was performed as described by Treco (1987).

Amplification of small subunit ribosomal (18S) DNA from DNA extracts was performed using standard polymerase chain reaction (PCR) protocols and general PCR primers A and B (Medlin et al. 1988). The standard protocol included a hot start at $95^{\circ} \mathrm{C}$ for 5 min, and continued with 35 cycles of denaturation at $94^{\circ} \mathrm{C}$ for 1 min, annealing at $55^{\circ} \mathrm{C}$ for $45 \mathrm{sec}$ and extension at $72^{\circ} \mathrm{C}$ for $2 \mathrm{~min}$, concluded by a final extension at $72^{\circ} \mathrm{C}$ for $10 \mathrm{~min}$. PCR product was column-purified using a Wizard PCR Prep (Promega, Madison, Wisconsin) following manufacturers protocols and sequenced directly on an ABI 377 Automated Sequencer using fluorescence-labeled sequencing dideoxyoligonucleotides. Internal sequencing primers (primer 514F: 5'-GTG CCA GCA SCC GCG G-3'; primer 920F: 5'GAA ACT TAA AGR AAT TG-3'; primer 690R: 3'-S TCT CCA CTT TAA GAA-5'; and primer 1055R: 3'-CC ACC ACG TAC CGG CRA-5') and flanking primers A and B were used to generate overlapping sequence contigs which covered the length of the 18S rDNA gene in both $3^{\prime}$ and $5^{\prime}$ directions. Overlapping sequence contigs were aligned and assembled using the AssemblyLIGN application within the MacVector Sequence Analysis Program (v 6.5, Oxford Molecular Limited). The sequence was deposited in GenBank under the accession number AF174363 (Atkins et al. in press).

Database search and phylogenetic analysis. Phylogenetically relevant $18 \mathrm{~S}$ rRNA sequences were obtained for species representing most of the major 'crown group' eukaryotes and euglenozoan flagellates. Initial alignments obtained with ClustalW (Thompson et al. 1994) were edited manually based on eukaryotic secondary structure consensus (Van de Peer et al. 1997). In the final analyses, regions which did not allow an unambiguous sequence alignment were excluded. These included motifs and helices whose length differed considerably between different phyla and sequences in the alignment: the 
variable region between helices 8 and 9; the tip of helix 10; the distal halves of helixes E101 and 11; the unpaired distal loop of helix 17; the complete helices E23-1 and 23-2; the tetraloop of helix 23-7; the unpaired distal loop of helix 29 ; the distal half of helix 43 ; the unpaired distal loop of helix 44; and the unpaired region connecting helix 45 and 46 . Incompletely sequenced terminal regions of the $18 \mathrm{~S}$ rRNA gene (Helices $1-4,49,50$ ) also were excluded from the alignment (Van de Peer et al. 1997). After masking these regions (655 alignment positions), the remaining sequence alignments included 1455 nucleotide positions.

Phylogenetic analyses of these alignments were performed using maximum parsimony, minimum evolution and maximum likelihood optimality criteria as performed by the computer program PAUP 4.0b2 (Swofford 1999). To obtain a sample of many equally parsimonious local minima, parsimony analyses were performed using 300 randomaddition replicates with tree-bisection-reconnection (TBR) branch swapping and restriction to a maximum of 20 trees per replicate. Since this random-addition approach would not find all equally parsimonious trees but instead a sample of each local minimum, the shortest nonidentical trees found were then subjected to further TBR swapping to find all equally or more parsimonious trees. Initial sampling of local minima in this manner saves computation time by avoiding complete swapping of possibly identical topologies found in different random-addition replicates. Bootstrapping of parsimony analyses used 1000 bootstrap replicates of 10 random-addition replicates each. Heuristic searches under the minimum evolution criterion were performed using 1000 random-addition replicates with TBR branch swapping. Bootstrapping of minimum evolution analyses used 1000 bootstrap replicates of 10 random-addition replicates each. Heuristic searches under the maximum likelihood criterion were performed using 5 random-addition replicates with TBR branch swapping. Bootstrapping of maximum likelihood analyses used 100 bootstrap replicates of 1 randomaddition replicate each. Models for use in minimum evolution and maximum likelihood 
searches were chosen using the likelihood ratio test (LRT) in the Modeltest program version 2 (Posada and Crandall 1998). In maximum likelihood analyses, models, their parameters and likelihood scores were initially estimated from the most parsimonious tree topologies. In case substitution dynamics may have severely mislead parsimony, models and parameters were then re-estimated from the best trees found under the initial likelihood criteria and the likelihood search was repeated. The significance of differences in likelihood among different topologies was examined using the test of Kishino and Hasagawa (1989) as implemented in PAUP. The alignment and model parameters used in these analyses are available upon request.

\section{Results and Discussion}

To examine the phylogenetic position of Ancyromonas, we included the lineages of the Opisthokont clade (animals, DRIP's, choanoflagellates and fungi) and the eukaryotic sister lineages basal to this clade, all of which constitute the 'crown group'. We use this term as short hand for the dense clustering of protist and plant lineages near the animal-fungal divergence that includes the stramenopiles, alveolates, green plants, green algae, red algae, cryptomonads, coccolithophores, and the chlorarachniophyte lineage (Van de Peer and De Wachter 1997). Sequences of known unstable phylogenetic position (Acanthamoeba, Hartmanella) were excluded from the final analysis, after initial heuristic searches and bootstrap runs had shown that these organisms are not related to Apusomonas and Ancyromonas. Acanthamoeba, for example, was shown to branch off the Opisthokont clade in one analysis (Wainright et al. 1993), and in another it was suggested that both Acanthamoeba and Hartmannella branch together off the plant lineage (Weekers et al. 1994). 
The best maximum likelihood tree (Figure $3.1 \mathrm{~A}$ ) and the best minimum evolution tree (Figure 3.1 B) consistently place Ancyromonas sigmoides closest to the basal node of animals, DRIP's, choanoflagellates and fungi. Here, it shares a common node with Apusomonas proboscoidea, with low bootstrap support (30 ML/ $44 \mathrm{ME} / 40 \mathrm{MP}$ ). Parsimony analysis separates Ancyromonas and Apusomonas into two distinct lineages that are intertwined with the green plants, red algae, cryptomonads and haptophytes; bootstrap does not support a specific branching order among these groups (Figure $3.1 \mathrm{C}$ ). The main lineages of the opisthokonts and the crown group remain mutually exclusive in all three trees and always show high bootstrap support of over $80 \%$. The shared node of Apusomonas and Ancyromonas in the maximum likelihood and minimum evolution tree does not have this strong bootstrap support, and is also not retrieved by parsimony analysis. A conservative interpretation of the sequence data holds that Ancyromonas and Apusomonas form phylogenetic lineages near the base of the Opisthokont clade. The Ancyromonas lineage, originally named Ancyromonadida (Cavalier-Smith 1998), cannot for now be robustly subsumed under any other crown group lineage, including the Apusomonadida.

Our results are congruent with the finding of Cavalier-Smith and Chao (1995) that Apusomonas is related to the common ancestor of the opisthokonts. The recent suggestion (Cavalier-Smith 1999) that Ancyromonas and Apusomonas are related based on loosely defined taxonomic criteria which permit inclusion of Jakoba, Reclinomonas and Caecitellus within the subphylum Apusozoa (Cavalier-Smith 1998) has to be modified. Apusomonas has been shown not to be related to Jakoba and Reclinomonas (Lang et al. 1999); and Apusomonas and Ancyromonas represent phylogenetic lineages different from the stramenopile Caecitellus parvulus (Atkins et al. in press). 
Figure 3.1 (next 3 pages). Best maximum likelihood (A) and minimum evolution (B) trees and one of six equally parsimonious trees (C) for Ancyromonas and Apusomonas within the eukaryotic crown group. All trees are unrooted. (A) This tree shows Ancyromonas and Apusomonas as a weakly supported monophyletic lineage basal to the opisthokonts; the same result was obtained in the best minimum evolution tree (B). (C) This tree resulted two times out of six equally parsimonious trees. An alternative tree occurred four times and placed Apusomonas as a paraphyletic lineage just basal to Ancyromonas (position A, Figure 3.1 C). Bootstrap support is lower for this alternate placement: $19 \mathrm{ME} /<5 \mathrm{MP}$ for the basal node of Ancyromonas/Apusomonas and $8 \mathrm{ME} /<5 \mathrm{MP}$ for the node between them (both of these trees have alternate versions where Chlorella/Zea mays becomes basal to the Rhodophyta, Cryptomonads and Coccolithophores; the four trees with Ancyromonas in position A show monophyletic DRIP's and choanoflagellates). Each tree in Figure 3.1 shows bootstrap values from 100 replicates in maximum likelihood and 1000 replicates each for minimum evolution and maximum parsimony (ML/ME/MP). Taxa with clearly defined synapomorphies showing $>90 \%$ bootstrap support in both minimum evolution and parsimony (except Mallomonas striata and Bacillaria paxillifer which were 84/61) were constrained to common ancestry in the maximum likelihood analysis to minimize computational intensity. These taxa are shown in Figure 3.1 with asterisks next to maximum likelihood bootstrap values. 


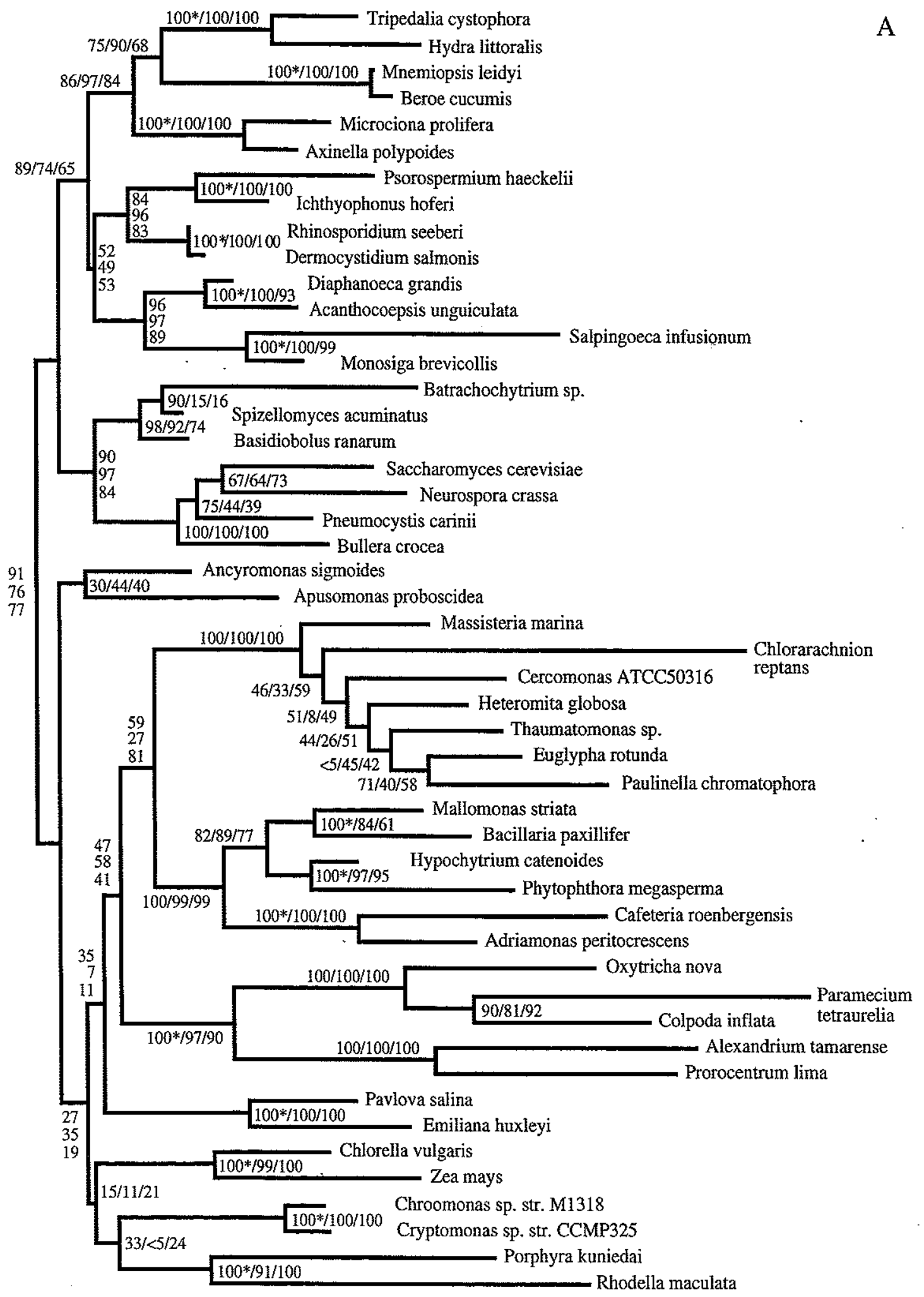

0.1

ML/ME/MP 


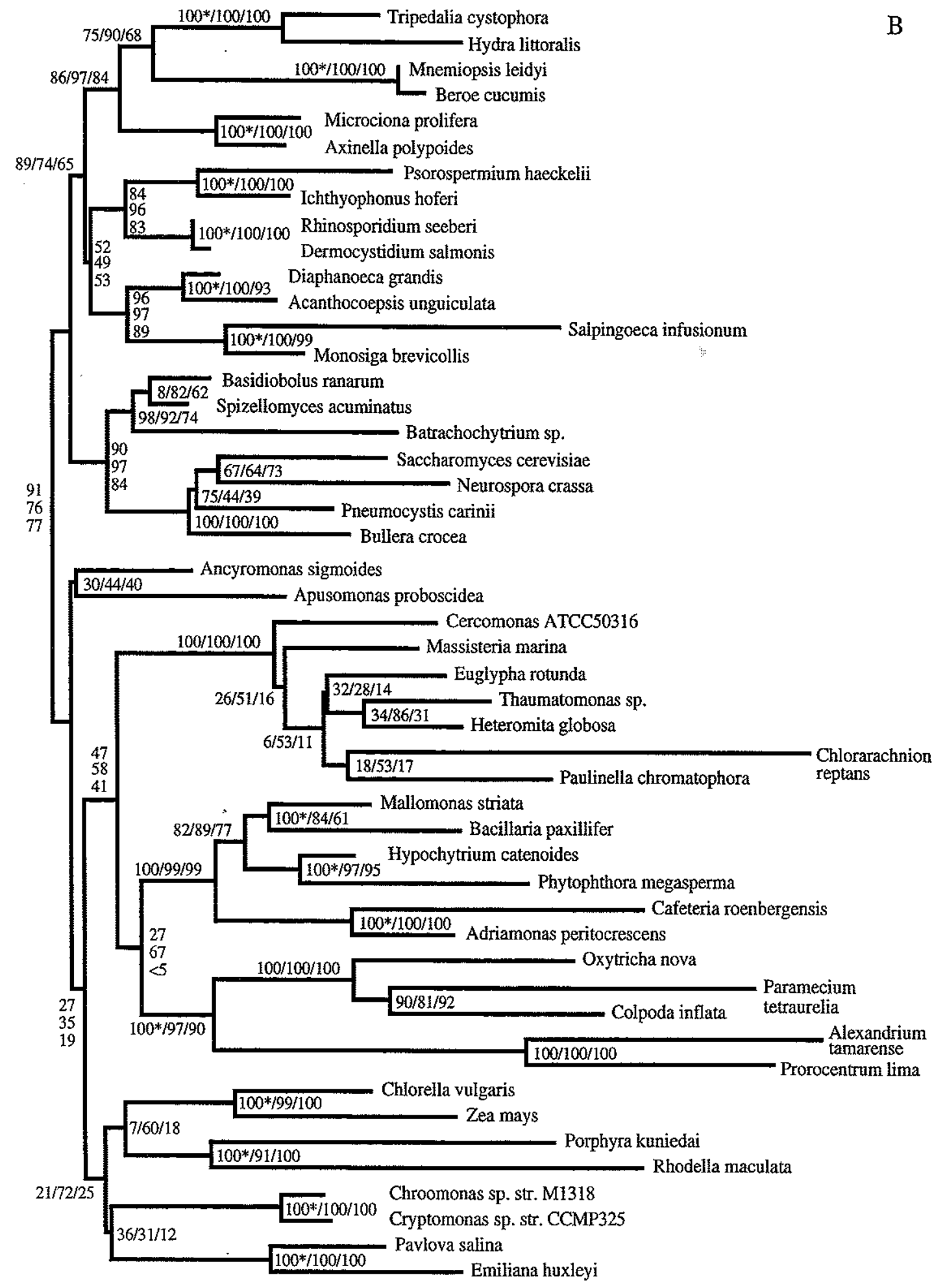

0.1

ML/ME/MP 


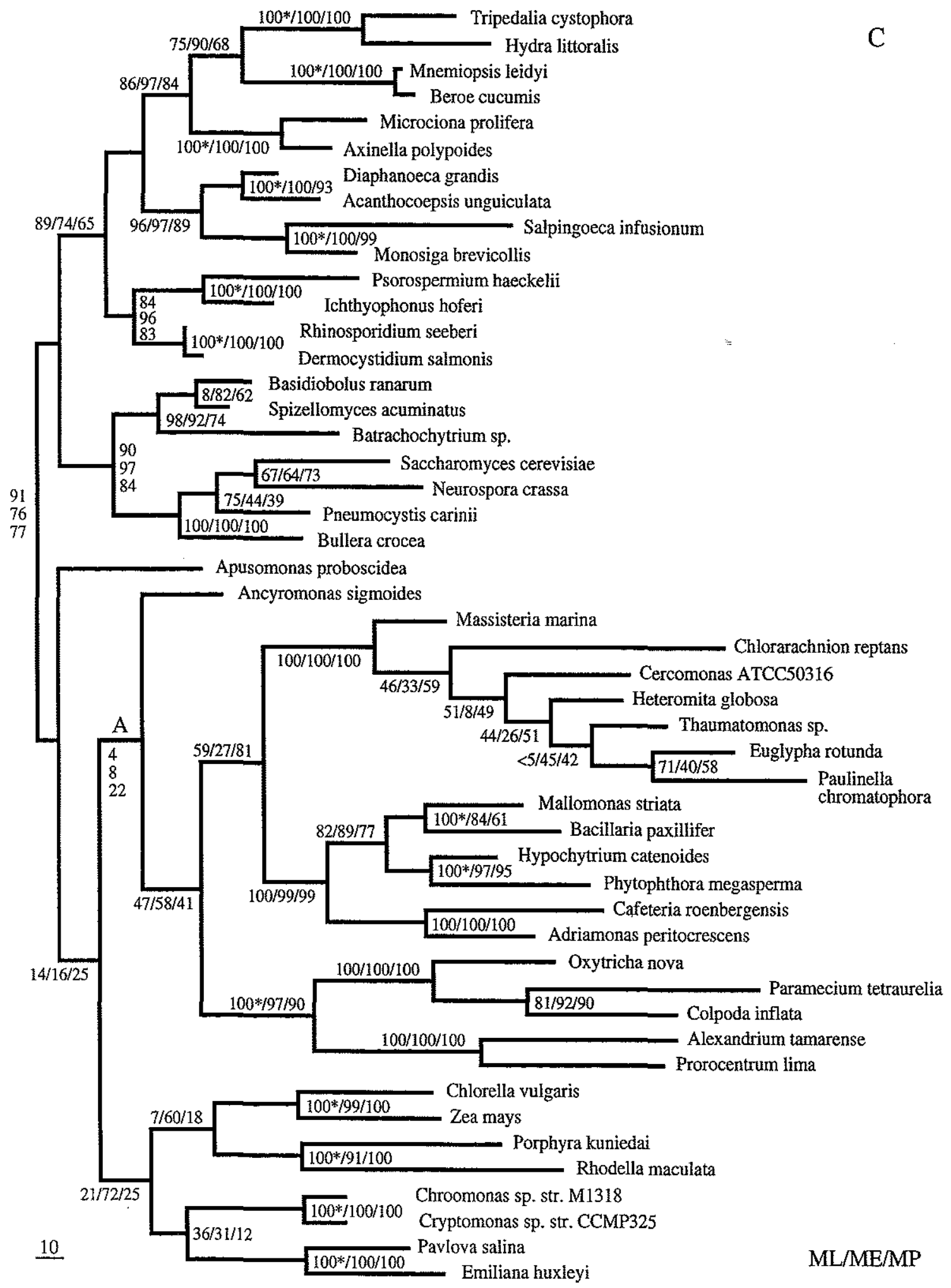


Analysis of 18S rDNA sequence data leave open whether Ancyromonas or Apusomonas is more closely related to the opisthokonts; a consistent hierarchical branching pattern that would place one organism closer to the base of the opisthokonts than another is not evident. The ultrastructure of mitochondrial cristae reveals significant differences between Ancyromonas and Apusomonas; Ancyromonas has flattened mitochondrial cristae (platycristae) whereas apusomonads are tubulocristate. Thus, Ancyromonas shares the characteristic flattened mitochondrial cristae of the opisthokonts, implying shared ancestry. CavalierSmith and Chao (1995) suggest that, based on molecular and morphological evidence, the flattened mitochondrial cristae of opisthokonts evolved from the tubular cristae of an apusomonad-like ancestor. We propose an alternative hypothesis in which the flattened cristae of opisthokonts were primarily evolved from an ancyromonad-like ancestor whose platycristate structure would have required fewer evolutionarily reconstructive events to derive contemporary opisthokont morphology than does the tubulocristate Apusomonas. This hypothesis does not rule out the possibility that the flattened cristae of Ancyromonas evolved from tubular cristae, but it does suggest that Ancyromonas is more closely related to the common ancestor of all opisthokonts than is Apusomonas, a hypothesis not incongruent with current molecular and ultrastructural data.

General phylogenetic patterns. We note some recurring features of this crown group phylogeny which have been found in previous attempts to resolve deep nodes between crown group lineages. The distance tree places alveolates and stramenopiles as sister groups (Figure $3.1 \mathrm{~B}$, bootstrap support 67\%), as previously found in distance analyses that took 18S rDNA site-to-site rate variation into account (Van de Peer and De Wachter 1996; Van de Peer and De Wachter 1997). In the maximum likelihood tree and the maximum parsimony tree, the cercomonad lineage, including Heteromita globosa, Massisteria marina and Chlorarachnion reptans, appears as the sister group of the stramenopiles, and cercomonads and stramenopiles together form the sister group to the alveolates. Independently of 
these differing branching patterns, the cercomonads, stramenopiles and alveolates always share a common basal node, with weak bootstrap support (47 ML/ $58 \mathrm{ME} / 41 \mathrm{MP})$. The green plants and algae, the red algae, cryptomonads and coccolithophores (haptophytes) do not fall into this group; these lineages branched off in variable configurations between the alveolate/stramenopile/cercomonad group on one side and Ancyromonas, Apusomonas and the opisthokont clade on the other. Although this pattern has no significant bootstrap support, it has been found independently several times in methodologically different crown group phylogenies (Cavalier-Smith and Chao 1995; Van de Peer and De Wachter 1997).

The poor or nonexistent bootstrap support for these hierarchical deep nodes among the crown group lineages indicates that $18 \mathrm{~S}$ rDNA data have reached the limits of their resolving power and do not resolve deep node topologies reliably (if the assumption of a sudden evolutionary radiation is no longer taken for granted; Philippe and Laurent 1998). It becomes impossible to decide with certainty between alternative connecting nodes for deeply branching phylogenetic lineages. Likelihood scores for different topologies for the placement of Ancyromonas and Apusomonas were examined using the Kishino-Hasagawa test (1989) (Table 3.1). Two alternative topologies to the best maximum likelihood tree (Figure 3.1 A) were tested; a common root for Ancyromonas, Apusomonas, and the Cercomonad clade (Table 3.1, tree 2); and no shared node for Ancyromonas and Apusomonas (Table 3.1, tree 3 and Figure 3.1 C). The first alternative topology reflects shared ancestry of Ancyromonas, Apusomonas and cercomonads in the phylum Opalozoa as previously suggested (Cavalier-Smith 1993). The second alternative topology corresponds to major ultrastructural differences between Ancyromonas and Apusomonas, especially with respect to the mitochondrial cristae. In both cases, the alternative topologies cannot be ruled out based on $18 \mathrm{~S}$ rDNA data alone. 


\begin{tabular}{|c|r|r|r|r|r|r|}
\hline Tree & - Ln Likelihood & Difference & S.D. & T-Value & P-value & Null Hypothesis \\
\hline 1 & 17251.26452 & BEST & & & & \\
\hline 2 & 17269.89549 & 18.63096 & 15.59707 & 1.1945 & 0.2325 & cannot reject \\
\hline 3 & 17262.09868 & 10.83416 & 12.83096 & 0.8444 & 0.3986 & cannot reject \\
\hline
\end{tabular}

Table 3.1. Results from Kishino-Hasagawa (1989) tests comparing different trees under maximum likelihood. Tree 1 is the very best maximum likelihood tree shown in Figure 3.1 A; tree 2 used the same data but constrained Ancyromonas and Apusomonas to be within the Cercomonad clade; tree 3 enforced separation of Ancyromonas and Apusomonas into two discrete clades (same as parsimony tree in Figure $1 \mathrm{C}$ ). The null hypothesis states that there is no significant difference between the best likelihood tree (Figure $1 \mathrm{~A}$ ) and the other trees tested.

In the case of Ancyromonas sigmoides, ultrastructural data suggest how to resolve the ambiguous phylogenetic placement found by our $18 \mathrm{~S}$ rDNA sequence analyses. Since 18S rDNA phylogeny and mitochondrial cristae morphology are not inconsistent (Taylor 1999), the shared feature of platycristate mitochondria ties Ancyromonas more strongly to the base of the opisthokont clade than 18S rDNA sequence alone. Additional gene phylogenies for Ancyromonas and Apusomonas could further clarify Ancyromonas' role as a possible precursor of multicellular life.

\section{Acknowledgements.}

MSA was supported by the Education Office of the Woods Hole Oceanographic Institution, AGM was supported by funds to M. Sogin from the G. Unger Vetlesen Foundation and NASA Astrobiology Cooperative Agreement NCC2-1054; APT was supported by a WHOI subcontract of this NASA Astrobiology Cooperative Agreement. This is Woods Hole Oceanographic Institution contribution number 0000. 


\section{References}

Atkins, M. S., A. P. Teske, and O. R. Anderson. 2000. A Survey of Flagellate Diversity at Four Deep-Sea Hydrothermal Vents in the Eastern Pacific Ocean Using Structural and Molecular Approaches. J. Euk. Microbiol., 47(4): In Press.

Baldauf, S. L. 1999. A search for the origins of Animals and Fungi: Comparing and combining molecular data. Am. Nat., 154 (supplement):S178-S188.

Baldauf, S. L., and J. D. Palmer. 1993. Animals and fungi are each other's closest relatives: congruent evidence from multiple proteins. Proc. Nat. Acad. Sci. USA, 90:1155811562.

Cavalier-Smith, T. 1987. The origin of Fungi and pseudofungi. In: Rayner, A. D. M., C. M. Brasier, and D. Moore (ed.), Evolutionary biology of the Fungi, Cambridge University Press, Cambridge. pp. 339-353.

Cavalier-Smith, T. 1993. The protozoan phylum Opalozoa. J. Euk. Microbiol., 40:609-615.

Cavalier-Smith, T. 1997. Amoeboflagellates and mitochondrial cristae in eukaryote evolution: megasystematics of the new protozoan subkingdoms Eozoa and Neozoa. Archiv. Protistenkd, 147:237-258.

Cavalier-Smith, T. 1998. Neomonadida and the origin of animals and fungi. In: Coombs, G. H., K. Vickerman, M. A. Sleigh, and A. Warren (ed.), Evolutionary Relationships Among Protozoa, Klewer Academic Publishers, London. pp. 375-407.

Cavalier-Smith, T. 1999. Zooflagellate Phylogeny and the Systematics of Protozoa. Biol. Bull., 196:393-396.

Cavalier-Smith, T., and E. E. Chao. 1995. The opalozoan Apusomonas is related to the common ancestor of animals, fungi and choanoflagellates. Proc. Roy. Soc. Lond. B, Biol. Sci., 261:1-6.

Harbison, G. R. 1985. Conway Morris, S., J. D. George, R. Gibson, and H. M. Platt (ed.), The Origins and Relationships of Lower Invertebrates, Clarendon Press, Oxford. pp. 78-100.

Hirt, R. P., J. M. Logsdon, B. Healy, M. W. Dorey, W. F. Doolittle, and T. M. Embley. 1999. Microsporidia are related to fungi: evidence from the largest subunit of RNA polymerase II and other proteins. Proc. Nat. Acad. Sci. USA, 95:580-585. 
Kishino, H., and M. Hasegawa. 1989. Evaluation of the maximum likelihood estimate of the evolutionary tree topologies from DNA sequence data, and the branching order of Hominoidea. J. Mol. Evol., 29:170-179.

Lang, B. F., E. Seif, M. W. Gray, C. J. O'Kelly, and G. Burger. 1999. A comparative genomics approach to the evolution of eukaryotes and their mitochondria. J. Euk. Microbiol., 46(4):320-326.

Medlin, L., H. J. Elwood, S. Stickel, and M. L. Sogin. 1988. The characterization of enzymatically amplified eukaryotic 16S-like rRNA-coding regions. Gene, 71:491-499.

Nikoh, N., N. Hayase, E. Iwabe, K. Kuma, and T. Miyata. 1994. Phylogenetic relationship of the kingdoms Animalia, Plantae, and Fungi, inferred from 23 different protein species. Mol. Biol. Evol., 11:762-768.

Patterson, D. J. 1999. The diversity of Eukaryotes. Am. Nat., 154 (supplement):S96-S124.

Philippe, H., and J. Laurent. 1998. How good are deep phylogenetic trees? Curr. Opin. Genet. Dev., 8:616-623.

Posada, D., and K. A. Crandall. 1998. MODELTEST: testing the model of DNA substitution. Bioinformatics, 14(9):817-818.

Roger, A. J. 1999. Reconstructing early events in eukaryotic evolution. Am. Nat., 154 (supplement):S146-S163.

Smothers, J. F., C. D. von Dohlen, L. H. J. Smith, and R. D. Spall. 1994. Molecular evidence that the Myxozoan protists are metazoans. Science, 265:1719-1721.

Stewart, K. D., and K. R. Mattox. 1984. The case for a polyphyletic origin of mitochondria: morphological and molecular comparisons. J. Mol. Evol., 21:54-57.

Swofford, D. L. 1999. PAUP*. Phylogenetic Analysis Using Parsimony (*and Other Methods). Sinauer Associates, Sunderland, Massachusetts.

Taylor, F. J. R. 1976. Flagellate phylogeny: a study in conflicts. J. Protozool., 23:28-40.

Taylor, F. J. R. 1978. Problems in the development of an explicit hypothetical phylogeny of the lower eukaryotes. BioSys., 10:67-89.

Taylor, F. J. R. 1999. Ultrastructure as a control for protistan molecular phylogeny. Am. Nat., 154 (supplement):S125-S136.

Thompson, J. D., D. G. Higgins, and T. J. Gibson. 1994. CLUSTAL W: improving the sensitivity of progressive multiple sequence alignment through sequence weighting, positions-specific gap penalties and weight matrix choice. Nucleic Acids Res., 22:46734680 . 
Treco, D. A. 1987. Preparation of genomic DNA. In: Ausubel, F. M., R. Brent, R. E. Kingston, D. D. Moore, J. G. Seidman, J. A. Smith, and K. Struhl (ed.), Current Protocols in Molecular Biology, 1. John Wiley and Sons, Inc., New York. pp. 2.1.1-2.1.3.

Van de Peer, Y., and R. De Wachter. 1996. The evolution of Stramenopiles and Alveolates as derived by "substitution rate calibration" of small ribosomal subunit RNA. J. Mol. Evol., 42:201-210.

Van de Peer, Y., and R. De Wachter. 1997. Evolutionary relationships among the eukaryotic crown taxa taking into account site-to-site rate variation in 18S rRNA. J. Mol. Evol., 45:619-630.

Van de Peer, Y., J. Jensen, P. De Rijk, and R. De Wachter. 1997. Database on the structure of small ribosomal subunit RNA. Nucleic Acids Res., 25:111-116.

Wainright, P. O., G. Hinkle, M. L. Sogin, and S. K. Stickel. 1993. Monophyletic origins of the metazoa: an evolutionary link with fungi. Science, 260:340-342.

Weekers, P. H. H., R. J. Gast, P. A. Fuerst, and T. J. Byers. 1994. Sequence variation in small-subunit ribosomal RNAs of Hartmannella vermiformis and their phylogenetic implications. Mol. Biol. Evol., 11(4):684-690.

Wilmer, P. 1990. Invertebrate relationships: patterns in animal evolution, Cambridge University Press, Cambridge. 


\section{Chapter 4}

Detection and distribution patterns of kinetoplastid flagellates at deep-sea hydrothermal vents as determined by culturing and denaturing gradient gel electrophoresis

Michael S. Atkins and Andreas P. Teske

Applied and Environmental Microbiology, In Preparation 
Abstract: To determine the presence and distribution patterns of flagellates at deep-sea hydrothermal vents, we tested the combined approach of a culture-dependent and a cultureindependent method. Deep-sea vent samples were both cultured to select for kinetoplastid flagellates and analyzed without culturing by Denaturing Gradient Gel Electrophoresis (DGGE) using PCR primers specific to all kinetoplastids and some euglenids. By comparing these two different methods of analysis, our goal was to decrease the biases and/or errors inherent in either method alone and to improve our ability to assess flagellate diversity and distribution in these remote environments. Three species of kinetoplastid flagellates (Bodo saliens, Rhynchomonas nasuta, and an unidentified kinetoplastid isolate were isolated and cultured from two deep-sea vents, Juan de Fuca and $9^{\circ} \mathrm{N}$ on the East Pacific Rise. PCR and DGGE was used to specifically isolate and amplify target DNA's from these three species in matching vent samples, thus corroborating the findings of culturing. Molecular methods had the additional ability to detect the presence of Bodo saliens and Rhynchomonas nasuta at two vent sites where culturing did not, thereby providing a better indication of the distribution of these species.

Key Words: Kinetoplastids $\bullet$ Bodo saliens $\cdot$ Rhynchomonas nasuta $\bullet$ deep-sea hydrothermal vents $\bullet$ culturing $\bullet$ denaturing gradient gel electrophoresis $\bullet$ small subunit ribosomal DNA 
Flagellated protists are ubiquitous members of the vast majority of Earth's habitable environments. They are an important intermediary in energy and nutrient transfer between bacteria and metazoa and in remineralization processes within microbial food webs (Azam and Ammerman 1984; Caron et al. 1985). Methods of determining their presence and abundance in natural environments, therefore, are useful in estimating the significance of their role in these ecological processes. Determining the presence and identity of flagellate species in environmental samples is usually accomplished by direct observation and culturing (Alongi 1986; Bloem et al. 1986; Caron et al. 1989; Epstein 1995; Gasol 1993). If laboratory cultivation or microscopical identification turn out to be difficult, or if an assay for parallel screening of multiple samples is required, molecular approaches can monitor presence and identify taxa of phylogenetically defined target organisms which share similarities in conserved marker genes. For example, the steadily improving data base of small subunit ribosomal RNA genes of protists allows the development of group-specific PCR-based or fluorescent hybridization assays for phylogenetically defined protist groups (Lim et al. 1993; Lim et al. 1995; Marché et al. 1995; Maslov et al. 1996; Wright et al. 1999). These molecular tools becomé especially relevant for monitoring the presence of organisms whose physiological responses to particular environmental stresses are known. Furthermore, the molecular detection of an organism at specific locations under specific environmental stresses will allow researchers to infer to some degree the currently activated physiological responses. By comparing results of independent methods of analysis (e.g., culturing and molecular analysis of environmental samples in addition to measuring physiological responses of cultured organisms to environmental conditions) the presence of specific species in remote locations can be determined more accurately and connected to physiological responses or properties that allow survival and growth under in-situ conditions.

We determined the presence of flagellates at deep-sea hydrothermal vents with the combined approach of a culture-dependent and a culture-independent (i.e., molecular) 
method. Among PCR-based detection and identification methods, Denaturing Gradient Gel Electrophoresis has become a very versatile and widely applied approach for simultaneous determination of presence and species diversity of microorganisms in environmental samples (Muyzer and Smalla 1998). In this study, DGGE was used to compare cultured kinetoplastid flagellates from vent samples to the uncultured kinetoplastid population in the same samples, and to identify uncultured community members. By comparing these two different methods of analysis, our goal was to decrease the biases and/or errors inherent in either method alone and to improve our ability to assess flagellate diversity in these remote environments. The pattern of kinetoplastid distribution determined using this combined approach is hypothesized to be more consistent than the results of cultivation or DGGE alone.

\section{Methods and Materials}

Sample collection, culturing and identification. Collection and culturing of hydrothermal vent flagellates was reported previously (Atkins et al. 1998; Atkins et al. in press). In short, samples were collected for cultivation and inoculated into several kinds of enrichment media, some selective for kinetoplastid flagellates (Nerad and Daggett 1992); replicate subsamples of the same materials were fixed in $3.7 \%$ formalin and in $70 \%$ ethanol, and also frozen at $-80^{\circ} \mathrm{C}$. Cultured hydrothermal vent flagellates were isolated in pure culture, and were identified by microscopy and ssrDNA sequence analysis (Atkins et al. in press) as members of the kinetoplastid clade within the Euglenozoa, (Figure 4.1).

DGGE primer design. The $18 \mathrm{~S}$ small subunit ribosomal DNA genes of vent isolates were sequenced and aligned with database sequences of several eukaryotic taxa to generate ssrDNA phylogenies (Atkins et al. in press; Atkins et al. submitted) and to design clade-specific PCR primers for use in DGGE analyses. PCR primer sites complementary to 


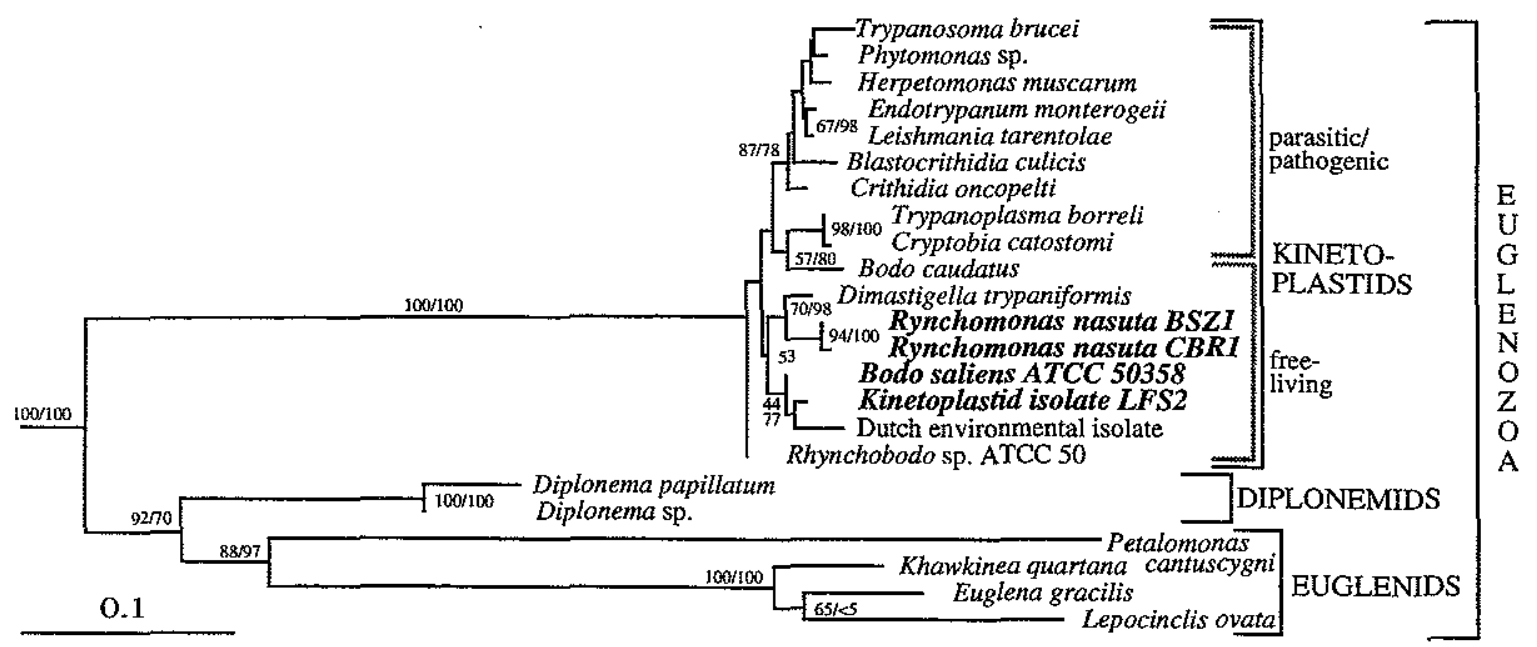

Figure 4.1. Detail from a previously published ssrDNA distance tree (Atkins et al. in press) showing three of the four subgroups within the Euglenozoan clade (Simpson 1997). Cultured hydrothermal vent isolates (and shallow-water strain CBR1) are shown in bold type. An isolate identified as Bodo saliens that later failed to culture was replaced by an ATCC strain of that species. Taxa whose sequences were obtained from ribosomal databases are shown in regular type. The evolutionary distance between two organisms is obtained by the summation of the length of the connecting branches along the horizontal axis, using the scale at the bottom. The unit of distance is one substitution per nucleotide. Numbers at nodes show percent bootstrap support from distance (minimum evolution) and maximum parsimony, using 1,000 replicates each.

euglenozoa-specific targets within the $18 \mathrm{~S}$ gene were found which amplified a 329-432 base pair fragment. The fragment includes the $5^{\prime}$-end of stem 32, the $5^{\prime}$-side of stems 33 and 34 , helix 35 , the 5 'side of stem 36 , helix 37 , and the complete stems and helices $38,39,40,41$, 42, 43 and 44 (Van de Peer et al. 1997). Although the primer design originally aimed at including all euglenozoan flagellates, and at a broader specificity compared to primers targeted at more narrowly defined kinetoplastid subgroups of clinical interest (trypanosomatids), it became impossible to include all currently sequenced euglenozoa (as listed in Linton et al. 1999). Diplonemids, euglenids and kinetoplastids are currently represented in the ssrDNA database and represent three of the four major euglenozoan subgroups (Simpson 1997); Postgaardi sequences have not been published. The primer pair developed in this study excludes a number of euglenozoan taxa, in particular diplonemids and a number of euglenids 
(Table 4.1), and is therefore specific for kinetoplastids and a limited set of euglenozoa, but not for all euglenozoa. For this reason, the primers are not considered euglenozoa-specific. With their broader target range including some euglenozoa, these primers differ from the kinetoplastid-specific probe described by van Hannen et al. (1998). Primer Kinetoplastid Forward (Kin F) is a 20 -mer with two ambiguous bases at loci 16 and 17 (5'-GAA TGG CAC CAC AAG RYG TG-3'). Primer Kinetoplastid Reverse (Kin R) is also a 20-mer, but without any ambiguities (3'-GT CGT CCA GAC ACT ACG AGG-5'). A 40 base GC-tail (3'-G GGG GGC ACG GGG GCG GGG CGG GCG GCG CGC GCC GCC CGC-5') was added to the 5' end of primer Kin R to generate fragments with a GC-'zipper' for use in DGGE (see Lessa and Applebaum (1993); Muyzer et al. (1993) and Muyzer et al. (1996) for theoretical and applied descriptions of DGGE).

\begin{tabular}{|l|c|c|c|c|c|}
\hline \multicolumn{1}{|c|}{ No Mismatches } & F/R & One Mismatch & F/R & Two or More Mismatches & F/R \\
\hline Kinetoplastids (all) & $0 / 0$ & & & & \\
\hline Euglenids & & Euglenids & & Euglenids & \\
\hline Astasia longa & $0 / 0$ & Euglena mutabilis & I/0 & Distigma spp. (2 species) & $1 / 2$ \\
\hline Colacium vesiculosum & $0 / 0$ & Euglena stellata & $0 / 1$ & Gyropaigne lefevrei & $0 / 2$ \\
\hline Euglena spp. (6 species) & $0 / 0$ & Eutreptiella gymnasticum & $0 / 1$ & Peranema trichophorum & $2 / 0$ \\
\hline Khawkinea quartana & $0 / 0$ & Eutreptiella pertyi & $1 / 0$ & Petalomonas cantuscygni & $5 / 1$ \\
\hline Lepocinclis spp. (3 species) & $0 / 0$ & & & Diplonemids & \\
\hline Phacus spp. (3 species) & $0 / 0$ & & & Diplonema spp. (2 species) & $2 / 1$ \\
\hline Strombomonas sp. & $0 / 0$ & & & & \\
\hline Trachelomonas spp. (2 species) & $0 / 0$ & & & Non-Euglenozoa & $>2$ \\
\hline
\end{tabular}

Table 4.1. The number of mismatches between euglenozoan target sequences in the ssrDNA gene and the PCR primers Kin F (F) and Kin R (R), which match kinetoplastids and several euglenid taxa. There are 2 mismatches between Kin $\mathrm{F}$ and both diplonemid species. The ubiquitous marine euglenid, Petalomonas showed 5 mismatches with Kin F. Mismatches to other major flagellate taxa were in all cases $>2$. The Euglenozoan clade includes four major subgroups: diplonemids euglenids, kinetoplastids, and Postgaardi (Simpson 1997). 
Testing primer specificity. To test the specificity of primers Kin $F$ and $R$ for euglenozoan flagellates during PCR amplification, an Eppendorf Mastercycler Gradient thermal cycler (Hinz GmbH, Hamburg, Germany) was used to determine the approximate annealing temperature that yielded PCR products for euglenozoan flagellates and no products for any other flagellate taxa tested. Small subunit ribosomal DNA from pure-cultured flagellates was prepared for PCR as described by Atkins et al. (in press). The gradient cycler was set with a mid-point block temperature of $67^{\circ} \mathrm{C}$ and a gradient of $\pm 10^{\circ} \mathrm{C}$. The PCR program included a hot start at $95{ }^{\circ} \mathrm{C}$ for $5 \mathrm{~min}$, and continued with 35 cycles of denaturation at $94{ }^{\circ} \mathrm{C}$ for $1 \mathrm{~min}$, annealing at variable temperatures along the gradient for 45 sec and extension at $72{ }^{\circ} \mathrm{C}$ for $2 \mathrm{~min}$, concluded by a final extension at $72{ }^{\circ} \mathrm{C}$ for $10 \mathrm{~min}$. The gradient cycler indicated an optimal annealing temperature near $68^{\circ} \mathrm{C}$ (Figure 4.2). Subsequently, annealing temperatures near $68^{\circ} \mathrm{C}$ were tested in $0.5^{\circ} \mathrm{C}$ increments using the Perkin-Elmer GeneAmp PCR System 9700 thermal cycler (Roche Molecular Systems, Inc., Branchburg, NJ, USA). The optimal annealing temperature for kinetoplastid specificity using primers Kin $\mathrm{F} / \mathrm{R}$ was determined to be $68.5^{\circ} \mathrm{C}$ (Figure 4.3). For Caecitellus parvulus and Cafeteria sp. there is a very narrow range between specific and non-specific annealing temperatures $\left(0.5^{\circ} \mathrm{C}\right)$. Therefore, we tested our instrument's ability to accurately achieve experimental temperatures using a Type $\mathrm{K}$ Thermocouple Thermometer (Model 360, Omega Engineering, Inc.). There was $100 \%$ agreement between our instrument and the thermocouple thermometer at all experimental temperatures. The GeneAmp PCR System 9700 thermal cycler is certified by Perkin Elmer Applied Biosystems to have a temperature accuracy of $\pm 0.25^{\circ} \mathrm{C}$ over the range $35-100{ }^{\circ} \mathrm{C}$ (PE Applied Biosystems). 
Figure 4.2. Agarose gel results of a temperature gradient PCR with primers $\mathrm{Kin} F / \mathrm{R}$, to determine an approximate annealing temperature that would specifically amplify euglenozoan flagellates while excluding non-euglenozoa. Euglenozoans: E. gracilis and B. caudatus; Non-euglenozoans: cercomonads, M. marina; choanoflagellates, Monosiga sp.; stramenopiles, C. parvulus, Cafeteria sp., and M. papillosa. Fragment sizes range from 329432 base pairs. Vertical lines indicate approximate annealing temperatures along the PCR block gradient; the heavy line $\left(68^{\circ} \mathrm{C}\right)$ corresponds to the approximate temperature at which specificity occurs. 


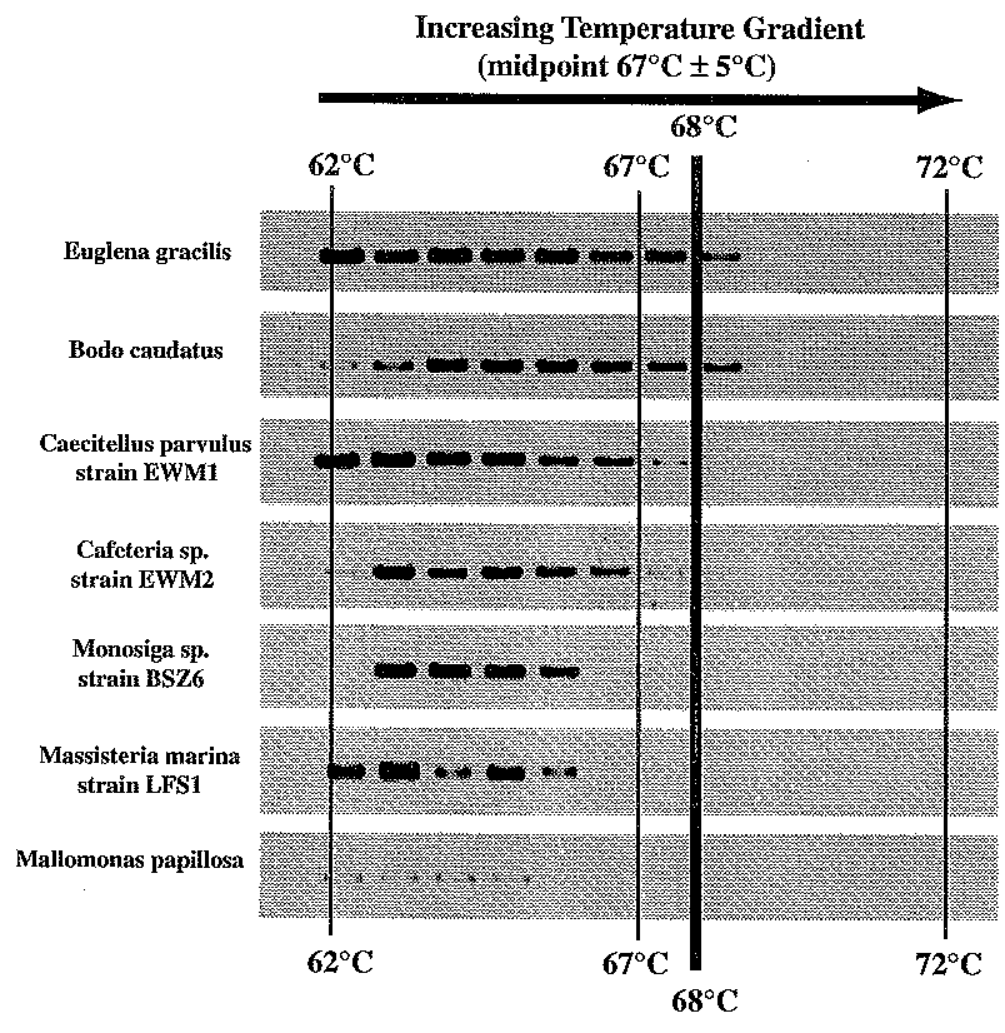


Figure 4.3. Agarose gel results of PCR products amplified while optimizing annealing temperature for euglenozoan specificity using primers KinF/R. Taking the results from temperature gradient PCR (Figure 4.2), the optimal annealing temperature for the desired specificity was determined to be $68.5^{\circ} \mathrm{C}$. The difference of $0.5^{\circ} \mathrm{C}$ between specific and non-specific results is within the accuracy of the instrument used. $M=1 \mathrm{~kb}$ ladder marker (Promega Corp.); Lanes: euglenozoa: 1 = Euglena gracilis; $2=$ Bodo caudatus; $3=$ Rhynchomonas nasuta strain CBR1; 4 = Rhynchomonas nasuta strain BSZ1; 5 = kinetoplastid isolate LFS2; non-euglenozoa: 6 = Ancyromonas sigmoides; 7-12 = Massisteria marina strains GBB2, DFS1, LFS1, CAS1 and TPC1; 13 = Monosiga sp. strain BSZ6; $14=$ Cafeteria sp. strain EWM2; 15 = Cafeteria sp. strain VENT1; $16=$ Caecitellus parvulus strain EWM1; $17=$ Caecitellus parvulus strain NBH4; $18=$ Mallomonas papillosa $; 19=$ Cafeteria sp. strain EPM1;20 = Cafeteria sp. strain EWM2;21 = Jakoba libera $; 22=$ unidentified vent isolate GBB1; 23 = Paraphysomonas sp. strain TPC2; Neg = negative control. 

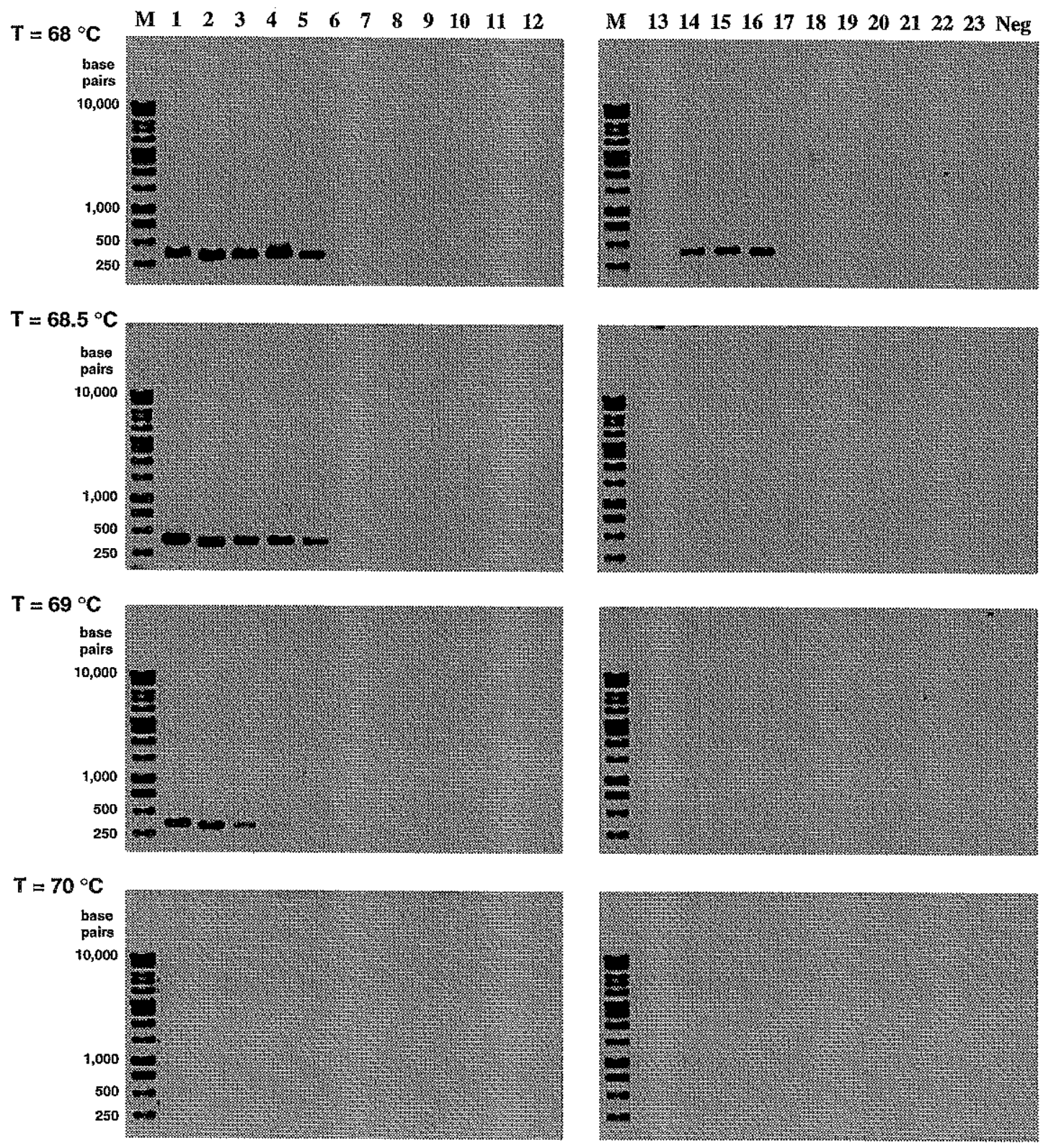
DNA isolation. Environmental samples from Juan de Fuca, $21^{\circ} \mathrm{N}$ and $9{ }^{\circ} \mathrm{N}$ EPR contained biogenic materials (worm tubes, shells, organic debris, etc.) from the bases of mussel and tube worm beds, inorganic substrates (chimney walls, basalts) and overlying water. Samples from Guaymas Basin were rich in organic sediments and overlying water. Fixed and frozen (later thawed) samples were filtered over Millipore 2.0 $\mu \mathrm{m}$ TTTP Isopore Membrane Filters (cat no. TTTP04700) to remove most bacteria and PCR-inhibiting substances while retaining $>3 \mu \mathrm{m}$ sized flagellates and substrates with attached flagellates. $\mathrm{Nu}-$ cleic acids were isolated by hot phenol extraction: cells and substrates bound on individual filters were incubated in $5 \mathrm{ml}$ Lysis Buffer ( $10 \mathrm{~g}$ sucrose, $2 \mathrm{ml} 1 \mathrm{M}$ Tris $\mathrm{pH}$ 8.0, brought up to $40 \mathrm{ml}$ with $\left.\mathrm{MQH}_{2} \mathrm{O}\right), 750 \mu \mathrm{L} 10 \%$ SDS and $250 \mu \mathrm{L}$ Proteinase $\mathrm{K}(20 \mathrm{mg} / \mathrm{ml})$ for $1.5 \mathrm{hr}$ at $65^{\circ} \mathrm{C}$. Then, $6 \mathrm{ml}$ hot $\left(65^{\circ} \mathrm{C}\right)$ phenol: chloroform: isoamyl alcohol $(25: 24: 1)$ (Tris equilibrated to $\mathrm{pH}$ 8.0) was added; after mixing aqueous and phenol phases, the incubation continued at $65^{\circ} \mathrm{C}$ for an additional $15 \mathrm{~min}$. The top, aqueous phase was extracted multiple times with hot phenol:chloroform:isoamyl alcohol until there was little color change in the organic phase. This high-temperature, chemical-lysis protocol consistently yielded better PCR results than did protocols employing low-temperature and/or physical lysis steps (e.g, bead-beating sensu Stahl et al. 1988). Chemical lysis is less destructive of genomic DNA and may permit better extraction and PCR amplification of large, intact genes than physical lysis. Physical lysis methods may therefore be better suited to prokaryotic organisms with sturdy cell walls, whereas chemical lysis methods may be better suited to flagellates and other microorganisms without cell walls.

PCR amplification of kinetoplastid rDNA from vent samples. PCR amplification of DGGE fragments was performed using standard protocols and a nested series of primers. The general primer combination A (forward) / B (reverse) for eukaryotic ssrRNA gene amplification (Medlin et al. 1988) showed mismatches to published euglenozoa sequences. Therefore, we used modified versions of the 3'- and 5'-eukaryotic ssrDNA 
primers $\mathrm{A}$ and $\mathrm{B}$, which included a mixed pyrimidine site to account for $\mathrm{C} / \mathrm{T}$ variability among euglenozoans and non-euglenozoans, for complete amplification of euglenozoan ssrRNA genes (Atkins et al. in press). In some cases, reamplification of $\mathrm{A} / \mathrm{B}$ products was performed with the newly designed internal primers $\mathrm{C}$ (forward) and $\mathrm{D}$ (reverse), targeting a few bases internal to the modified primers A and B (Atkins et al. in press). Specific PCR conditions are described in each figure legend. PCR amplifications were run on a PerkinElmer GeneAmp PCR System 9700 with a hot start at $95{ }^{\circ} \mathrm{C}$ for $5 \mathrm{~min}$, followed by $35 \mathrm{cy}-$ cles of 1 min denaturation at $94^{\circ} \mathrm{C}, 45 \mathrm{sec}$ annealing at empirically optimized temperatures, and 2 min extension at $72{ }^{\circ} \mathrm{C}$, before a final extension at $72{ }^{\circ} \mathrm{C}$ for $10 \mathrm{~min}$. Once high quantity and quality of $18 \mathrm{~S}$ target was amplified using this nested combination, reamplification at the empirically-determined optimal annealing temperature using primers Kin F/R generated 400 bp PCR fragments for use in DGGE. In each step, PCR products were column-purified using Wizard PCR Preps (Promega) following manufacturer's protocols. The nested PCR procedure was necessary for successful amplification of kinetoplastid rRNA gene fragments from the hydrothermal vent samples; the use of the kinetoplastid-specific DGGE primers alone, without previous reamplification, did not result in detectable PCR products.

DGGE analysis. A BIO-RAD Dcode Universal Mutation Detection System (BIORAD Laboratories) was used for denaturing gradient gel electrophoresis. The Model 475 Gradient Delivery System was replaced by a standard two-chamber linear gradient gel former of $16 \mathrm{ml}$ chamber volume (Sigma-Aldrich Co.). The gradient former was connected to a BIO-RAD EP-1 peristaltic Econo Pump set at $4 \mathrm{ml} / \mathrm{min}$ flow rate, which allowed homogeneous pouring of the gradient gel with clearly improved results. All gels were made with $1 \times \mathrm{TAE}$ and $6 \%$ acrylamide:bis acrylamide following established protocols (Muyzer et al. 1996). A 40-60\% parallel denaturing gradient was selected empirically, based on perpendicular gel runs and time-travel series as described by Muyzer et al. (1993). The gel was run at $75 \mathrm{~V}$ and $60^{\circ} \mathrm{C}$ for $16 \mathrm{hr}$. 
Detection limits. Using whole Euglena gracilis cells as an internal control we were able to establish the detection limits of these methods (data not shown): $10^{5}$ live cells were inoculated into $5 \mathrm{~g}$ of Guaymas Basin sediments (GBB). Nucleic acids were extracted and diluted up to $1: 10^{5}$; these dilutions were PCR-amplified and run on DGGE following our protocols. DGGE bands corresponding to E. gracilis were obtained from dilutions up to $1: 10^{4}$. Since $E$. gracilis has about $10^{3}$ ssrDNA copies per cell (Cook and Cook 1985), we estimated that our methods have a detection limit of ca. 10 ssrDNA copies in a $5 \mathrm{~g}$ sample $\left[10^{5}\right.$ cells $\times 10^{3} \mathrm{ssrDNA}$ copies/cell $=10^{8}$ ssrDNA copies $/ 10^{7}$ dilution $(1 \mu \mathrm{L}$ from $1000 \mu \mathrm{L}$ of a $10^{4}$ dilution $)=10$ ssrDNA copies $]$.

\section{Results and Discussion}

Culturing. Three species of kinetoplastid flagellates were cultured and isolated from two deep-sea vents. Rhynchomonas nasuta and Bodo saliens were isolated from two different stations at the $9^{\circ} \mathrm{N}$ vent on the East Pacific Rise and an unidentified kinetoplastid flagellate, LFS2, was isolated from the Lobo Flange station at the Juan de Fuca vent. Rhynchomonas nasuta was cultured and isolated from the Biovent Serpulid Zone on three separate cruises to $9^{\circ} \mathrm{N}$ over a two and one-half year period, suggesting a consistently-present population of this species there; $B$. saliens and isolate LFS2 were isolated one time each at their respective vent stations (Atkins et al. in press).

These species previously were found to be related to different free-living kinetoplastid flagellates by phylogenetic analysis of ssrDNA sequences (Atkins et al. in press) (Figure 4.1). Two isolates of $R$. nasuta (BSZ1, vent; CBR1, shallow) formed a monophyletic group with Dimastigella trypaniformis, a deep-branching, free-living kinetoplastid (Berchtold et al. 1994). B. saliens and isolate LFS2 formed a monophyletic group with an environmental isolate obtained from detritus-enriched lake water in the Netherlands (van 
Hannen et al. 1999). Rhynchomonas nasuta and B. saliens are among a small group of very common heterotrophic flagellates, occurring in a wide range of environments with what appears to be a global distribution (Lee and Patterson 1998); their occurrence at deep-sea vents, therefore, was not surprising. The isolate LFS2 was not identified by any morphological criteria and its ssrDNA sequence did not assign it to a known kinetoplastid species.

PCR primer design and specificity. Specificity of the newly designed kinetoplastid primers was shown empirically, through annealing temperature optimization using different kinetoplastid and non-kinetoplastid protists with known sequences (Figures 4.2, 4.3). Kinetoplastid rRNA genes were consistently amplified, to the exclusion of nonkinetoplastid target, at the optimal annealing temperature, $68.5^{\circ} \mathrm{C}$. Such stringent conditions and high annealing temperatures were necessary for preventing amplification of some non-euglenozoan flagellate ssrDNA's whose primer sites, regardless of several well centered mismatches, showed an unsually high affinity for the primer pair Kin F/R, even at high temperatures and stringency. This was the case for Caecitellus parvulus and Cafeteria sp., whose published 18S sequences each had 3 mismatches to both primers, yet amplification was still detectable at $68^{\circ} \mathrm{C}$ (Figures $\left.4.2,4.3\right)$. Here, a very narrow temperature gradient $(0.5$ $\left.{ }^{\circ} \mathrm{C}\right)$ separated specific and non-specific amplification. The temperature difference between specific and unspecific amplification was $2^{\circ} \mathrm{C}$ for the two other test organisms, a hydrothermal vent Monosiga sp. strain and a Massisteria marina isolate, which showed nevertheless the same mismatch pattern as the Cafeteria roenbergensis and Caecitellus parvulus ssrRNA gene sequences. Possibly, these two species possess additional ssrRNA gene copies whose target regions match the Kinetoplastid primers to a considerable degree.

PCR amplification of community DNA's and DGGE fragments. Formaldehyde- and ethanol-fixed environmental samples did not yield positive PCR amplifications. Frozen environmental samples yielding positive results were in some cases pooled, concentrated and reamplified prior to agarose gel analysis in order to produce visible bands. The 
use of a nested series of PCR primers with increasing specificity toward kinetoplastid flagellates proved better at amplifying high quality and quantity of DGGE target fragment than did one or two primer pairs alone (Figures 4.4,4.5). PCR amplification of community ssrDNA's using general primers A/B yielded moderate to good products for 4 of 6 vent samples (Figure 4.4 A; GBB, CAS, BRM, BSZ). However, reamplification of those products using internal primers C/D yielded very good products for all 6 vent samples (Figure 4.4 B), indicating that very low amplification had occurred with primers $\mathrm{A} / \mathrm{B}$, but that it was not visibly detectable. In most cases, the use of nested internal primers greatly improved the quality and quantity of PCR products obtained from recalcitrant environmental samples.

This finding was important in generating target fragments from environmental samples for use with DGGE (Figure 4.5). Direct PCR amplification of vent samples using primers Kin $\mathrm{F} / \mathrm{R}$ at high stringency $\left(68.5^{\circ} \mathrm{C}\right)$ resulted in no products except for control DNA (Figure 4.5 A). Amplification of near-complete, eukaryotic ssrRNA genes from vent samples with primers $\mathrm{A} / \mathrm{B}$ (modified) at low stringency $\left(55^{\circ} \mathrm{C}\right)$, followed by reamplification with primers Kin F/R at high stringency, resulted in very low DGGE fragment yield from samples CAS, BRM, and (barely visible) LFS and BSZ (Figure 4.5 B). Amplification of near-complete, eukaryotic ssrRNA genes with the nested series $A / B$, and then $C / D$ at low stringency, and followed by Kin F/R at high stringency resulted in very high yield of DGGE fragments for 4 of 6 vent samples (CAS, BRM, LFS and BSZ) (Figure 4.5 C). In this way, use of this nested primer series and different stringencies enabled selection for and production of very high quality and quantity of specific target DNA's from complex environmental samples. Similar nested, empirically-optimized PCR strategies were required to amplify 16S rRNA genes of target bacterial groups from environmental samples to detect a specific minority population against a high background of non-target DNA (Brinkhoff and Muyzer 1997). 
Figure 4.4. Agarose gel results from PCR amplification of deep-sea hydrothermal vent samples using nested primers designed to selectively amplify euglenozoan ssrDNA. (A) PCR amplification of environmental samples using general eukaryotic primers A and B (Medlin et al. 1988). (B) reamplification of products in (A) using euglenozoa-selective primers C and D (Atkins et al. in press). Double bands in (B) result from known length heterogeneity among kinetoplastids and euglenids. PCR amplifications were run on a Perkin-Elmer GeneAmp PCR System 9700 with a hot start at $95^{\circ} \mathrm{C}$ for 5 min, 35 cycles of denaturation at $94^{\circ} \mathrm{C}$ for $1 \mathrm{~min}$, annealing at $55^{\circ} \mathrm{C}$ for $45 \mathrm{sec}$, extension at $72{ }^{\circ} \mathrm{C}$ for $2 \mathrm{~min}$, concluded by a final extension at $72{ }^{\circ} \mathrm{C}$ for $10 \mathrm{~min} . \mathrm{M}=1 \mathrm{~kb}$ ladder marker (Promega Corp.); DFS = Dante Flange Substrate (Juan de Fuca vent); LFS = Lobo Flange Substrates (Juan de Fuca vent); GBB = Guaymas Basin Beggiatoa mat (Guaymas Basin vent); CAS = Clam Acres Spire $\left(21^{\circ} \mathrm{N}\right.$ vent); BRM = Biovent Riftia and Mussels bed ( ${ }^{\circ} \mathrm{N}$ EPR vent); $\mathrm{BSZ}=$ Biovent Serpulid Zone $\left(9^{\circ} \mathrm{N}\right.$ vent $) ; \mathrm{EUG}=$ Euglena gracilis $\mathrm{DNA}$ extracts as positive control; $\mathrm{CAF}=$ Cafeteria sp. strain $\mathrm{EWM} 2$ as positive control; $\mathrm{NEG}=$ negative control (no target DNA). 

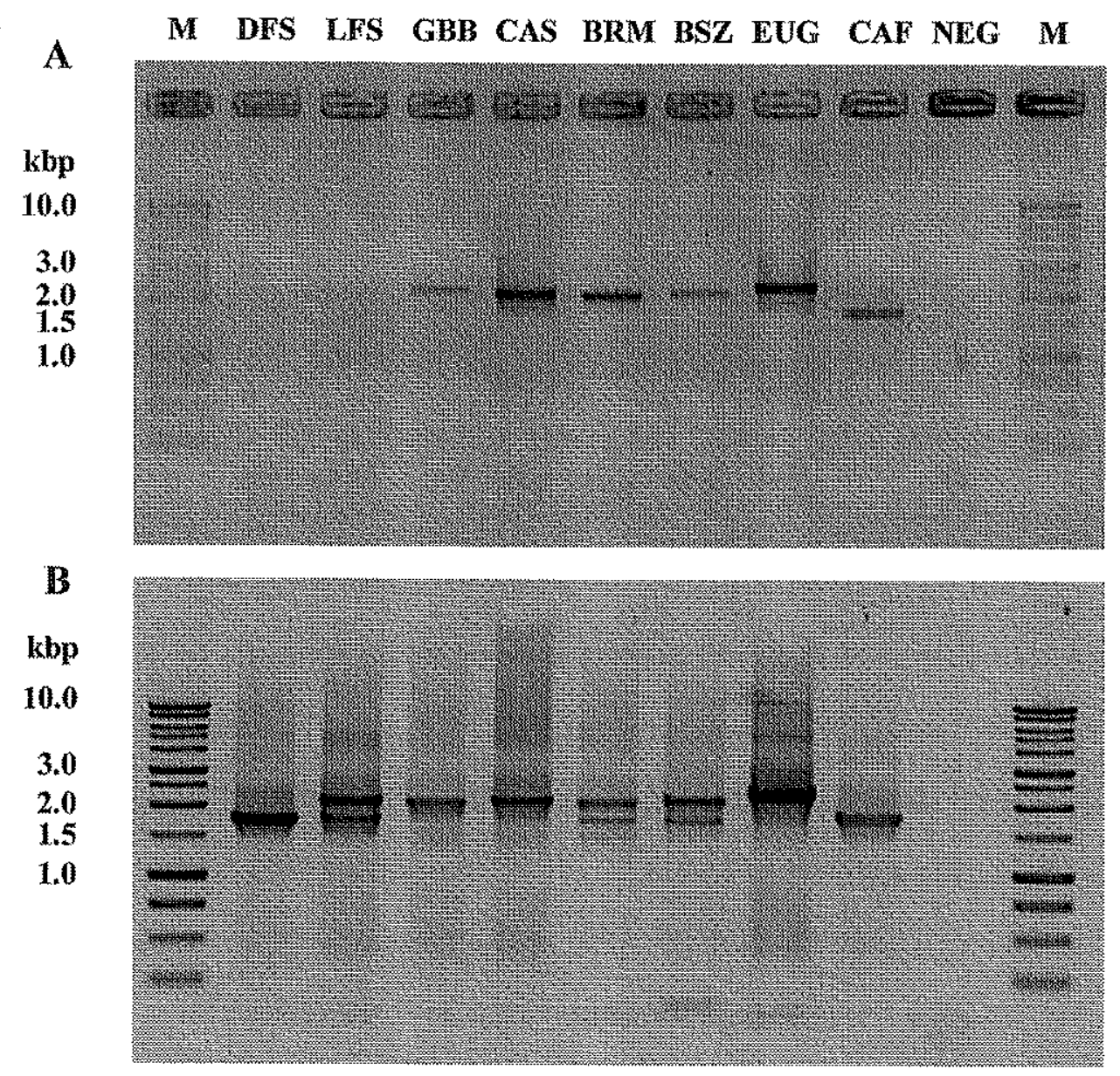
Figure 4.5. Agarose gel results from PCR amplification of deep-sea hydrothermal vent samples using nested primers designed to specifically amplify euglenozoan DGGE fragment within ssrDNA. This figure shows the importance of nested primers in amplifying good PCR products from environmental samples for use in DGGE. (A) PCR amplification of environmental samples using general eukaryotic primers A and B (Medlin et al. 1988) $\left(55^{\circ} \mathrm{C}\right.$ annealing temp) followed by reamplification with primers $\mathrm{Kin} F / \mathrm{R}\left(68.5^{\circ} \mathrm{C}\right.$ annealing temp). (B) PCR amplification of environmental samples using euglenozoa-selective primers $\mathrm{C}$ and $\mathrm{D}$ (Atkins et al. in press) $\left(55^{\circ} \mathrm{C}\right.$ annealing temp) followed by reamplification with primers Kin $\mathrm{F} / \mathrm{R}\left(68.5^{\circ} \mathrm{C}\right.$ annealing temp). (C) PCR amplification of environmental samples using general eukaryotic primers $\mathrm{A} / \mathrm{B}\left(55^{\circ} \mathrm{C}\right.$ annealing temp) followed by reamplification with euglenozoa-selective primers $\mathrm{C} / \mathrm{D}\left(55^{\circ} \mathrm{C}\right.$ annealing temp), then reamplification of $\mathrm{C} / \mathrm{D}$ products with primers $\mathrm{Kin} \mathrm{F} / \mathrm{R}\left(68.5^{\circ} \mathrm{C}\right.$ annealing temp). $\mathrm{M}=1 \mathrm{~kb}$ ladder marker (Promega Corp.); DFS = Dante Flange Substrate (Juan de Fuca vent); LFS = Lobo Flange Substrates (Juan de Fuca vent); GBB = Guaymas Basin Beggiatoa mat (Guaymas Basin vent $) ; \mathrm{CAS}=\mathrm{Clam}$ Acres Spire $\left(21^{\circ} \mathrm{N}\right.$ vent $) ; \mathrm{BRM}=$ Biovent Riftia and Mussels bed $\left(9^{\circ} \mathrm{N}\right.$ vent); BSZ = Biovent Serpulid Zone $\left(9^{\circ} \mathrm{N}\right.$ vent $) ; \mathrm{EUG}=$ Euglena gracilis $\mathrm{DNA}$ extracts as positive control; $\mathrm{CAF}=$ Cafeteria sp. strain EWM2 as negative control (primers Kin F/R are kinetoplastid specific); NEG = negative control (no target DNA). 
$M$ DFS LFS GBB CAS BRM BSZ EUG CAF NEG M
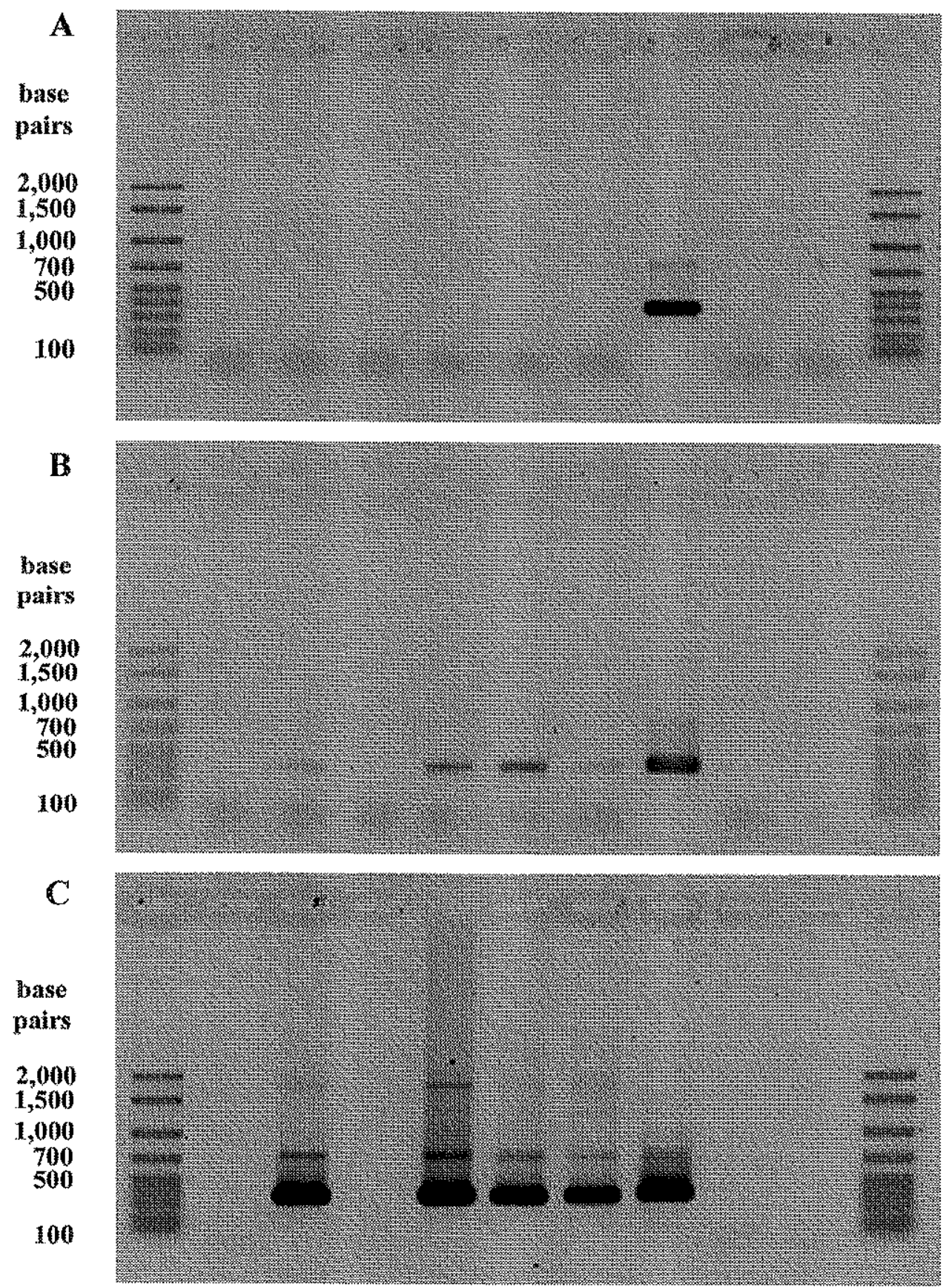
Denaturing gradient gel electrophoresis. The discovery that primers Kin F/R were specific only to kinetoplastids and a limited number of euglenozoan taxa had important implications for our DGGE results. It was expected that only a few or no bands would be present in vent samples since there are only a few species of kinetoplastids (and euglenids) known to widely inhabit marine environments (Lee and Patterson 1998; Patterson and Larsen 1991). Figure 4.6 shows the results from DGGE analysis of the 4 positive vent samples (shown in Figure $4.5 \mathrm{C}$ ) along with DGGE fragments from 5 pure-cultured kinetoplastid isolates. In all, six DGGE bands were resolved from the environmental samples. Band excision and sequencing revealed that all bands corresponded to cultured kinetoplastid flagellates. From the $9^{\circ} \mathrm{N}$ BRM site, two bands were resolved which corresponded to $B$. saliens and $R$. nasuta, and at the $9^{\circ} \mathrm{N} \mathrm{BSZ}$ site, one band was resolved which corresponded to $R$. nasuta. From the LFS site at the Juan de Fuca vent, one band was resolved which corresponded to the kinetoplastid flagellate isolated from that site, LFS2. Finally, from the CAS site at the $21^{\circ} \mathrm{N}$ EPR vent, two bands were resolved which corresponded to $B$. saliens and R. nasuta.

Table 4.2 compares the results of culturing and DGGE analysis. Using PCR and DGGE, we were able to retrieve and resolve the same kinetoplastid flagellates cultured and isolated from 3 different vent sites and to show the presence of cultured species at vent sites where they were not cultured. These results show that the PCR and DGGE protocols developed here have the power to determine species distribution in geographically widelyseparated vent sites and diversity among very specific targets from complex and very remote environments.

The fact that more species were not detected could be taken as an indication that the species retrieved here are the predominant or only kinetoplastid flagellates present at these vents. Based on an approximate detection limit of ca. 10 ssrDNA copies per sample, these flagellates do not have to be dominant to be detected. Furthermore, there could exist primer 
Figure 4.6. Results of denaturing gradient gel electrophoresis of PCR-amplified products from Figure 4.5 C. Euglenozoan pure-culture isolates (lanes 1-2 and 9-11) and environmental samples (lanes 4-7). Isolates were cultured from the same environmental samples later used in DGGE. Lanes: Environmental samples (shown under bracket): $4=$ Biovent Riftia and Mussels bed (BRM, $9^{\circ} \mathrm{N}$ vent); $5=$ Biovent Serpulid Zone (BSZ, $9^{\circ} \mathrm{N}$ vent); $6=$ Lobo Flange Substrate (LFS, Juan de Fuca vent); $7=$ Clam Acres Spire (CAS, $21^{\circ} \mathrm{N}$ vent); Isolates: 1 = Bodo caudatus; $2=$ Bodo saliens; $3=$ mixed PCR products of euglenozoan isolates; $8=$ mixed PCR products of euglenozoan isolates; $9=$ Rhynchomonas nasuta strain BSZ1 (vent isolate); 10 = unidentified kinetoplastid isolate LFS2; and 11 = Euglena gracilis. Mixed product lanes were run to show that discrete band resolution occurs with complex mixed samples. 


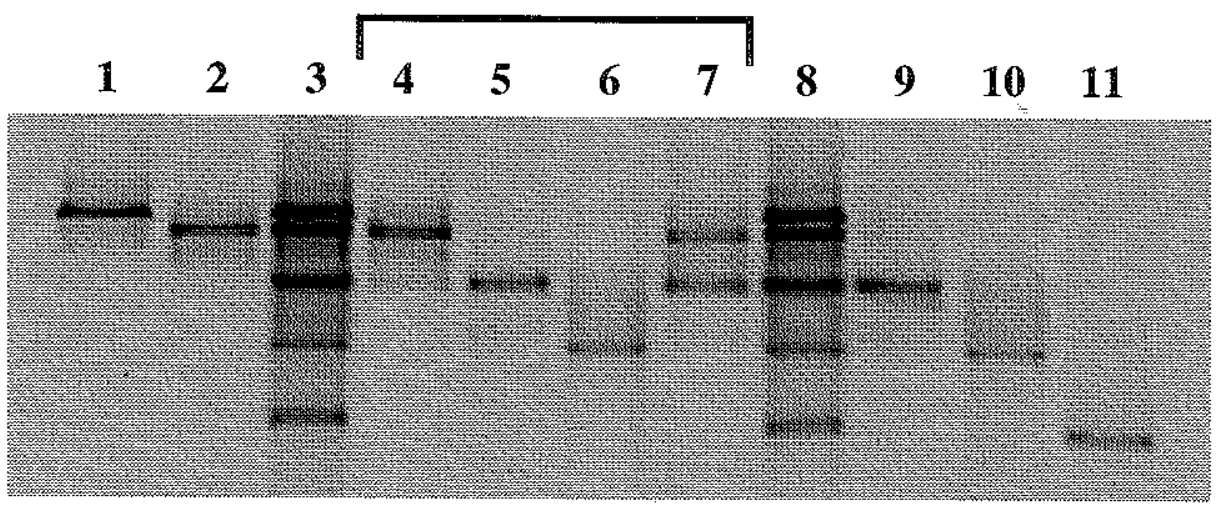




\begin{tabular}{|l|c|c|c|c|}
\hline Vent & Juan De Fuca & $21^{\circ} \mathrm{N}$ & \multicolumn{2}{|c|}{$9^{\circ} \mathrm{N}$} \\
\hline Specific Site & LFS & CAS & BRM & BSZ \\
\hline Organism & & & & \\
\hline Bodo caudatus & & & & \\
\hline Bodo saliens & & D & C D & \\
\hline Rhynchomonas nasuta & & D & D & C D \\
\hline Isolate LFS2 & C D & & & \\
\hline Other euglenozoa & & & & \\
\hline Non-euglenozoa & C (2) & C (3) & C (1) & C (3) \\
\hline
\end{tabular}

Table 4.2. A comparison between culturing (C) and DGGE (D) methods of determining the presence of kinetoplastid flagellates at different vent sites. Also shown are other euglenozoan and non-euglenozoan flagellates detected at these sites using the methods indicated. Numbers in parenthesis indicate the number of flagellates $(>1)$ detected by that method. LFS = Lobo Flange Substrates; CAS = Clam Acres Spire; BRM = Biovent Riftia and Mussels; BSZ $=$ Biovent Serpulid Zone (see Atkins et al., in press).

mismatches among truly dominant species of kinetoplastid flagellates whose sequence identity is not yet known. Multiple mistmatches to target sequences among euglenid species known to be abundant in marine environments (e.g., Petalomonas) underscores this possibility. Another possibility is that our methods were optimized specifically for the isolates that later were selectively retrieved from these vent samples. Still, our results clearly show that these species are present at the vent sites sampled and that results from culturing and DGGE are corroborative.

The DGGE result also revealed that species such as $R$. nasuta occur throughout the vent fields at $9^{\circ} \mathrm{N}$ and $21^{\circ} \mathrm{N}$ EPR and that $R$. nasuta and $B$. saliens are more widely dispersed than was indicated by culturing. The molecular survey using DGGE indicated a wider distribution pattern than culturing alone. Wide distribution patterns at vents of these cosmopolitan species correlates well with previous studies that suggested $R$. nasuta and $B$. saliens are globally distributed (Lee and Patterson 1998). In addition to determining pres- 
ence of species at remote locations, another strength of DGGE is to determine whether a particular microbial species (ssrDNA genotype) occurs over a wide spatial (geographical) range, as was also shown here.

Taken together, these results strongly indicate the presence of these flagellates at vent sites along the Eastern Pacific Ocean. The combined approach of culture-dependent and -independent methods of determining species presence in remote environments offers an improvement in our ability to assess and measure the distribution and diversity of microorganisms over either method used alone.

\section{Acknowledgements}

Sampling at the $9^{\circ} \mathrm{N}$ EPR vents was made possible by NSF grant OCE-9019575 to Dr. Lauren S. Mullineaux. Sampling at the Guaymas Basin and $21^{\circ} \mathrm{N}$ EPR vents was made possible by NSF grant OCE-9714195 to APT from the Life in Extreme Environments (LEXEN) Program. Denaturing gradient gel electrophoresis supplies and equipment were purchased in part with grants to MSA from the Ocean Ventures Fund and the Rhinehart Coastal Research Center at the Woods Hole Oceanographic Institution and the PADI Foundation. This is Woods Hole Oceanographic Institution contribution number 0000. 


\section{References}

Alongi, D. M. 1986. Quantitative estimates of benthic protozoa in tropical marine systems using silica gel: a comparison of methods. Estuar. Coast. Shelf Sci., 23:443-450.

Atkins, M. S., O. R. Anderson, and C. O. Wirsen. 1998. Effect of hydrostatic pressure on the growth rates and encystment of flagellated protozoa isolated from a deep-sea hydrothermal vent and a deep shelf region. Mar. Ecol. Prog. Ser., 171:85-95.

Atkins, M. S., A. McArthur, and A. P. Teske. submitted. Ancyromonadida: a new phylogenetic lineage among the protozoa closely related to the common ancestor of Metazoans, Fungi, and Choanoflagellates (Opisthokonta). J. Mol. Evol.

Atkins, M. S., A. P. Teske, and O. R. Anderson. 2000. A Survey of Flagellate Diversity at Four Deep-Sea Hydrothermal Vents in the Eastern Pacific Ocean Using Structural and Molecular Approaches. J. Euk. Microbiol, 47(4): In Press.

Azam, F., and J. W. Ammerman. 1984. Cycling of organic matter by bacterioplankton in pelagic marine ecosystems: microenvironmental considerations. In: Fasham, M. J. R. (ed.), Flows of energy and materials in marine ecosystems, Plenum Publishing Corp., New York. pp. 345-360.

Berchtold, M., H. Philippe, A. Breunig, G. Brugerolle, and H. König. 1994. The phylogenetic position of Dimastigella trypaniformis within the parasitic kinetoplastids. Parasitol. Res., 80:672-679.

Bloem, J., M. J. B. Bär-Gilissen, and T. E. Cappenberg. 1986. Fixation, counting, and manipulation of heterotrophic nanoflagellates. Appl. Environ. Microbiol., 52:1266-1272.

Brinkhoff, T., and G. Muyzer. 1997. Increased species diversity and extended habitat range of sulfur-oxidizing Thiomicrospira spp. Appl. Environ. Microbiol., 63:3789-3796.

Caron, D. A., P. G. Davis, and J. M. Sieburth. 1989. Factors responsible for the differences in cultural estimates and direct microscopical counts of populations of bacterivorous nanoflagellates. Microb. Ecol., 18:89-104.

Caron, D. A., J. C. Goldman, O. K. Andersen, and M. R. Dennett. 1985. Nutrient cycling in a microflagellate food chain. II. Population dynamics and carbon cycling. Mar. Ecol. Prog. Ser., 24:243-254.

Cook, J. R., and B. S. Cook. 1985. Transcripts of the plasmid-like DNA in Euglena gracilis. J. Cell Biol., 101 (abstracts):313a. 
Epstein, S. S. 1995. Simultaneous enumeration of protozoa and micrometazoa from marine sandy sediments. Aquat. Microbial Ecol., 9(3):219-227.

Gasol, J. M. 1993. Benthic flagellates and ciliates in fine fresh-water sediments: calibration of a live counting procedure and estimation of their abundances. Microb. Ecol., 25:247262.

Lee, W. J., and D. J. Patterson. 1998. Diversity and geographic distribution of free-living heterotrophic flagellates - analysis by PRIMER. Protist, 149:229-244.

Lessa, E. P., and G. Applebaum. 1993. Screening techniques for detecting allelic variation in DNA sequences. Mol. Ecol., 2:119-129.

Lim, E. L., L. A. Amaral, D. A. Caron, and E. F. DeLong. 1993. Application of rRNA-based probes for observing marine nanoplanktonic protists. Appl. Environ. Microbiol., 59(5): 1647-1655.

Lim, E. L., D. A. Caron, and E. F. DeLong. 1996. Development and field application of a quantitative method for examining natural assemblages of protists with oligonucleotide probes. Appl. Environ. Microbiol., 62(4):1416-1423.

Linton, E. W., D. Hittner, C. Lewandowski, T. Auld, and R. E. Triemer. 1999. A molecular study of euglenoid phylogeny using small subunit rDNA. J. Euk. Microbiol., 46:217223.

Marché, S., C. Roth, H. Philippe, M. Dollet, and T. Baltz. 1995. Characterization and detection of plant trypanosomatids by sequence analysis of the small subunit ribosomal RNA gene. Mol. Biochem. Parasitol., 71:15-26.

Maslov, D. A., J. Lukes, M. Jirku, and L. Simpson. 1996. Phylogeny of trypanosomes as inferred from the small and large subunit rRNA's: implications for the evolution of parasitism in the trypanosomatid protozoa. Mol. Biochem. Parasitol., 75:197-205.

Medlin, L., H. J. Elwood, S. Stickel, and M. L. Sogin. 1988. The characterization of enzymatically amplified eukaryotic 16S-like rRNA-coding regions. Gene, 71:491-499.

Muyzer, G., E. C. de Waal, and A. G. Uitterlinden. 1993. Profiling of complex microbial populations by denaturing gradient gel electrophoresis analysis of polymerase chain reaction-amplified genes coding for 16S rRNA. Appl. Environ. Microbiol., 59:695-700.

Muyzer, G., S. Hottenträger, A. Teske, and C. Wawer. 1996. Denaturing gradient gel electrophoresis of PCR-amplified 16S rDNA - a new molecular approach to analyze the genetic diversity of mixed microbial communities. In: Akkermans, A. D. L., J. D. Van Elsas, and F. J. de Bruijn (ed.), Molecular Microbial Ecology Manual, 2nd ed., Kluwer Academic Publishers, Dordrecht, The Netherlands. 
Muyzer, G., and K. Smalla. 1998. Application of denaturing gradient gel electrophoresis (DGGE) and temperature gradient gel electrophoresis (TGGE) in microbial ecology. Antonie van Leeuwenhoek, 73:127-141.

Nerad, T. A., and P.-M. Daggett. 1992. Cultivation of free-living bodonids. In: Lee, J. J. and A. T. Soldo (ed.), Protocols in Protozoology, Society of Protozoologists, Lawrence, KS. pp. A-24.21-A-24.23.

Patterson, D. J., and J. Larsen (ed.). 1991. The biology of free-living heterotrophic flagellates, Clarendon Press, Oxford.

Simpson, A. G. B. 1997. The identity and composition of the Euglenozoa. Arch. Protistenkd., 148:318-328.

Stahl, D., B. Flesher, H. R. Mansfield, and L. Montgomery. 1988. Use of phylogenetically based hybridization probes for studies of ruminal microbial ecology. Appl. Environ. Microbiol., 54(5):1079-1084.

Van de Peer, Y., J. Jensen, P. De Rijk, and R. De Wachter. 1997. Database on the structure of small ribosomal subunit RNA. Nucleic Acids Res., 25:111-116.

van Hannen, E. J., W. Mooij, M. P. van Agterveld, H. J. Gons, and H. J. Laanbroek. 1999. Detritus-dependent development of the microbial community in an experimental system: qualitative analysis by denaturing gradient gel electrophoresis. Appl. Environ. Microbiol., 65:2478-2484.

van Hannen, E. J., M. P. van Agterveld, H. J. Gons, and H. J. Laanbroek. 1998. Revealing genetic diversity of eukaryotic microorganisms in aquatic environments by denaturing gradient gel electrophoresis. J. Phycol., 34:206-213.

Wright, A.-D. G., S. Li, S. Feng, D. S. Martin, and D. H. Lynn. 1999. Phylogenetic position of the kinetoplastids, Cryptobia bullocki, Cryptobia catostomi, and Cryptobia salmositica and monophyly of the genus Trypanosoma inferred from small subunit ribosomal RNA sequences. Mol. Biochem. Parasitol., 99:69-76. 


\section{Part II}

\section{Physiological Experiments}




\section{Chapter 5}

The effect of hydrostatic pressure on the growth rates and encystment of flagellated protozoa isolated from a deep-sea hydrothermal vent and a deep shelf region

Michael S. Atkins, O. Roger Anderson, and Carl O. Wirsen

Marine Ecology Progress Series 171:85-95; 1998 
Abstract: Six isolates of deep-sea flagellated protozoa were grown in culture at 1-300 atm to measure their growth response to increasing hydrostatic pressure. Three kinetoplastid flagellates and one choanoflagellate were isolated from deep-sea hydrothermal vent samples and two chrysomonads were isolated from deep continental shelf sediments. The growth rates of two species isolated from the vent, Caecitellus parvulus and Rhynchomonas nasuta, were compared to the growth rates of shallow-water strains of the same species. Deep-sea isolates of $C$. parvulus and $R$. nasuta had a higher rate of growth at higher pressures than did their shallow-water counterparts. This feature could result from adaptation to higher pressure upon sinking to depth or with time on the ocean bottom. Four of the six deep-sea isolates - C. parvulus, $R$. nasuta and the two chrysomonads - were capable of growth at pressures corresponding to their respective depths of collection, indicating that these species could be metabolically active at these depths. C. parvulus and $R$. nasuta encysted at pressures greater than their depth of collection. The choanoflagellate isolate was observed to encyst at pressures greater than $50 \mathrm{~atm}$. These findings suggest a potential ecological role for encystment in deep sea/water column coupling. Cosmopolitan or epipelagic species, such as $C$. parvulus and $R$. nasuta, may be transported on sedimenting particles into the deep sea, where encystment at high pressure could serve as a mechanism for pelagic renewal by advection via hydrothermal plume entrainment and thermohaline circulation.

Key Words: Protozoa - Flagellate - Kinetoplastid • Choanoflagellate • Chrysomonad • Hydrostatic pressure - Growth rate - Encystment - Deep sea - Hydrothermal vent - Continental shelf $\bullet$ Extreme environment 
Flagellated protozoa are ubiquitous components of the complex microbial food webs found in every habitable environment on this planet. The presence and species richness of protozoan organisms has been documented throughout terrestrial and aquatic ecosystems worldwide. In shallow benthic and pelagic marine ecosystems the importance of protozoan associations in energy transfer through aquatic food webs has been well established (Alldredge et al. 1986; Azam et al. 1983; Patterson et al. 1993). High bacterial productivity coupled with consumption of bacterial biomass by heterotrophic flagellates has been suggested as one possible mechanism for the transfer of energy, carbon and nutrients to higher trophic level organisms (Azam and Fuhrman 1984; Caron 1991a; Caron et al. 1985; Fuhrman and Azam 1980). Bacterivorous flagellates also have been found to be important nutrient remineralizers, capable of regenerating nutrients and other inorganic molecules, enhancing the bioavailability of these compounds to other organisms (Caron and Goldman 1990; Fenchel 1982; Sherr et al. 1983). These data have shown that flagellated protozoa of the neritic benthos and epipelagos are integral components of carbon and nutrient cycling within oceanic microbial food webs. However, the importance of microbial associations and particularly protozoan assemblages in deep sea regions is not well known. This is due to the difficulty and expense in obtaining live samples from the deep sea. Yet with greater than $88 \%$ of earth's biosphere below 1000 meters of seawater, the ecological significance of microbial decomposition and remineralization in the deep sea becomes apparent (Jannasch and Wirsen 1984).

The present study was done to increase our knowledge of one aspect of flagellate activity in the deep sea; flagellate growth as affected by hydrostatic pressure. Attempts to culture natural populations of benthic and planktonic protozoa from the deep-sea bring into question the effect of pressure as a selective mechanism, thereby preventing the isolation of pressure adapted species. To address this and other ecologically relevant questions, the effect of hydrostatic pressure was measured on the growth rates of four flagellate species 
isolated from $2500 \mathrm{~m}$ at the $9^{\circ} \mathrm{N}$ hydrothermal vent site on the East Pacific Rise and two flagellates isolated from a $1500 \mathrm{~m}$ station on the continental shelf in the North Atlantic. These organisms were examined in pure culture at pressures ranging from 1-300 atm to determine the extent of barotolerance within each culture. The growth rates of two species isolated from the vent site, Caecitellus parvulus and Rhynchomonas nasuta, were compared to the growth rates of shallow-water strains of the same species.

\section{Materials and Methods}

Sampling and enrichment. East Pacific Rise: Samples were collected from several sites at $2500 \mathrm{~m}$ depth within the $9^{\circ} \mathrm{N}$ hydrothermal vent site on the East Pacific Rise (EPR) using DSV Alvin. Samples were collected using two methods: 1.) placement of substrates (e.g., rocks, mussels, tube-worms, glass-slides and settling blocks) into chambers on Alvin for subsequent retrieval; and 2.) suction-pump concentration of water samples into sterile sample jars. North Atlantic: A box-core sediment sample was collected in July 1996 from a $1500 \mathrm{~m}$ station on the continental shelf in the North Atlantic Ocean.

All deep-sea samples were subjected to decompression during retrieval to the surface, where sub-samples were aliquoted into 1.) enrichment media $(0.22 \mu \mathrm{m}$ filtered/autoclaved Vineyard Sound Water (VSW) and $0.01 \%$ sterile yeast extract); 2.) Formalin, at a final concentration of 3.7\%; and, 3.) Molecular Grade ethyl alcohol (Quantum Laboratories), at a final concentration of $70 \%$.

Shallow-water samples: A sediment sample was collected in August 1996 from 2.5 $m$ depth north of Pope's Island in New Bedford Harbor (NBH). A Chesapeake Bay isolate (CBR 1) was obtained from the culture collection of David Caron at the Woods Hole. Oceanographic Institution. 
Isolation and identification. Single cells were isolated from mixed populations in enriched cultures using the micromanipulation and dilution/extinction techniques outlined by Caron (1993) and by flow cytometry, in which individual cells were sorted using an Argon-ion laser (Becton-Dickinson FACStar ${ }^{\text {pus }}$ Cell Sorter). Cell viability using flow cytometry was approximately $20-30 \%$.

Once cells were isolated in pure culture they were identified to the genus or species level using light or transmission-electron microscopy. Microscopical observations were compared to the Biogeochemical Ocean Flux Study Protist Video Database (University of Bristol, UK) and to Patterson and Larsen (1991). Table 5.1 lists the protists obtained from each of the experimental stations.

Hydrostatic pressure experiments. Prey preparation: Bacterial prey cultures (Halomonas halodurens) were heat killed to prevent overgrowth, washed free of yeast extract secondary metabolites and growth inhibitors by repeated centrifugation and resuspension, and finally distributed into microfuge storage tubes and pelleted. Microfuge tubes, containing an equivalent quantity and quality of pelleted bacteria, were stored at $-70^{\circ} \mathrm{C}$ until used as a food source in the pressure experiments.

Experimental organism preparation: Each isolate was grown in sterile $50 \mathrm{~mL}$ tissue culture flasks (Fisher Scientific) in growth media $(0.22 \mu \mathrm{m}$ filtered/autoclaved VSW and $10^{8}-10^{9}$ heat-killed prey cells $/ \mathrm{mL}$ ) prior to the start of each experiment to bring flagellate cells up to a density between $10^{5}-10^{6} / \mathrm{mL}$.

Pressure vessel and syringe preparation: Seven OC-16 reactor pressure vessels (High Pressure Equipment Co., Inc.), previously described by Jannasch and Wirsen (1984), were rinsed, filled with water and equilibrated at the experimental temperature. Sterile syringes (10 cc, Becton Dickinson) capped with rubber serum-stoppers were used as incubation tubes inside the pressure vessels. 


\begin{tabular}{|c|c|c|c|c|c|c|}
\hline Isolate & Collection Location & Collection Date & Collection Depth & Positive Identification & Tentative Identification & $\mathbf{T}\left({ }^{\circ} \mathrm{C}\right)$ \\
\hline BRM 1 & $9^{\circ} \mathrm{N}$ Biovent Riftia and Mussels Bed & December 1995 & $2500 \mathrm{~m}$ & & Bodo saliens & 20 \\
\hline BRM 2 & $9^{\circ} \mathrm{N}$ Biovent Riftia and Mussels Bed & December 1995 & $2500 \mathrm{~m}$ & & Ancyromonas $\mathrm{sp}$. & 3.5 \\
\hline BSZ 1 & $9^{\circ} \mathrm{N}$ Biovent Serpulid Zone & April 1995 & $2500 \mathrm{~m}$ & Rhynchomonas nasuta & & 20 \\
\hline BSZ2 & $9^{\circ} \mathrm{N}$ Biovent Serpulid Zone & December 1995 & $2500 \mathrm{~m}$ & Rhynchomonas nasuta & & 20 \\
\hline BSZ3 & $9^{\circ} \mathrm{N}$ Biovent Serpulid Zone & December 1995 & $2500 \mathrm{~m}$ & & Massisteria marina & 20 \\
\hline BSZ 4 & $9^{\circ} \mathrm{N}$ Biovent Serpulid Zone & December 1995 & $2500 \mathrm{~m}$ & & Monosiga sp. & 20 \\
\hline BSZ 5 & $9^{\circ} \mathrm{N}$ Biovent Serpulid Zone & December 1995 & $2500 \mathrm{~m}$ & & Monosiga sp. & 20 \\
\hline BSZ 6 & $9^{\circ} \mathrm{N}$ Biovent Serpulid Zone & December 1995 & $2500 \mathrm{~m}$ & & Monosiga sp. & 20 \\
\hline BSZ7 & $9^{\circ} \mathrm{N}$ Biovent Serpulid Zone & December 1995 & $2500 \mathrm{~m}$ & Caecitellus parvulus & & 20 \\
\hline BSZ 8 & $9^{\circ} \mathrm{N}$ Biovent Serpulid Zone & December 1995 & $2500 \mathrm{~m}$ & & benthic foraminifera & 3.5 \\
\hline EWM 1 & $9^{\circ} \mathrm{N}$ East Wall Mussels Bed & December 1995 & $2500 \mathrm{~m}$ & Caecitellus parvulus & & 20 \\
\hline & & & & & & \\
\hline $\mathrm{DA} 1$ & Deep Atlantic Shelf & July 1996 & $1500 \mathrm{~m}$ & & scuticociliate & 3.5 \\
\hline DA 2 & Deep Atlantic Shelf & July 1996 & $1500 \mathrm{~m}$ & & chrysomonad & 3.5 \\
\hline DA 3 & Deep Atlantic Shelf & July 1996 & $1500 \mathrm{~m}$ & & chrysomonad & 3.5 \\
\hline DA 4 & Deep Atlantic Shelf & July 1996 & $1500 \mathrm{~m}$ & & chrysomonad & 3.5 \\
\hline CBR 1 & Chesapeake Bay, Maryland & N/A & $0.5 \mathrm{~m}$ & Rhynchomonas nasuta & & 20 \\
\hline NBH 4 & New Bedford Harbor, MA & August 1996 & $2.5 \mathrm{~m}$ & Caecitellus parvulus & & 20 \\
\hline
\end{tabular}

Table 5.1. Protozoa collected from deep-sea and shallow locations. Flagellates in bold print were used in these experiments. Positive identification was made for Rhynchomonas nasuta and Caecitellus parvulus; all others have tentative identifications only. Temperature shown is the temperature at which these organisms currently are grown in laboratory culture. 
Control experiments: To determine if the syringes inside the pressure vessels or the vessels themselves introduced artifacts, growth rates were measured using replicate syringes inside (internal) and outside (external) pressure vessels and compared with growth rates in culture flask controls (Figure 5.1). With the exception of the vent isolate BSZ 3 (Massisteria marina), growth rates of flagellates in syringes internal and external to pressure vessels were generally the same and closely approximated growth rates in culture flask controls. Organisms that failed to show similar growth rates among the controls, such as BSZ 3 , were not used in these experiments. Note in Figure 5.1 that, with the exception of Rhynchomonas nasuta strain BSZ 1, the absolute number of protists was higher in flask controls as the cultures approached stationary phase. This result indicated the depletion through time of some essential growth requirement, most likely oxygen. The depletion of specific growth factors was expected to occur in syringes, since they are closed systems. However, as all syringes and growth factors were replicated for each organism at each pressure, it was the effect of pressure which was considered to exert the most influence on growth rate differences.

Pressure experiments: To control for differences between syringes, aliquots were taken from a single, well-mixed culture containing $5 \times 10^{8}-5 \times 10^{9}$ heat-killed bacterial cells $/ \mathrm{mL}$ and approximately $5 \times 10^{3}$ flagellates $/ \mathrm{mL}$. Ten milliliter aliquots were placed inside each of 7 syringes, labeled 1,50,100, 150, 200, 250 and 300 atm following the experimental design outlined below. Three replicate syringes for each organism were placed inside each of the 7 pressure vessels, the vessels were topped with water, then compressed to the experimental pressure. Two strains of the same species (6 syringes per vessel) simultaneously could be measured at each of the 7 pressures. Each experiment was performed three times. 
Figure 5.1 Mean growth of several species of deep-sea flagellates in control experiments designed to test the feasibility of using pressure tubes (syringes) as culturing containers inside pressure vessels. Lines are best-fit lines drawn through mean abundance values $( \pm 1$ SD) plotted against time of sample collection. 

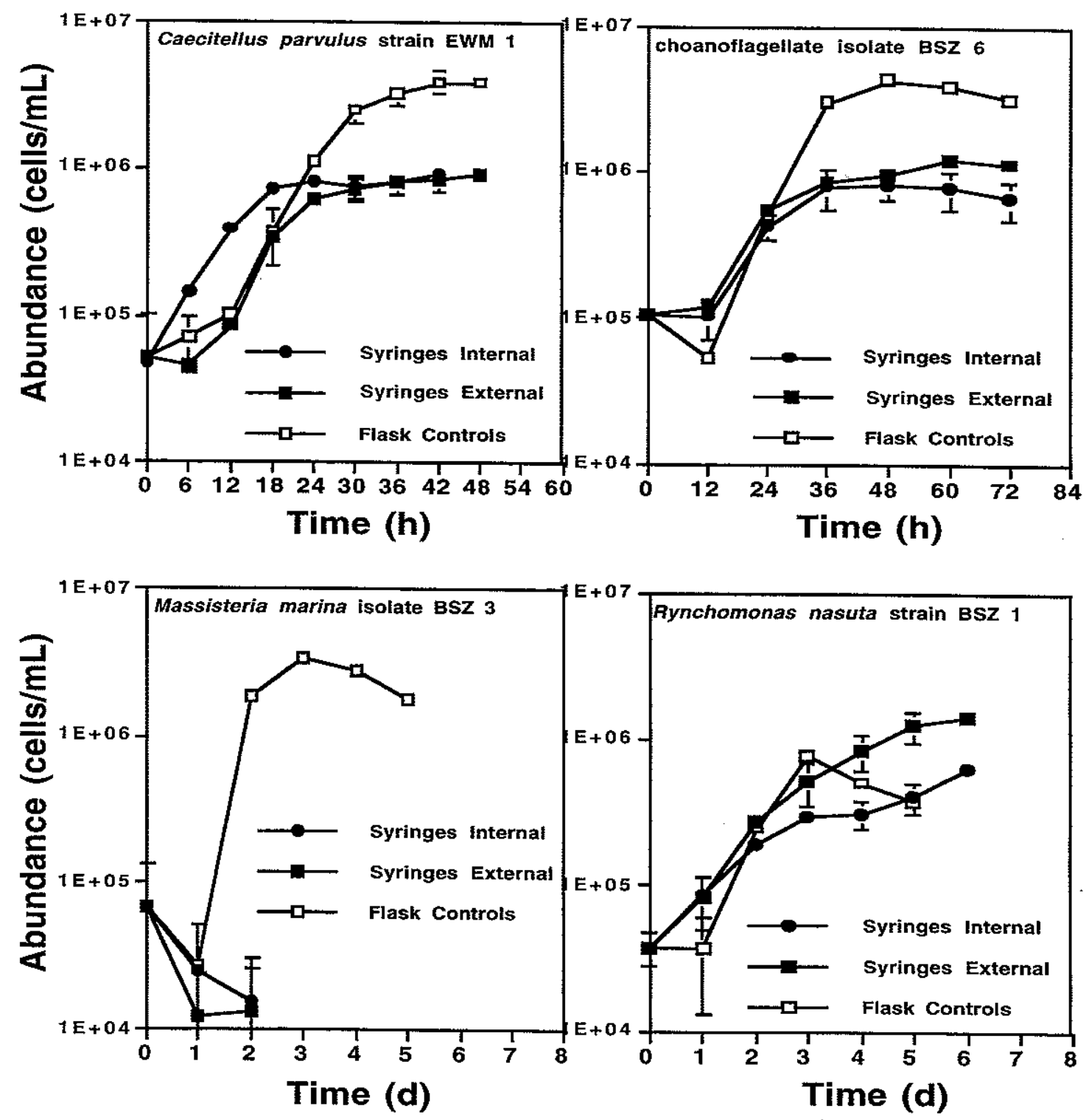
Sampling. Cell counts were done using both multiple time points and end points. In time-point sampling, pressure vessels were slowly decompressed to atmospheric pressure, opened and the syringes removed. Each syringe was inverted, the serum-stopper cap removed and the plunger withdrawn about $0.5 \mathrm{cc}$ to introduce a small air bubble into the syringe chamber. The serum stopper was replaced and the syringe was inverted several times using the air bubble to detach and mix flagellates. The air bubble was removed and approximately $200 \mu \mathrm{L}$ was transferred into a sterile microfuge tube. The syringes were recapped, replaced into the vessels and recompressed within 10-15 min after decompression. In end point sampling, samples were taken only once, at the end of exponential growth, the timing of which had previously been determined during time-point sampling. End-point sampling eliminated the effects of decompression, which may have affected growth rate results. Because time-point sampling introduced several decompression/recompression events into an experiment in which relative growth rates are a function of constant pressure, control experiments were done to determine whether end-point sampling and time-point sampling yielded similar results. Figure 5.2 shows data from an experiment with Caecitellus parvulus strain EWM 1 which compares end-point and time-point sampling under conditions of variable hydrostatic pressure at $20^{\circ} \mathrm{C}$. This figure shows that both sampling methods yield similar mean growth rates at pressures greater than $1 \mathrm{~atm}$. The general trend between end points and time points remains approximately the same, which is a decrease in growth rate with increasing pressure. Because end-point sampling does not require a decompression/recompression event during the course of an experiment, it was used instead of timepoint sampling in these experiments. This does not apply to experiments at atmospheric pressure, which were still done using multiple time points. End-point sampling did require, however, that measurements be made close to the beginning and termination of exponential growth and accurate end-points were determined using time-point sampling curves. 
Figure 5.2. Mean growth rates of Caecitellus parvulus strain EWM 1 measured by endpoint and time-point sampling methods at different hydrostatic pressures. Lines are best-fit lines drawn through mean growth rate values $( \pm 1 \mathrm{SD}$ ) plotted against hydrostatic pressure values at which growth was measured. 


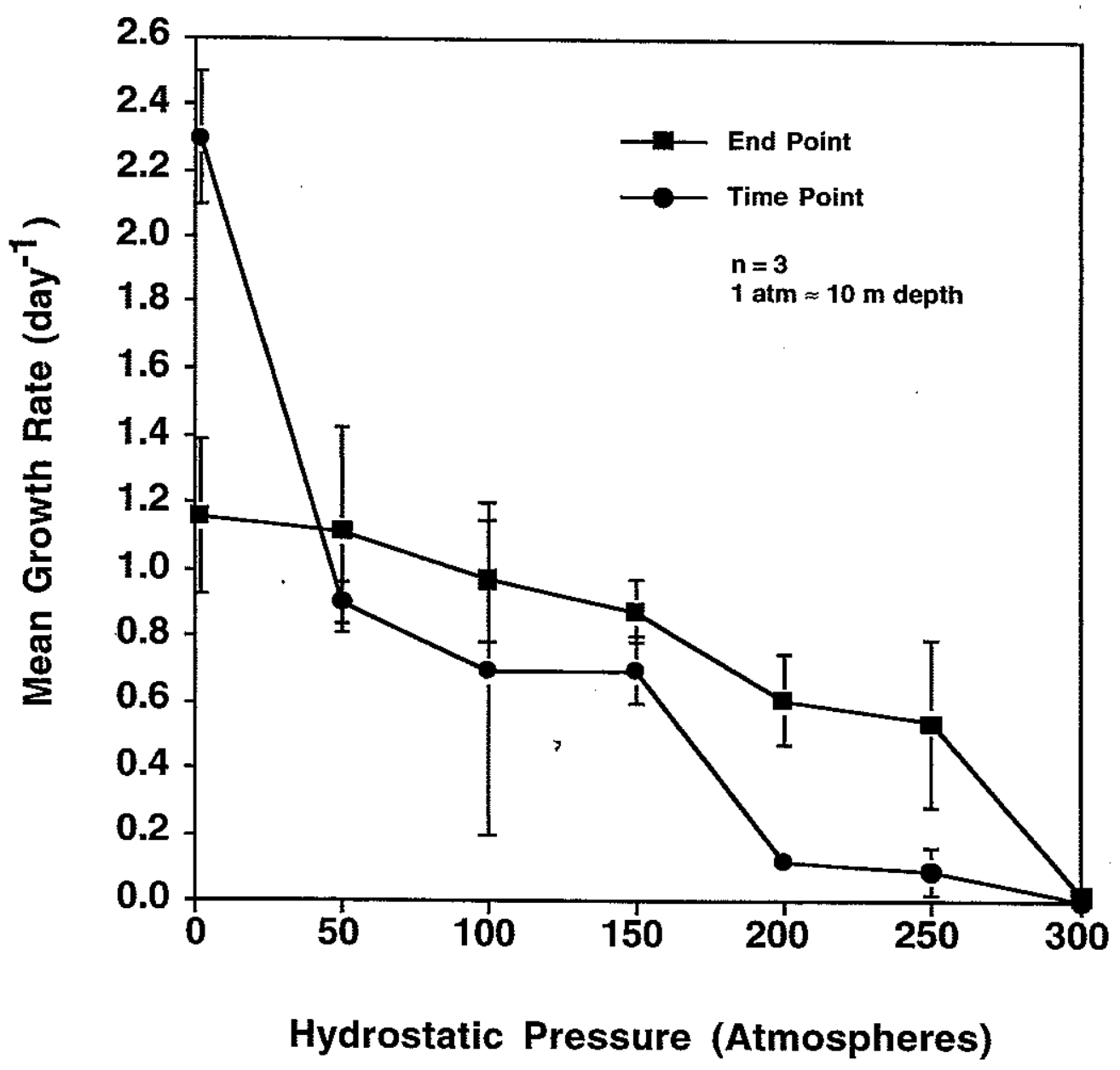


Cell counts and growth rate calculations. From the microfuge tube, exactly 90 $\mu \mathrm{L}$ was aliquoted into a labeled borosilicate glass tube containing $10 \mu \mathrm{L}$ of Acid Lugol's Solution ( $1 \mathrm{~g}$ iodine $(\mathrm{I})+2 \mathrm{~g}$ potassium iodide (KI) dissolved in $200 \mathrm{~mL} \mathrm{MQ} \mathrm{H}_{2} \mathrm{O}$; add 20 $\mathrm{mL}$ glacial acetic acid). The remaining $110 \mu \mathrm{L}$ was observed directly on a Palmer-Maloney depression slide using phase contrast light microscopy at $400 \mathrm{x}$ magnification. In this way, the physical condition and general abundance of the cells was assessed just prior to counting. Cells were counted two times on the center grid of a hemocytometer, unless culture densities were low, in which case two whole-grid ( $9 \mathrm{x}$ center) counts were made and averaged. These data were used to calculate mean relative growth rates at variable hydrostatic pressure and constant temperature. In time-point sampling, the per-capita growth rate was determined from a linear regression of a plot of the natural logarithm of cell abundance through time. In end-point sampling, the per-capita growth rate was calculated using the following equation:

$$
\ln \mathrm{N}_{\mathrm{t}} / \mathrm{N}_{\mathrm{o}} * 1 / \mathrm{t}
$$

where $N_{t}$ is the number of flagellates in the culture at time $t$, the end point, and $N_{o}$ is the initial number of flagellates in the culture.

Transmission electron microscopy. Samples collected from high pressure treatments were gently sedimented by centrifugation and fixed for 20 minutes at $5^{\circ} \mathrm{C}$ in $2 \%$ electron microscopic grade glutaraldehyde (Ladd Res. Industries, VT) prepared in $0.05 \mathrm{M}$ cacodylate buffer ( $\mathrm{pH}$ 7.8). Particle preparations were washed, deposited on carbon-coated, formvar-covered grids, air dried and negatively stained with $2 \%$ potassium phosphotungstate solution ( $\mathrm{pH} 6.5$ ) or shadowed with a carbon platinum source. Preparations for transmission microscopy used standard methods for fixation and embedding (e.g., Anderson 1992) and were observed with a Philips 201 transmission microscope operated at $60 \mathrm{kV}$. 
Experimental design and statistical analyses. The following experiments were manipulated to fit a split split-plot design in which the measured mean relative growth rate of two strains simultaneously could be tested for pressure dependence and time invariance (see Snedecor and Cochran (1982) p. 328, example 16.15.1, for a more comprehensive description of this design). Each experiment was conducted at 7 different pressures, from 1 atm-300 atm in $50 \mathrm{~atm}$ increments $(1,50,100,150,200,250,300 \mathrm{~atm})$, and was repeated three different times, $T_{1}, T_{2}$ and $T_{3}$ for each organism.

\section{Results}

Isolation procedures yielded 11 isolates from the $9^{\circ} \mathrm{N}$ hydrothermal vent sites and 4 isolates from the continental shelf region in the North Atlantic (Table 5.1). Two vent isolates, BRM2 and BSZ8, and all continental shelf isolates are psychrophilic, with growth optima near $3.5^{\circ} \mathrm{C}$. All other vent isolates and the two shallow-water strains grow well at $20^{\circ} \mathrm{C}$. Several isolates were identified as different strains of two species in two different genera: Caecitellus parvulus (Strains BSZ7, EWM1 and NBH4) and Rhynchomonas nasuta (Strains CBR1, BSZ1 and BSZ2). Patterson et al. (1993) point out that Griessmann (1913) previously assigned $C$. parvulus to the genus Bodo, but ultrastructural analysis revealed 1) mitochondria with tubular cristae, 2) lack of paraxial rods, 3) a mouth supported by a horseshoe-shaped arc of microtubules, 4) the microtubules are associated with massive electrondense material, and 5) there is no kinetoplast. They concluded that these observations contradict assignment to the genus Bodo. Although Caecitellus is a genus of uncertain taxonomic affinity, it is used throughout this paper with regard to the species parvulus. Isolates with tentative species and/or genera assignments include BRM1 (Bodo saliens), BRM2 (Ancyromonas sp.), BSZ3 (Massisteria marina) and BSZ4, 5 and 6 (Monosiga sp.). None of the continental shelf isolates have been positively identified. 
Pressure experiments. The growth rates of $C$. parvulus strains EWM1 (vent) and NBH4 (shallow-water) were measured and compared under conditions of variable hydrostatic pressure (Figure 5.3). Both strains had a decreasing growth rate with increasing pressure, but the vent strain had a higher rate of growth at all pressures relative to the shallowwater strain $(\mathrm{P} \leq .01)$. Both strains exhibited barotolerance to increasing pressure. Within 2-4 days of compression to pressures greater than $250 \mathrm{~atm}$, both strains began to encyst. After 5 days at $300 \mathrm{~atm}$, all cells observed and counted were encysted forms. All encysted cultures of compressed $C$. parvulus gave rise to dense cultures of swimming and feeding trophs within 3-5 days of decompression to atmospheric pressure and transfer to new media (data not shown). Similar results were obtained with $R$. nasuta strains BSZ1 (vent) and CBR1 (shallow-water) (Figure 5.4). Both strains exhibited a decreasing growth rate with increasing pressure, but the vent strain had a higher rate of growth at higher pressures relative to the shallow-water strain $(\mathrm{P} \leq .05)$. Both strains exhibited barotolerance toward increasing pressure. However, only the vent strain grew at $250 \mathrm{~atm}$ - the pressure at its collection depth. Both strains of $R$. nasuta began to form cysts within 2-4 days of compression to pressures greater than 250 atm and these cysts also gave rise to dense cultures of swimming, feeding trophs upon release from the inhibitory pressure. The choanoflagellate vent isolate, BSZ6, showed little barotolerance (Figure 5.5). It did not grow at pressures greater than or equal to $100 \mathrm{~atm}$. At $100 \mathrm{~atm}$ and higher, all cells encysted. These cysts gave rise to dense cultures of swimming choanoflagellates within 3-5 days of decompression to atmospheric pressure. The psychrophilic vent isolate, BRM2, showed high barotolerance to $150 \mathrm{~atm}$. It did not grow or encyst at pressures higher than $150 \mathrm{~atm}$ (Figure 5.5). Figure 5.6 compares two psychrophilic continental shelf isolates, DA2 and DA3. The growth rate of isolate DA2 decreased with increasing pressure up to $200 \mathrm{~atm}$. Isolate DA3 grew best at $50 \mathrm{~atm}$ and was barotolerant to $150 \mathrm{~atm}$. No growth was observed at pressures greater than 150 atm. Encystment of DA2 and DA3 did not occur at any pressure. 
Figure 5.3. Mean growth rates of Caecitellus parvulus strain EWM 1 from $2500 \mathrm{~m}$ and strain NBH4 from a shallow-water location with increasing hydrostatic pressure (Error bars are $\pm 1 \mathrm{SD})$. 


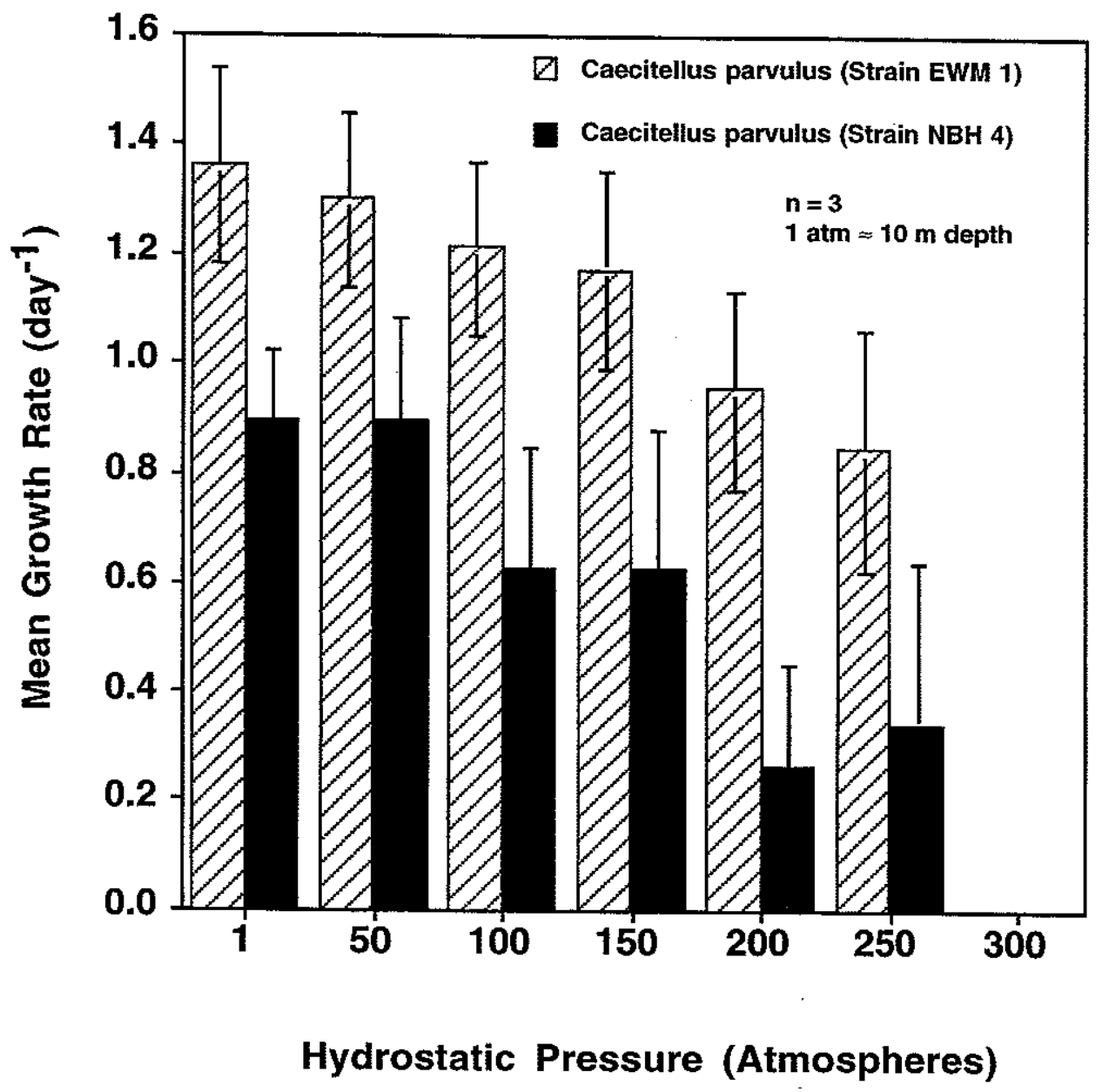


Figure 5.4. Mean growth rates of Rhynchomonas nasuta strain BSZ1 from $2500 \mathrm{~m}$ and strain CBR1 from a shallow-water location with increasing hydrostatic pressure (Error bars are $\pm 1 \mathrm{SD})$. 


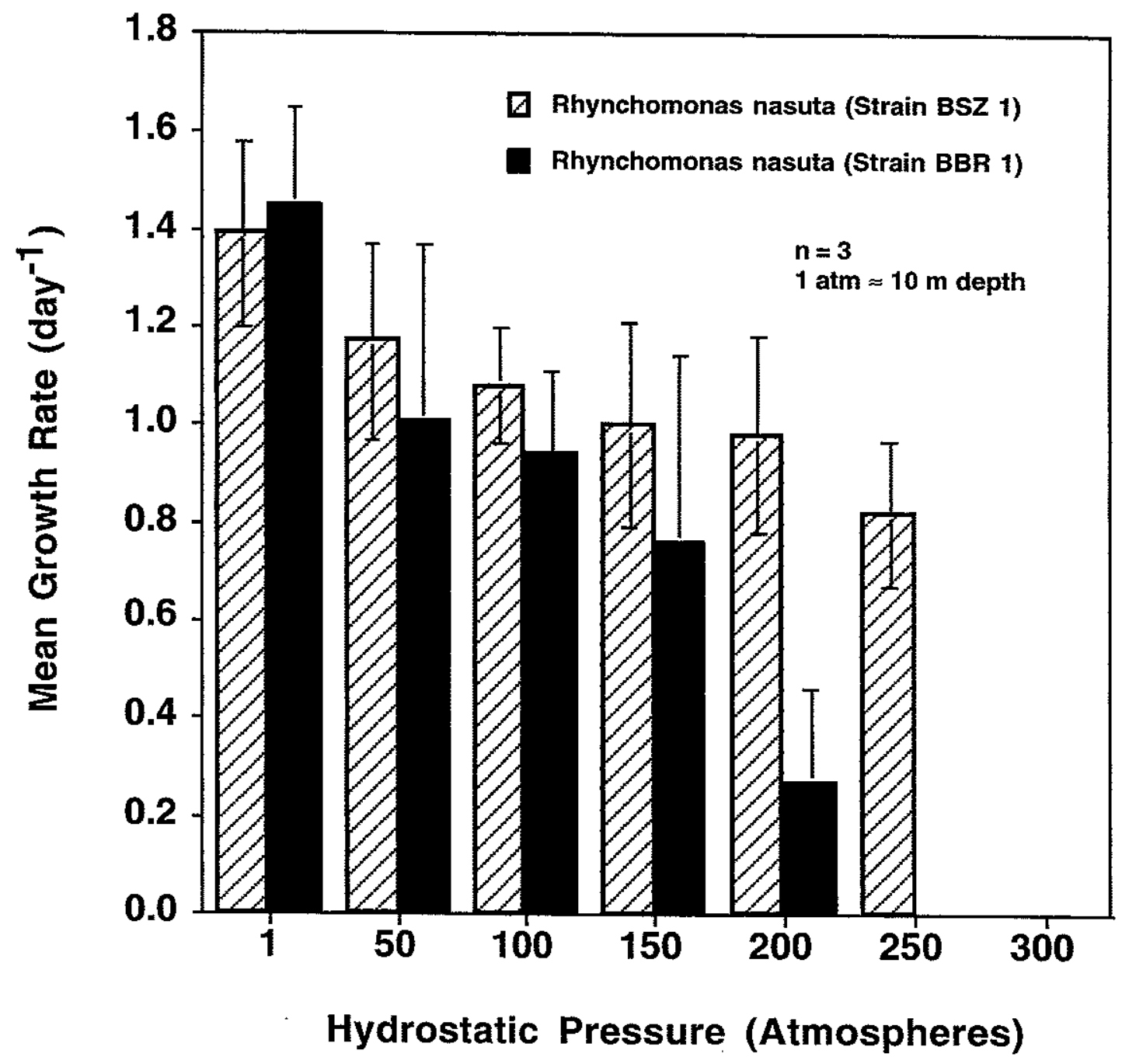


Figure 5.5. Mean growth rates of a choanoflagellate isolate BSZ6 and the psychrophilic isolate BRM2 with increasing hydrostatic pressure. These organisms were collected at $2500 \mathrm{~m}$. (Error bars are $\pm 1 \mathrm{SD}$ ). 


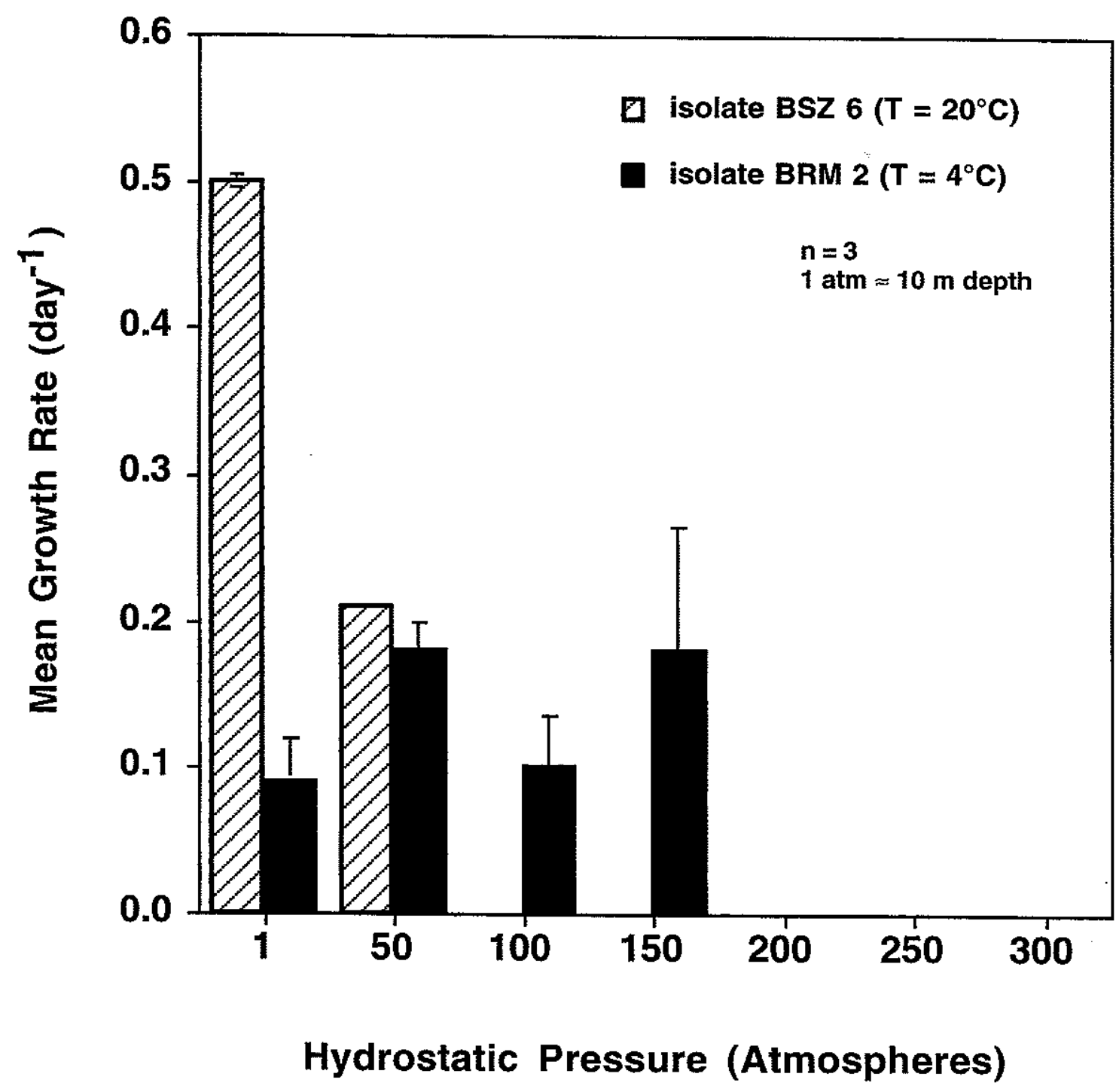


Figure 5.6. Mean growth rates of the psychrophilic isolates DA2 and DA3 with increasing hydrostatic pressure. These organisms were collected at $1500 \mathrm{~m}$. (Error bars are $\pm 1 \mathrm{SD}$ ). 
Illh. 
Light and electron microscopic observations. The process of cell encystment induced by hydrostatic pressure was investigated using light microscopy and transmission electron microscopy (Figures 5.7 and 5.8). Figure 5.7 shows C. parvulus strain EWM1 trophs in culture at atmospheric pressure (Figure $5.7 \mathrm{~A}$ ) and at $300 \mathrm{~atm}$ after 2 days (Figure $5.7 \mathrm{~B}$ ) and 5 days (Figure $5.7 \mathrm{C}$ ) exhibiting gradual thickening of the cell wall, increased opacity of the cytoplasm and resorption of the flagellum. Similar results were observed in $R$. nasuta cultures. Figure 5.7 D shows $R$. nasuta strain BSZ1 trophs in culture at atmospheric pressure. Cultures collected from high pressure treatment after four days, and immediately fixed for electron microscopy, contained flagellated and encysted cells (Figures 5.7 E-I). The long flagellum (5 - $7 \mu \mathrm{m}$ ), thickened in the middle portion, has fine trailing filaments approximately $30 \mathrm{~nm}$ thick (Figure $5.7 \mathrm{E}$ ). The tip was slightly swollen (Figures 5.7 $\mathrm{E}$ and F). Spherical Cysts (Figure $5.7 \mathrm{H}$ ) observed in the same preparation were approximately $6 \mu \mathrm{m}$, although larger ones (up to $10 \mu \mathrm{m}$ ) were also present. Higher magnification, negative-stained preparations (Figure $5.7 \mathrm{I}$ ) show that the cyst wall is smooth and lacks ornamentation.

Ultrathin sections of the choanoflagellate isolate BSZ6, grown in cultures at ambient atmospheric pressure (Figure $5.8 \mathrm{~A}$ ), contained a prominent nucleus, mitochondria with flattened cristae and a lightly granular matrix, osmiophilic reserve bodies, and digestive vacuoles with ingested bacteria. Portions of the fringe of microvilli were observed in longitudinal sections. Cells collected from high pressure treatments after four days showed varying stages of encystment (Figures 5.8 B-D). Some cells appeared nearly normal (Figure 5.8 B) and contained microvilli in some sections, although the mitochondria were consistently enlarged in the pressure-treated cells. As the cells encysted no microvilli were observed, the nucleus became increasingly smaller and irregular in shape, reserve bodies were fewer, remaining digestive vacuoles contained only late stages of digested matter, and the cell was gradually enclosed in a thickened wall that at first was thin and granular (Figures 
Figure 5.7. Light microscopic images of Caecitellus parvulus strain EWM 1 (A-C) and Rhynchomonas nasuta strain BSZ 1 (D), and transmission electron microscopic images of $R$. nasuta motile cells (E-G) and cysts $(\mathrm{H}, \mathrm{I})$ in whole particle preparations. (A) C. parvulus trophic cells cultured at atmospheric pressure showing normal apical and trailing flagella. (B) A cell after two days at 300 atm showing early stages of cyst wall formation (arrow) and resorption of flagella. Note increase in cell size. (C) A fully encysted cell after 5 days at 300 atm. (D) $R$. nasuta trophic cells cultured at atmospheric pressure showing typical proboscis and trailing flagellum. (E) A carbon-platinum, shadowed flagellum (F) with trailing $30 \mathrm{~nm}$ thick filaments (arrow) and characteristic swollen tip (T). (F) Negatively stained motile cell showing the proboscis (P) and curved flagellum (F) with a denselystained, rod-shaped bacterium near the tip. (G) Carbon-platinum, shadowed motile cell with curved flagellum (F). (H) Carbon-platinum, shadowed cyst (C), with a smooth surface, casting a typical shadow (S) for a spheroidal body. (I) An enlarged view of the edge of a cyst showing the smooth surface with a thin negatively stained outer layer (arrow). Scale bars in (A), (B), and (D) $5 \mu \mathrm{m}$; (C) $2 \mu \mathrm{m}$; (E) and (I) $0.3 \mu \mathrm{m}$; and (F-H) $2 \mu \mathrm{m}$. 


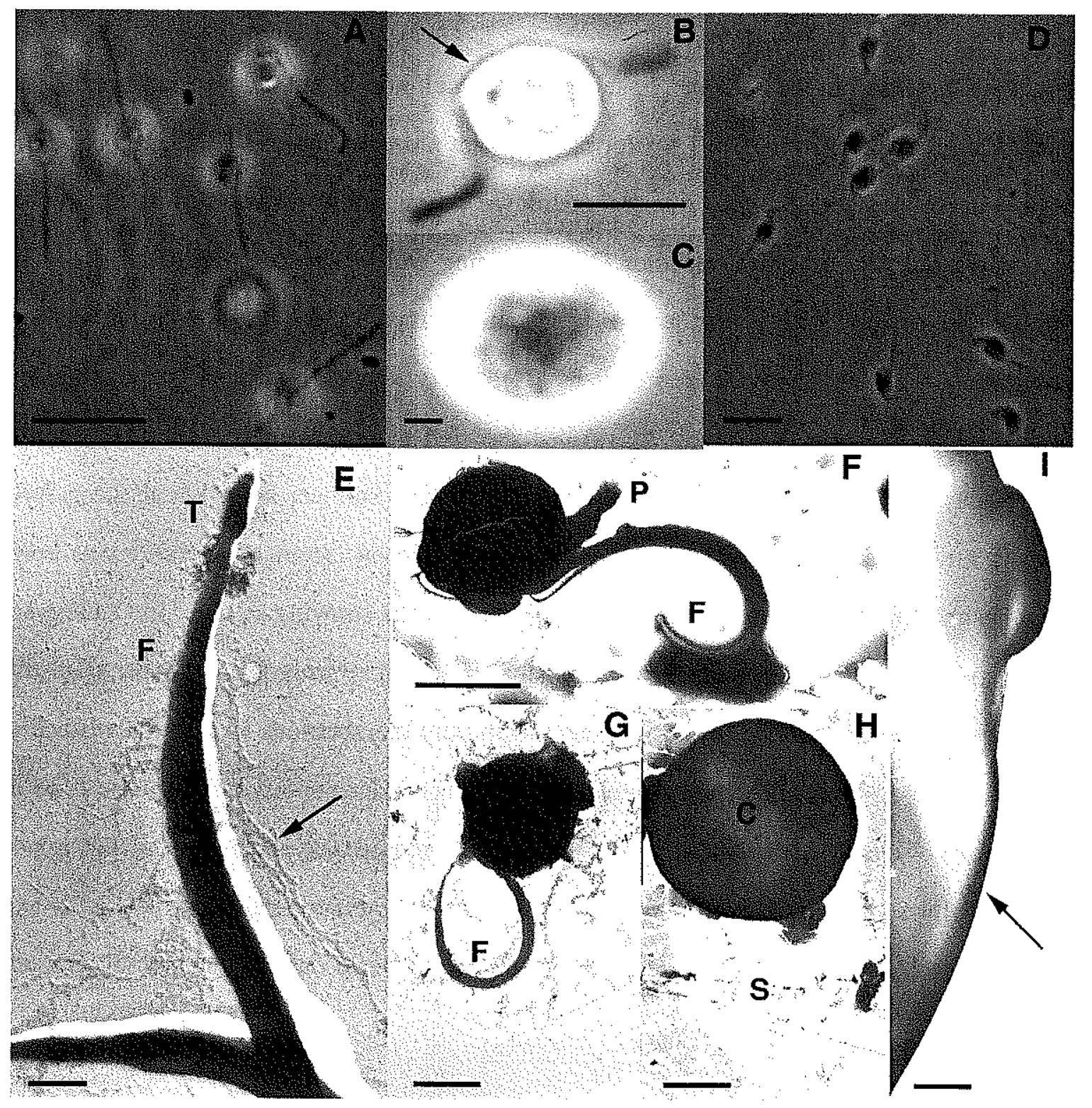


Figure 5.8. Ultrathin sections of choanoflagellates cultured at ambient atmospheric pressure (A) and at $300 \mathrm{~atm}$ (B-E). (A) Normal cell with prominent nucleus (N), mitochondria with flattened cristae and lightly granular matrix $(\mathrm{M})$, osmiophilic, reserve bodies that appear to be lipid (L), and digestive vacuoles (V) containing early stages of digested food. (B) Pressure-treated cell with almost normal appearance compared to (A) showing, however, a somewhat more irregularly-shaped nucleus $(\mathrm{N})$, some reserve bodies $(\mathrm{L})$, and digestive vacuoles $(\mathrm{V})$ mainly in late stages. (C) A cell showing more advanced evidence of encystment (note light deposit of granular material on the cell surface, arrow) with irregularly shaped nucleus $(\mathrm{N})$, enlarged digestive vacuoles with loosely arranged membranous components and few dense reserve bodies. (D) A series of cells showing signs of increasing encystment (right to left). The nucleus $(\mathrm{N})$ is smaller and more irregular in shape. Digestive vacuoles $(V)$, when present, are in late stages with only membranous matter; the surface of the cell is increasingly enclosed by an electron-dense granular deposit that appears to be an early stage of cyst wall deposition (CW). (E) An electron-opaque section of a wall, apparently a fully-formed cyst, exhibiting a brittle quality and smooth outer surface as is also characteristic of kinetoplastid cysts as in Figure 5.7 I. Scale bars in (A) and (E) $0.5 \mu \mathrm{m}$, others $1 \mu \mathrm{m}$. 


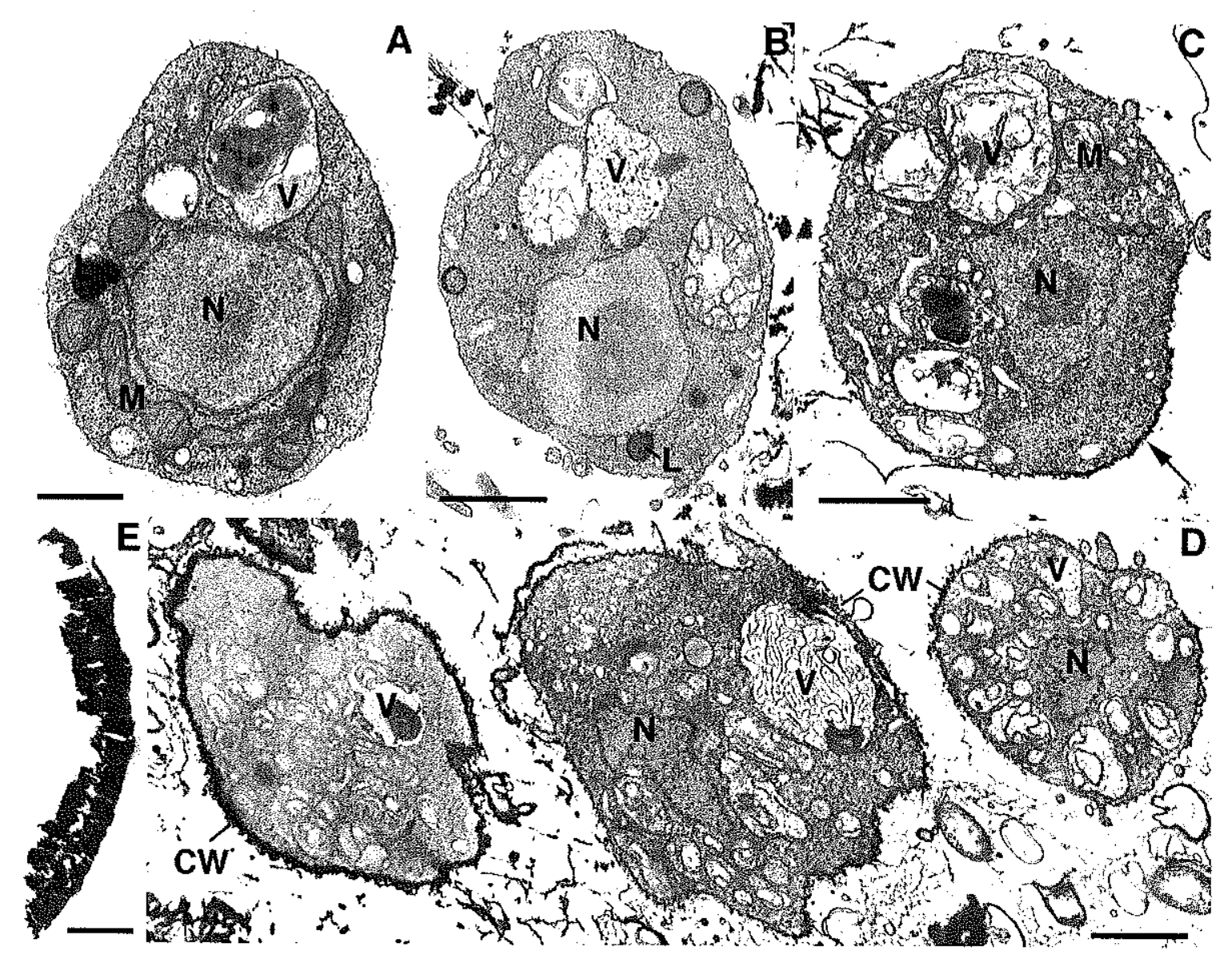


5.8 C and D). Subsequent stages showed a more complete coating of the granular material and the cytoplasm stained less densely, perhaps due to reduced penetration through the developing wall (Figure 5.8 D, left). In the most advanced stages, a thick, electron-dense wall (c. 0.3 to $0.7 \mu \mathrm{m}$ ) was formed (Figure $5.8 \mathrm{E}$ ). It was impervious to the resin. Hence, we could not observe the state of the cytoplasm in the fully encysted cells. These fine structural data support light microscopic observations that high pressure treatment gradually induces encystment. Flagellated stages of Rhynchomonas persist for some time up to several days during onset of pressure treatments, but the choanoflagellates appear to be more susceptible to pressure-induced encystment based on light and electron microscopic evidence.

Encystment was only observed in hydrothermal vent isolates cultured at $20^{\circ} \mathrm{C}$. Live observation of Caecitellus parvulus strains after 8 days at 250 atm revealed a very low abundance of mostly swimming cells; very few cells had encysted. But after only 2 days at $300 \mathrm{~atm}$, most cells had encysted or were in the process of encysting (Figure $5.7 \mathrm{~B}$ ). After 5 days at $300 \mathrm{~atm}$, all cells were encysted (Figure 5.7 C). When decompressed to atmospheric pressure and transferred to new media, all encysted cultures grew to a density of approximately $1 \times 10^{6}$ trophs per $\mathrm{mL}$ within 5 days.

To determine if this organism resumes its growth rate upon release from an inhibitory pressure, pressure was varied over the course of an experiment (Figure 5.9). Replicate cultures of Caecitellus parvulus strain EWM 1 initially were grown at 1 atm then compressed to $300 \mathrm{~atm}$ after 29 hours. Growth proceeded at a decreasing rate for an additional 40 hours at 300 atm then began to decline for 32.5 hours until the culture was decompressed to $1 \mathrm{~atm}$ at 101.5 hours. After a brief lag period, the growth rate increased to approximate that of the $1 \mathrm{~atm}$ exponential phase prior to the compression event. 
Figure 5.9. Mean growth of Caecitellus parvulus strain EWM 1 in an experiment to determine the effect of compression and decompression events on growth rate. Growth was initiated at atmospheric pressure (black squares) for 29 hours. Cultures then were compressed to 300 atm for 72.5 hours (white circles) and released from pressure at 101.5 hours (black squares). 


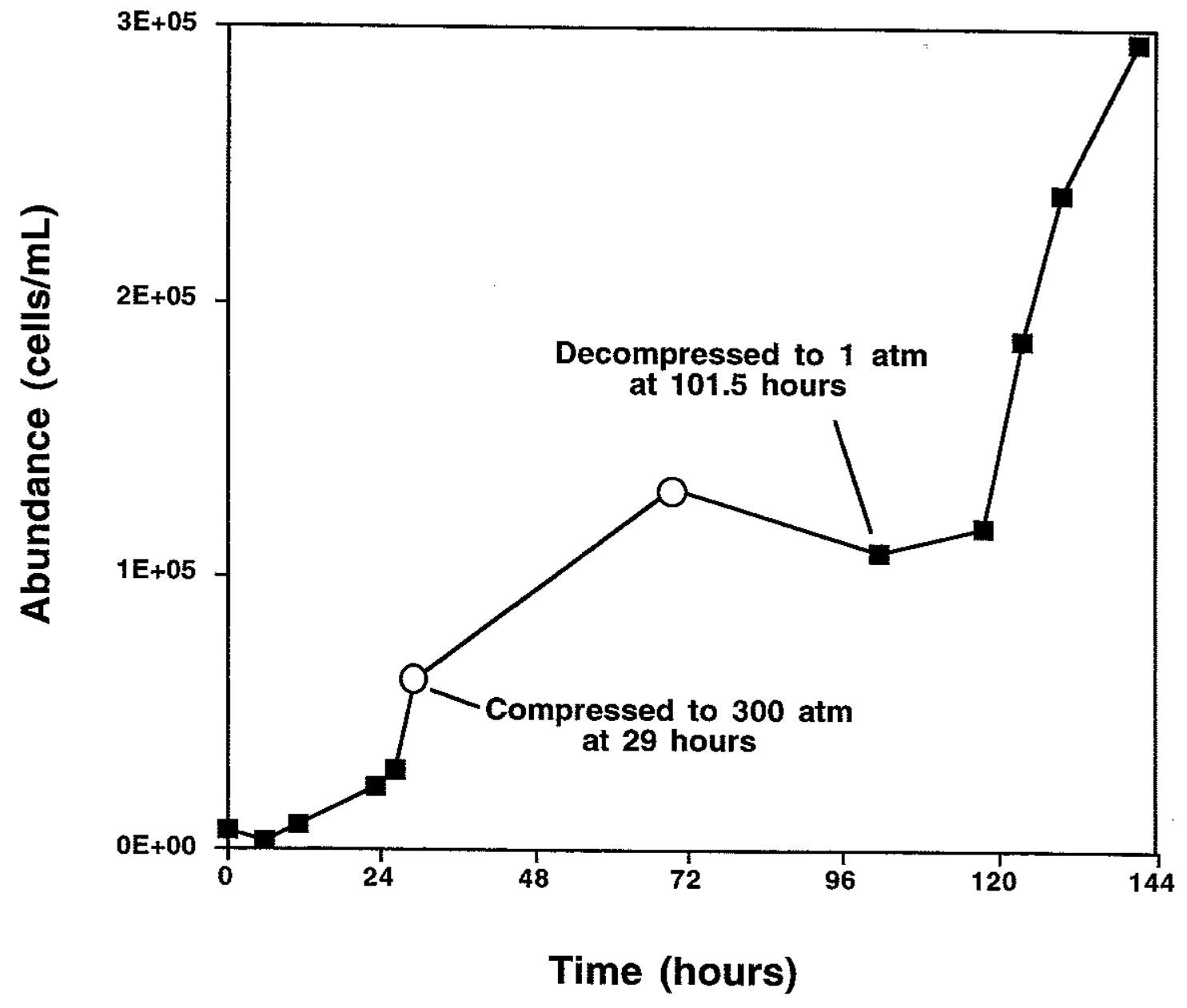




\section{Discussion}

The specific questions this work proposed to answer were: 1) what are the relative growth rates of deep-sea protozoa cultured under conditions of varying hydrostatic pressure, and 2) are species retrieved and cultured by the experimental methods barophilic - that is, do they have an optimal pressure for growth that is higher than atmospheric pressure - or do they simply exhibit levels of barotolerance to extreme deep-sea pressures? The observation of pressure-induced cell encystment in species of flagellates isolated from the $2500 \mathrm{~m}$ hydrothermal vent was unanticipated, as the pressures used in these experiments were not exceptionally high when compared with similar studies involving protozoan trophs retrieved from stations at greater depths and pressures (Burnett 1977; Grassle 1986; Small and Gross 1985; Turley and Carstens 1991; Turley et al. 1993; Turley et al. 1988). However, the discovery that pressure-induced cysts yield active trophs upon release from an inhibitory pressure has ecological implications regarding flagellate seeding if advection to shallow waters can occur.

Encystment may - and to some degree does - occur due to anoxic conditions developing through time within syringes. The abundance of organisms grown in syringes was shown to be lower than in flasks (Figure 5.1) and mitochondrial enlargement appeared to occur in cells grown in syringes under pressure (data not shown). However, encystment occurred faster and more completely in replicate cultures at higher pressures than at lower pressures, and since all syringes and growth factors were replicated, it was the effect of pressure that contributed the most to growth rate differences. For this reason, it also must be cautioned that the growth rates reported here are relative growth rates given the experimental conditions, and should not be considered as the absolute growth rates of these organisms in the deep sea: the demonstration of relative growth rates under controlled conditions in the laboratory does not imply that these growth rates occur in nature. 
Four of six deep-sea isolates ( 2 vent; 2 shelf) exhibited growth at pressures corresponding to their depth of collection. These species, Caecitellus parvulus strain EWM 1 (Figure 5.3), Rhynchomonas nasuta strain BSZ 1 (Figure 5.4), and continental shelf isolates DA 2 and DA 3 (Figure 5.6), potentially could be metabolically active at their respective depths of collection. The choanoflagellate isolate BSZ 6 is probably not active at its depth of collection, but may only exist there in an encysted state. Curiously, isolate BRM 2 and the other psychrophilic flagellates, DA 2 and DA 3, did not grow well at pressures greater than 150 atm and, perhaps more importantly, they did not encyst at any pressure, including pressures inhibitory to growth. By comparison, Wirsen and Jannasch (1975) also noted a decrease in metabolic activity at elevated pressures and cold temperatures, principally in biosynthesis more than respiration, for marine psychrophilic bacteria isolated from depths between 450 and $2500 \mathrm{~m}$.

Shallow-water strains of $C$. parvulus and $R$. nasuta exhibited growth up to or near the maximum pressures observed in deep-sea strains, and encystment occurred approximately at the same inhibitory pressure for both deep and shallow-water strains. However, it is interesting to note that deep-sea isolates had a higher rate of growth at higher pressures than did their shallow-water counterparts. This feature could result from some kind of genetic adaptation to higher pressure upon sinking to depth or with time on the ocean bottom. The difference currently is being investigated at the molecular level using DNA sequencing and denaturing-gradient gel electrophoresis (DGGE) analyses to determine if base-pair changes exist between the strains which could account for the observed difference in their response to growth under pressure. Alternatively, it has been suggested that variable responses to increasing pressure by different strains of a single species may result from differential expression of certain genes. Gene expression could show marked differences while DNA sequences could be identical in both shallow and deep-sea strains of the same species. 
Experimental evidence of cell encystment at high pressure was confirmed both by light microscopy and TEM analysis (Figures 5.7 and 5.8). Among the initial responses to cyst formation appears to be resorption of the flagella and the development of a cyst wall, as shown in Figures 5.7 B and C. Brown and Rogers (1978) showed that pressure-induced flagellar resorption occurred in the quadriflagellate Polytomella compressed to $\sim 500 \mathrm{~atm}$. At this pressure, they found that the flagellar axoneme is internalized and disassembled in the cytoplasm into precursor subunits, including tubulin proteins, which are reutilized in regenerating new flagella when the organism is returned to atmospheric pressure after a 30 min exposure. The flagellar membrane also was internalized and was assumed to have been incorporated into the plasma membrane (Brown and Rogers 1978). Loss of flagella may result in a decrease or absence of feeding in flagellates, and could be a stimulus for the early inducement of cyst formation. Evidence for this is found in the appearance only of late stages of digestive vacuoles accompanying early encystment in pressurized choanoflagellates (isolate BSZ 6) that eventually diminish during later stages of encystment (Figure 5.8).

The cell wall gradually becomes thickened with a dense, granular material (Figures $5.7 \mathrm{~B}, \mathrm{C}$ and $\mathrm{I}$ and $8 \mathrm{C}-\mathrm{E}$ ) that makes the cell relatively impermeable to harsh external conditions, as evidenced by the inability to fix and resinate fully encysted cells. The only evidence of fully encysted cells was a very thick, smooth cell wall with no cytoplasm or other internal structures (Figure 5.8 E). The cellular source of the granular wall material is not known. There is no evidence of it in the Golgi apparatus and it appears to be secreted at the surface of the cell membrane. As mentioned above, the cytoplasm was not observed in fully encysted cells, but the sequence in Figures 5.8 B-D shows a progression toward increasing electron dense granularity of the cytoplasm, a decrease in the number of digestive vacuoles, and changes in the shape and size of the nucleus. Flagellar resorption, generation of a thick, smooth cell wall, and the development of a spheroidal cyst was typical among encysting flagellates used in these experiments. 
The finding that all of the non-psychrophilic isolates encyst at pressures greater than those corresponding to their depths of collection suggests that some deep-sea isolates may exist only as cysts at greater depths. These cells potentially could arrive in the deep-sea from surface waters on sinking particulate matter (Bak et al. 1995; Caron 1991b; Patterson and Fenchel 1990; Patterson et al. 1993; Silver and Alldredge 1981; Silver et al. 1984). Figure 5.9 illustrates that encystment resulting from increased pressure may not be permanent in $C$. parvulus. This experiment showed that while high pressure does inhibit $C$. parvulus growth, release from this inhibitory pressure allows growth to continue at the same initial rate. Decompression to a more favorable pressure induced rapid growth of active trophs in all cyst cultures formed at high pressure. Cosmopolitan or epipelagic species, such as $C$. parvulus and $R$. nasuta, may be transported on sedimenting particles into the deep sea, where encystment at high pressure could serve as a mechanism for pelagic renewal by advective or diffusive upwelling. Entrainment of cysts in advective hydrothermal plume water has the potential for delivering cysts more than 300 meters above the vent field (Baker et al. 1994; Trivett 1991). Coupled with vertical flow along isopycnal lines and horizontal, especially upward, or diffuse flow across the thermocline (Gregg 1987), cysts can be carried to shallower waters on the order of days or weeks, where reduced pressure could favor the seeding of active trophs. These trophs could reattach to sedimenting detrital material, thereby reinitiating this benthic/pelagic cycle. It remains to be shown that cysts stay viable after long-term exposure to high pressure. These experiments currently are being conducted in laboratory incubators; however, in situ incubations of encysted cells should be conducted to assess the long-term responses of cysts and trophs in their natural setting. 


\section{Acknowledgments}

We would like to thank Drs. Lauren Mullineaux, Stacy Kim, and Ewann AgenbroadBerntson and the Alvin crew for their assistance in collecting specimens from the $9^{\circ} \mathrm{N}$ hydrothermal vent; Glen Paradis at the MIT Cell Sorter Facility for helping isolate cells via flow cytometry; Dr. David Patterson for assistance in flagellate identification; Dr. Victoria Starczak for advice regarding the experimental design and statistical analyses and Dr. David Caron for advice and the use of his laboratory and equipment. This work was supported by a National Science Foundation Graduate Research Fellowship. Sampling at the $9{ }^{\circ} \mathrm{N}$ EPR vents was made possible by NSF grant OCE-9019575 to Dr. Lauren S. Mullineaux. This is Woods Hole Oceanographic Institution contribution number 9715 and Lamont-Doherty Earth Observatory contribution number 5850. 


\section{References}

Alldredge, A. L., J. J. Cole, and D. A. Caron. 1986. Production of heterotrophic bacteria inhabiting macroscopic organic aggregates (marine snow) from surface waters. Limnol. Oceanogr., 31:68-78.

Anderson, O. R. 1992. Cytochemical localization of acid phosphatase (Lysosomal and digestive enzyme activity). In: Lee, J. J. and A. T. Soldo (ed.), Protocols in Protozoology, Allen Press, Kansas. pp. C22.21-C22.27.

Azam, F., T. Fenchel, J. G. Field, J. S. Gray, L. A. Meyer-Reil, and F. Thingstad. 1983. The ecological role of water-column microbes in the sea. Mar. Ecol. Prog. Ser., 10:257-263.

Azam, F., and J. A. Fuhrman. 1984. Measurement of bacterioplankton growth in the sea and its regulation by environmental conditions. In: Hobbie, J. E. and P. J. L. Williams (ed.), Heterotrophic activity in the sea, Plenum Publishing Corp., New York. pp. 179-196.

Bak, R. P. M., F. C. van Duyl, and G. Nieuwland. 1995. Organic sedimentation and macrofauna as forcing factors in marine benthic nanoflagellate communities. Microb. Ecol., 29(2):173-182.

Baker, E. T., R. A. Feely, M. J. Mottl, F. T. Sansone, C. G. Wheat, J. A. Resing, and J. E. Lupton. 1994. Hydrothermal plumes along the East Pacific Rise, $8^{\circ} 40^{\prime}$ to $11^{\circ} 50^{\prime} \mathrm{N}$ : Plume distribution and relationship to the apparent magmatic budget. Earth Planet. Sci. Lett., 128:1-17.

Brown, D. L., and K. A. Rogers. 1978. Hydrostatic pressure-induced internalization of flagellar axonemes, disassembly, and reutilization during flagellar regeneration in Polytomella. Exp. Cell Res., 117:313-324.

Burnett, B. R. 1977. Quantitative sampling of microbiota of the deep-sea benthos - I. Sampling techniques and some data from the abyssal central North Pacific. Deep-Sea Res., 24:781-789.

Caron, D. A. 1991a. Evolving role of protozoa in aquatic nutrient cycles. In: Reid, P. C., C. M. Turley, and P. H. Burkill (ed.), Protozoa and their role in marine processes, 25. Springer-Verlag, Berlin. pp. 387-415.

Caron, D. A. 1991b. Heterotrophic flagellates associated with sedimenting detritus. In: Patterson, D. J. and J. Larsen (ed.), The Biology of Free-Living Heterotrophic Flagellates, Special Volume 45. Clarendon Press, Oxford. pp. 77-92. 
Caron, D. A. 1993. Enrichment, isolation, and culture of free-living heterotrophic flagellates. In: Kemp, P. F., B. F. Sherr, E. B. Sherr, and J. J. Cole (ed.), Handbook of methods in aquatic microbial ecology, Lewis Publishers, Boca Raton. pp. 77-89.

Caron, D. A., and J. C. Goldman. 1990. Protozoan nutrient regeneration. In: Capriulo, G. M. (ed.), Ecology of marine protozoa, Oxford University Press, New York. pp. 283306.

Caron, D. A., J. C. Goldman, O. K. Andersen, and M. R. Dennett. 1985. Nutrient cycling in a microflagellate food chain. II. Population dynamics and carbon cycling. Mar. Ecol. Prog. Ser., 24:243-254.

Fenchel, T. 1982. Ecology of heterotrophic microflagellates. II. Bioenergetics and growth. Mar. Ecol. Prog. Ser., 8:225-231.

Fuhrman, J. A., and F. Azam. 1980. Bacterioplankton secondary production estimates for coastal waters of British Columbia, Antarctica, and California. Appl. Environ. Microbiol., 39:1085-1095.

Grassle, J. F. 1986. The ecology of deep-sea hydrothermal vent communities. In: Blaxter, J. H. S. and A. J. Southward (ed.), Advances in Marine Biology, Academic Press, New York. pp. pp. 302-362.

Gregg, M. C. 1987. Diapycnal mixing in the thermocline. J. Geophys. Res., 92(C5):52495286.

Griessmann, K. 1913. Über marine Flagellaten. Arch. Protistenkd., 32(1914):1-78.

Jannasch, H. W., and C. O. Wirsen. 1984. Variability of pressure adaptation in deep sea bacteria. Archiv. Microbiol., 139:281-288.

Patterson, D. J., and T. Fenchel. 1990. Massisteria marina Larsen \& Patterson 1990, a widespread and abundant bacterivorous protist associated with marine detritus. Mar. Ecol. Prog. Ser., 62:11-19.

Patterson, D. J., and J. Larsen (ed.). 1991. The biology of free-living heterotrophic flagellates, Clarendon Press, Oxford.

Patterson, D. J., K. Nygaard, G. Steinberg, and C. M. Turley. 1993. Heterotrophic flagellates and other protists associated with oceanic detritus throughout the water column in the mid North Atlantic. J. Mar. Biol. Assoc. U.K., 73:67-95.

Sherr, B. F., E. B. Sherr, and T. Berman. 1983. Grazing, growth, and ammonium excretion rates of a heterotrophic microflagellate fed four species of bacteria. Appl. Environ. Microbiol., 45:1196-1201. 
Silver, M. W., and A. L. Alldredge. 1981. Bathypelagic marine snow: deep-sea algal and detrital community. J. Mar. Res., 39:501-530.

Silver, M. W., M. M. Gowing, D. C. Brownlee, and J. O. Corliss. 1984. Ciliated protozoa associated with oceanic sinking detritus. Nature, 309:246-248.

Small, E. B., and M. E. Gross. 1985. Preliminary observations of protistan organisms, especially ciliates, from the $21^{\circ} \mathrm{N}$ hydrothermal vent site. Biol. Soc. Wash. Bull., 6:401410.

Snedecor, G. W., and W. G. Cochran. 1982. Statistical Methods, seventh ed., The Iowa State University Press, Ames, Iowa.

Trivett, D. A. 1991. Diffuse flow from hydrothermal vents. Ph. D. Woods Hole Oceanographic Institution/Massachusetts Institute of Technology, Cambridge, MA.

Turley, C. M., and M. Carstens. 1991. Pressure tolerance of oceanic flagellates: implications for remineralization of organic matter. Deep-Sea Res., 38(4):403-413.

Turley, C. M., A. J. Gooday, and J. C. Green. 1993. Maintenance of abyssal benthic foraminifera under high pressure and low temperature: some preliminary results. Deep-Sea Res., 40:643-652.

Turley, C. M., K. Lochte, and D. J. Patterson. 1988. A barophilic flagellate isolated from $4500 \mathrm{~m}$ in the mid-North Atlantic. Deep-Sea Res., 35(7):1079-1092.

Wirsen, C. O., and H. W. Jannasch. 1975. Activity of marine psychrophilic bacteria at elevated hydrostatic pressures and low temperatures. Mar. Biol., 31:201-208. 


\section{Chapter 6}

Tolerance of flagellated protozoa to extreme environmental conditions potentially encountered at deep-sea hydrothermal vents:

I. High sulfide; II. High concentrations of $\mathrm{Cu}, \mathrm{Fe}, \mathrm{Mn}$, and $\mathrm{Zn}$

Michael S. Atkins, Magda A. Hanna, Erine A. Kupetsky, Mak A. Saito,

Craig D. Taylor, and Carl O. Wirsen

Limnology and Oceanography, Submitted 


\begin{abstract}
The survival rates of three species of deep-sea hydrothermal vent flagellates were measured after exposure to chemical conditions potentially encountered in vent environments. The survival rates, measured as viability through time of Caecitellus parvulus, Cafeteria sp. and Rhynchomonas nasuta were determined and compared to shallow-water strains of the same species after exposure to increasing concentrations of sulfide or the metals $\mathrm{Cu}, \mathrm{Fe}, \mathrm{Mn}$ and $\mathrm{Zn}$. Responses were variable but in all cases these flagellates showed very high tolerance to extreme conditions. Cafeteria spp. were remarkable in that both strains showed $100 \%$ viability after a $24 \mathrm{~h}$ exposure to $30 \mathrm{mM}$ sulfide under anoxic conditions. By contrast, the highest naturally-occurring sulfide concentrations ever measured are only 18-20 mM. There was little effect from metals at concentrations up to $10^{-3} \mathrm{M}$ total metal, but a sharp decrease in viability occurred between $10^{-3} \mathrm{M}$ and $10^{-2} \mathrm{M}$ total metal, due either to a rapid increase in the availability of free metal ions or colloid formation or both. This study is consistent with other previously reported studies that indicate these flagellate species are present and capable of being active members of the microbial food webs at deepsea vents.
\end{abstract}

Key Words: Deep-sea hydrothermal vents $\bullet$ extreme environments $\bullet$ sulfide $\bullet$ metals $\bullet$ tolerance $\cdot$ flagellates 
Organisms living in extreme environments are exposed to physical and chemical conditions generally considered to be unfavorable for most other forms of life. An extreme environment may therefore be defined as one in which a restricted number of organisms can survive and grow; the majority are excluded due to unfavorable living conditions. Inhabitants of the most extreme environments found on Earth are predominantly prokaryotic organisms whose metabolic requirements often make them obligate members of specified habitats (Deming 1986; Jannasch et al. 1992; Stetter et al. 1993; Nelson and Fisher 1995; Godfroy et al. 1996; Delaney et al. 1998; Duffaud et al. 1998; Gonzalez et al. 1999; Paerl et al. 2000). However, bacterivorous protists also may be found in many of these extreme environments in close association with their bacterial prey (Small and Gross 1985; Patterson and Simpson 1996; Atkins et al. in press). Unlike prokaryotes, which may be specialized for their particular niche, bacterivorous protists found in extreme environments may be ubiquitous species with high tolerance or adaptability to extreme conditions (Atkins et al. in press). These organisms may be among the most tolerant or adaptable eukaryotes living on this planet, their ability to withstand or adapt to extreme environmental conditions enabling them to feed on an otherwise inaccessible food source.

Hydrothermal vents are comprised of some of the most extreme environments on Earth. Vent fluids are hotter, more acidic and enriched with metals and dissolved gasses than the surrounding seawater (see Table 6.1). Characterized by very steep physical and chemical gradients between vent fluids and seawater, vent fields may rival the abiotic environments characteristic of other planets. Still, life occurs at vents - and in abundance. The question remains as to how some organisms, particularly cosmopolitan species, are able to tolerate and survive under vent conditions. This is especially true for microorganisms like the flagellated protists that arrive in the deep sea in large numbers on sinking particulate matter (Silver and Alldredge 1981; Silver et al. 1984; Patterson and Fenchel 1990; Caron 1991; Patterson et al. 1993; Bak et al. 1995) and have been shown to be members of deep-sea 
(Burnett 1977; Turley et al. 1988) and deep-sea vent micro-environments (Atkins et al. 1998; Atkins et al. in press).

The present study determined the effects of both sulfide $\left(\mathrm{H}_{2} \mathrm{~S}, \mathrm{HS}^{-}\right.$and $\left.\mathrm{S}^{2-}\right)$ and metals, at concentrations approaching those found in end-member fluids emanating from deep-sea hydrothermal vents, on ubiquitous species of flagellates isolated from these environments. End-member vent fluid concentrations of transition metal species are enriched several orders of magnitude relative to average seawater (Seyfried and Mottl 1995), and sulfide concentrations may reach several millimolar (Table 6.1). Among protists, sulfide tolerance has been studied mostly in ciliates from natural environments with concentrations much lower than vent fluids (Bick and Kunze 1971; Matsuyama and Moon 1997). Other studies have measured the effect of metals at trace and somewhat higher concentrations on protistan taxa isolated from environments considered non-extreme (Prescott et al. 1977; Brand et al. 1986; Stoecker et al. 1986; Sunda 1989; Rijstenbil et al. 1994; Wong et al. 1995; Sunda and Huntsman 1996; Sunda and Huntsman 1998b).

To determine whether the ability to be active vent consumers exists, the survival rates of three species of deep-sea vent flagellates were measured after exposure to chemical conditions potentially encountered in vent environments. The flagellates used in this study were chosen on the basis of their ubiquity in very diverse and often extreme global environments, suggesting a high tolerance to a wide range of environmental conditions. The survival rates (measured as viability through time) of Caecitellus parvulus, Cafeteria sp. and Rhynchomonas nasuta were measured and compared to shallow-water strains of the same species after exposure to increasing concentrations of sulfide or the metals $\mathrm{Cu}, \mathrm{Fe}, \mathrm{Mn}$ and $\mathrm{Zn}$. 


\begin{tabular}{|c|c|c|c|c|c|c|c|c|}
\hline Vent & Site & Temperature $\left({ }^{\circ} \mathrm{C}\right)$ & $\mathbf{p H}$ & $\mathrm{H} 2 \mathrm{~S}(\mathrm{mM})$ & $\mathrm{Cu}(\mu \mathrm{M})$ & $\mathrm{Fe}(\mu \mathrm{M})$ & $\operatorname{Mn}(\mu \mathrm{M})$ & $\operatorname{Zn}(\mu \mathrm{M})$ \\
\hline & Average Deep-Sea Seawater & 2 & 7.8 & $\mathbf{0}$ & 0.007 & 0.001 & $\mathbf{0}$ & 0.01 \\
\hline \multirow[t]{3}{*}{\begin{tabular}{|l|} 
Juan De Fuca \\
\end{tabular}} & End-Member Fluids ${ }^{\mathrm{a}}$ & 224-285 & 3.2 & $2.9-8.1$ & 2 & 18,739 & 3,585 & 900 \\
\hline & Dante Flange Substrates (DFS) & & & & 2 & 5,887 & 70 & 558 \\
\hline & Lobo Flange Subtrates (LFS) & & & & 3 & 7,298 & 809 & 215 \\
\hline Guaymas & End-Member Fluids ${ }^{b}$ & 315 & 5.9 & $4.4-6.0$ & 1 & 180 & 236 & 40 \\
\hline \multirow[t]{3}{*}{ Basin } & sediment-water interface & & & & 2 & 3,511 & 447 & 65 \\
\hline & Beggiatoa mat (GBB) & & & & 32 & 5,765 & 2,038 & 514 \\
\hline & flange sample & & & & 10 & 8,825 & 5,626 & 521 \\
\hline \multirow[t]{3}{*}{$21^{\circ}$ N EPR } & End-Member Fluids ${ }^{\mathrm{c}}$ & 355 & 3.4 & 7.3 & 35 & $\mathbf{1 , 5 3 0}$ & 1,024 & $\mathbf{1 0 6}$ \\
\hline & Clam Acres Spire (CAS) & & & & 0 & 27 & 8 & 2 \\
\hline & Twin Peaks Chimney (TPC) & & & & 2 & 62 & 34 & 6 \\
\hline \multirow[t]{4}{*}{$9^{\circ} \mathrm{NEPR}$} & End-Member Fluids (eruption) ${ }^{\mathrm{d}}$ & $329(403)$ & $3 . \overline{5(2.5)}$ & $11.3(>65)$ & & 2,640 & 925 & $\overline{44}$ \\
\hline & Biovent Serpulid Zone (BSZ) & & & & 0 & 103 & 27 & 8 \\
\hline & Biovent Riftia and Mussels Bed (BRM) & & & & 5 & 227 & 44 & 12 \\
\hline & East Wall Mussels Bed (EWM) & & & & 2 & 30 & 21 & 2 \\
\hline
\end{tabular}

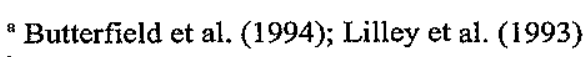

- $\quad{ }^{b}$ Campbell et al. (1988); Von Damm et al. (1985)

c Welhan and Craig (1983); Von Damm et al. (1985); Lilley et al. (1993)

¿Haymon et al. (1993); Von Damm et al. (1995); Von Damm (1990)

Table 6.1. Comparison among literature values for average deep-sea seawater and end-member fluids from deep-sea hydrothermal vents in the Eastern Pacific Ocean. Also compared are literature and experimental concentrations of total $\mathrm{Cu}, \mathrm{Fe}, \mathrm{Mn}$ and $\mathrm{Zn}$. Concentrations used in experiments were measured from frozen samples collected at the vent sites shown. Values shown in parenthesis for the $9^{\circ} \mathrm{N}$ EPR end-member fluids were taken during an eruption event. The organisms used in the present study all were obtained from the $9^{\circ} \mathrm{N}$ EPR hydrothermal vent. Caecitellus parvulus strain EWM1 was obtained from East Wall Mussels Bed; Cafeteria sp. strain VENT 1 was obtained from sulfidic $9^{\circ} \mathrm{N}$ vent water as described by Taylor et al. (1999) and Rhynchomonas nasuta strain BSZ1 was isolated from samples collected at the Biovent Serpulid Zone. 


\section{Materials and Methods}

Isolates. Hydrothermal vent and shallow-water flagellates were collected and isolated as described by Atkins et al. (1998; in press). Both strains of Cafeteria were isolated from hydrogen sulfide reactors used to culture sulfur-oxidizing bacteria from both vent and shallow-water samples (Taylor and Wirsen 1997; Taylor et al. 1999). Isolates were cultured in growth media [0.22 $\mu \mathrm{M}$ filtered, autoclaved Vineyard Sound Seawater (VSW) (made $10^{-3}$ $\mathrm{M}$ with Nitrilotriacetic Acid (NTA) in metals experiments), $0.01 \%$ yeast extract, Halomonas halodurens bacteria as prey], concentrated via centrifugation and inoculated into experimental vials at a density of $1 E 5$ cells/ml. Growth media supernatant was removed after concentrating isolates to prevent their growth during the experiments.

\section{Determining sulfide and metals concentration ranges used in experiments:}

The initial range of concentrations used in sulfide experiments was determined from literature values of end-member vent fluids shown in Table 6.1. The range of metal concentrations was determined from literature values and values obtained by atomic absorption spectrophotometry (AAS) of frozen, unfiltered vent samples from which flagellates were isolated (Table 6.1). Unfiltered samples were dried and prepared for AAS by complete digestion in hot $15 \%$ nitric acid. Acidified samples were analyzed on a Perkin Elmer AAnalyst 100 atomic absorption spectrophotometer, calibrated using standard solutions of known concentration for each metal.

Sulfide media: It should be noted that the term sulfide is generally used here to mean the three sulfide species present in these experiments: $\mathrm{H}_{2} \mathrm{~S}, \mathrm{HS}^{-}$and $\mathrm{S}^{2-}$. At the $\mathrm{pH}$ range used in these experiments, $\mathrm{HS}^{-}$is expected to be the dominant species. Toxicity mechanisms and effects among the three sulfide species are assumed to be similar. Sulfide media was prepared from anaerobic stock solutions of $\mathrm{Na}_{2} \mathrm{~S} \cdot 9 \mathrm{H}_{2} \mathrm{O}$ diluted to the experimental concentrations by addition to serum vials containing sterile, anoxic VSW. Sulfide 
concentrations in each vessel were measured at each timepoint using the spectrophotometric determination technique described by Cline (1969). Sulfide concentrations were relatively stable $( \pm 5 \%)$ throughout the experiments, indicating anoxic conditions were maintained. The $\mathrm{pH}$ was measured at each time point and ranged between 7 (lowest sulfide concentrations) and 9 (highest sulfide concentrations).

Metals media: Metal toxicity experiments were carried out in the presence of a synthetic metal ligand that buffers the free metal ion concentration (i.e. $\mathrm{Cu}^{2+}, \mathrm{Fe}^{3+}$, $\left.\mathrm{Mn}^{2+}, \mathrm{Zn}^{2+}\right)$ by binding the majority of the total dissolved metal and maintaining an equilibrium with the free metal ions. The high concentration of synthetic buffer in these types of experimental systems results in a free-ion concentration that is thought to be independent of any natural ligands present in the filtered seawater used to make the media (Brand et al. 1986). Nitrilotriacetic acid (NTA) was chosen as the synthetic metal ion ligand in expectation of a high degree of resistance to metal toxicity by these vent organisms. NTA has advantages over more commonly used metal buffers like EDTA, in that its binding constants for metals in seawater are significantly lower than that of EDTA. This allows higher free metal concentrations relative to the concentration of metal buffer (e.g., $\mathrm{Cu}^{2+} / \mathrm{NTA}>$ $\mathrm{Cu}^{2+} / \mathrm{CuEDTA}$ ). Control experiments were done to test sensitivity to NTA. These experiments showed that $10^{-3} \mathrm{M}$ NTA was the maximal concentration of NTA that could be used before the NTA itself became toxic (see Figure 6.1). Metal stock solutions were made from salts of $\mathrm{CuSO}_{4} \cdot 5 \mathrm{H}_{2} \mathrm{O}, \mathrm{FeCl}_{3} \cdot 6 \mathrm{H}_{2} \mathrm{O}, \mathrm{MnSO}_{4} \cdot \mathrm{H}_{2} \mathrm{O}$ and $\mathrm{ZnSO}_{4} \cdot 7 \mathrm{H}_{2} \mathrm{O}$ dissolved separately in Milli-Q water and acidified to $\mathrm{pH} 2$ to prevent precipitation of solids. These metal stock solutions were diluted to the experimental concentrations by addition to vials containing sterile, oxic VSW buffered with $10^{-3} \mathrm{MNTA}$ and were allowed to equilibrate for $24 \mathrm{~h}$ prior to inoculation with flagellates. The $\mathrm{pH}$ was measured at each time point and ranged between 5 and 7 for highest and lowest metal concentrations respectively. 
Experimental controls: Since these experiments measure flagellate survival as a function of exposure time, growth conditions for flagellates (i.e., bacterial prey) were not present in any of the experimental vials. Therefore, these experiments were performed under starvation conditions. Sulfide experiments were performed under the combined effect of starvation and anoxic conditions. Experimental controls were done to measure the effect of these conditions through time. Flagellates were prepared as above then inoculated into vials containing sterile VSW with no prey and no prey under anoxic conditions (Figure 6.1). These controls set the duration of both sulfide and metal experiments: $R$. nasuta was the most sensitive to anoxic/no prey conditions, with survival being affected after $24 \mathrm{~h}$; therefore, this was set as the duration of sulfide experiments. All organisms showed $100 \%$ viability up to $168 \mathrm{~h}(7 \mathrm{~d})$ without prey; therefore, this was set as the duration of the metals experiments. Additional controls were done to measure the effects of both pH and NTA buffer on survival to show that exposure to sulfide or metals, not $\mathrm{pH}$ or buffer, was responsible for the toxicity effect measured in actual experiments. For all species, there was $100 \%$ survival after $7 \mathrm{~d}$ exposures to $\mathrm{pH} \mathrm{5,7}$ and 9 (data not shown). Concentrations of NTA began to have deleterious effects at $10^{-2} \mathrm{M}$, whereas $10^{-3} \mathrm{M}$ NTA had $100 \%$ survival after $7 \mathrm{~d}$ (Figure 6.1). As a result, $10^{-3} \mathrm{M}$ NTA concentration was chosen for metal toxicity studies in order to maximize metal buffering at high concentrations of metal. These controls showed the efficacy of the experimental design.

Measuring survival using MPN dilutions: In both sulfide and metals experiments, samples were removed at discrete timepoints (sulfide: $1.0 \mathrm{~h}, 3.0 \mathrm{~h}, 6.0 \mathrm{~h}$, and $24.0 \mathrm{~h}$; metals: $24 \mathrm{~h}, 72 \mathrm{~h}$ and $168 \mathrm{~h}$, respectively), serially diluted from $1 \mathrm{E} 0$ to $1 \mathrm{E}-5 \mathrm{ml}$ (1/10 each subsequent dilution) and cultured in growth media up to 21 days. The cultures were then microscopically observed for positive or negative growth of flagellates. All experiments were done in triplicate and MPN tables were used to determine viable cell numbers from. positive and negative growth observations. 
Figure 6.1. Control experiments measuring survival under starvation and anaerobic conditions are in the left column and survival under NTA buffer concentrations are in the right column for the three vent strains shown. From these results, the duration of sulfide and metals experiments and the concentration of NTA used in metals media were chosen. 

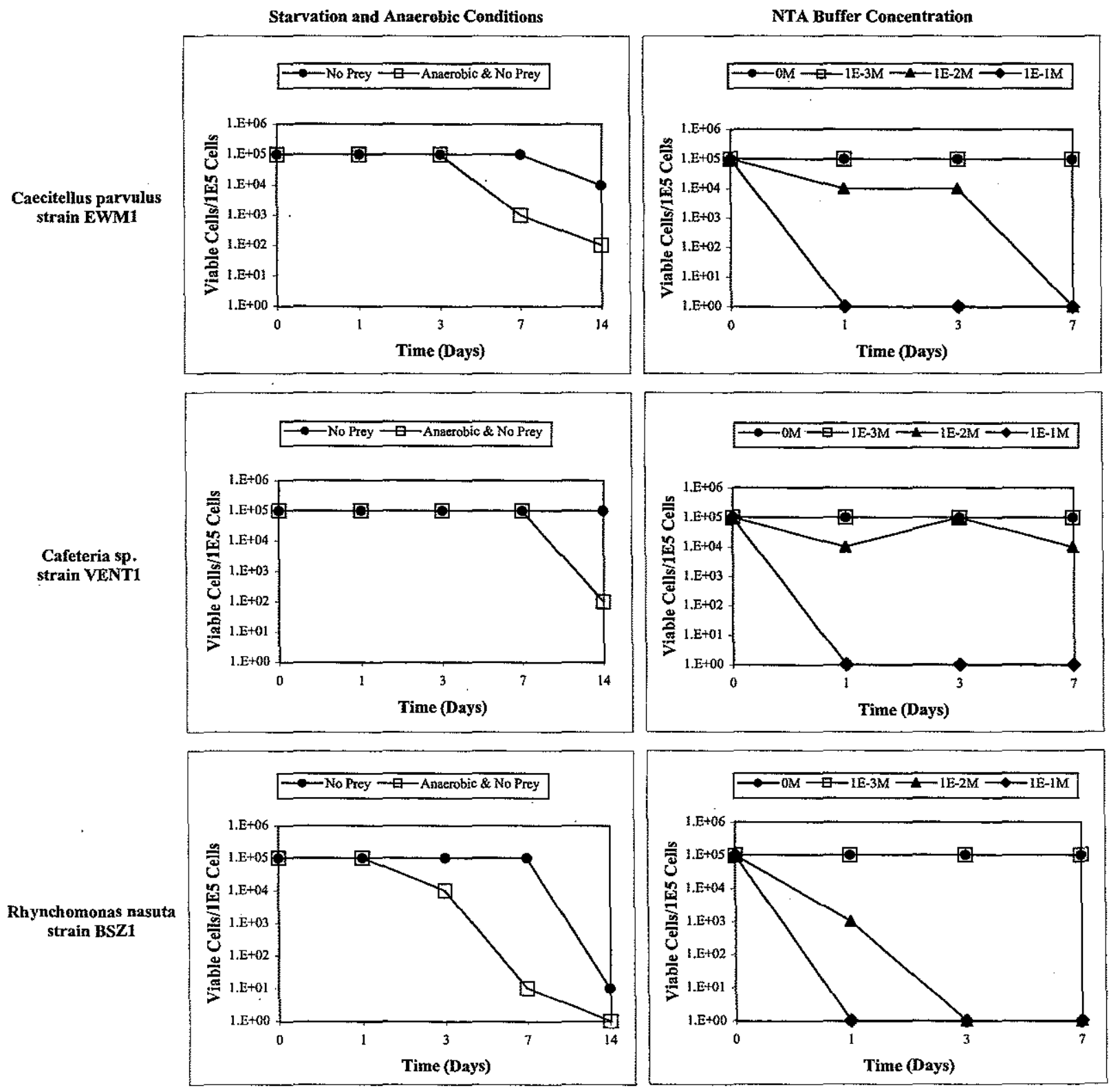


\section{Results}

Sulfide tolerance: Figure 6.2 shows the results of survival experiments conducted at variable concentrations of sulfide. There was no significant difference in survival between vent and shallow-water strains of the same species. However, there was high variability among different species, including the closely-related sister taxa Cafeteria and Caecitellus. Both strains of Cafeteria showed the greatest tolerance to high sulfide conditions, whereas Caecitellus strains showed the least tolerance of the three species tested. The dissolved sulfide concentrations used in this study are high relative to naturally-occurring concentrations; which have been recorded at a global maximum of 18-20 mM (Brown et al. 1994; Jonas and Tuttle 1996). Anomalously high dissolved sulfide concentrations ( $>65 \mathrm{mM}$ ) have been recorded during volcanic eruptions (Haymon et al. 1993; Von Damm et al. 1995), but these are ephemeral events, occurring only on very short time scales in superheated end-member fluids and therefore are not considered as part of a stable ecosystem, extreme or otherwise.

Cafeteria strains showed $100 \%$ viability at all concentrations up to $30 \mathrm{mM}$ throughout the course of the experiment $(24 \mathrm{~h})$. In this one case, the experiment was continued to test viability after one week (168 h). At 168 h, Cafeteria spp. showed $0.1 \%$ viability at 5 $\mathrm{mM}, 0.01 \%$ viability at $10 \mathrm{mM},>0.001 \%$ viability at $20 \mathrm{mM}$ and no survival at $30 \mathrm{mM}$. Both strains of $R$. nasuta showed the second highest tolerance to high sulfide conditions. There was no significant difference in viability between 0.1 and $5 \mathrm{mM}$ concentrations for either strain. Viability in this range was between $10 \%-100 \%$ over the $24 \mathrm{~h}$ period. However, $10 \mathrm{mM}$ sulfide resulted in $1.0 \%$ viability following a $6 \mathrm{~h}$ exposure and $0.01 \%$ viability after a $24 \mathrm{~h}$ exposure. Exposure to $20 \mathrm{mM}$ sulfide resulted in $0.01 \%$ viability after $6 \mathrm{~h}$ and $0 \%$ viability after $24 \mathrm{~h}$. Both strains of $C$. parvulus showed the lowest tolerance to high sulfide conditions of the three species tested. Viability generally was inversely proportional to sulfide concentration. Exposure to $2 \mathrm{mM}$ sulfide resulted in approximately $1 \%$ viability and exposure to $5 \mathrm{mM}$ resulted in no survival in either strain after $24 \mathrm{~h}$. 
Figure 6.2. Survival in sulfide toxicity experiments. Deep-sea vent strains are in the left column; shallow-water strains are in the right column. All sulfide concentrations shown in the figure legend were tested on each organism; overlaying of lines occurred at lower concentrations of sulfide for Caecitellus and Rhynchomonas up to $24 \mathrm{hr}$ and for all concentrations of sulfide up to $24 \mathrm{hr}$ for Cafeteria. 

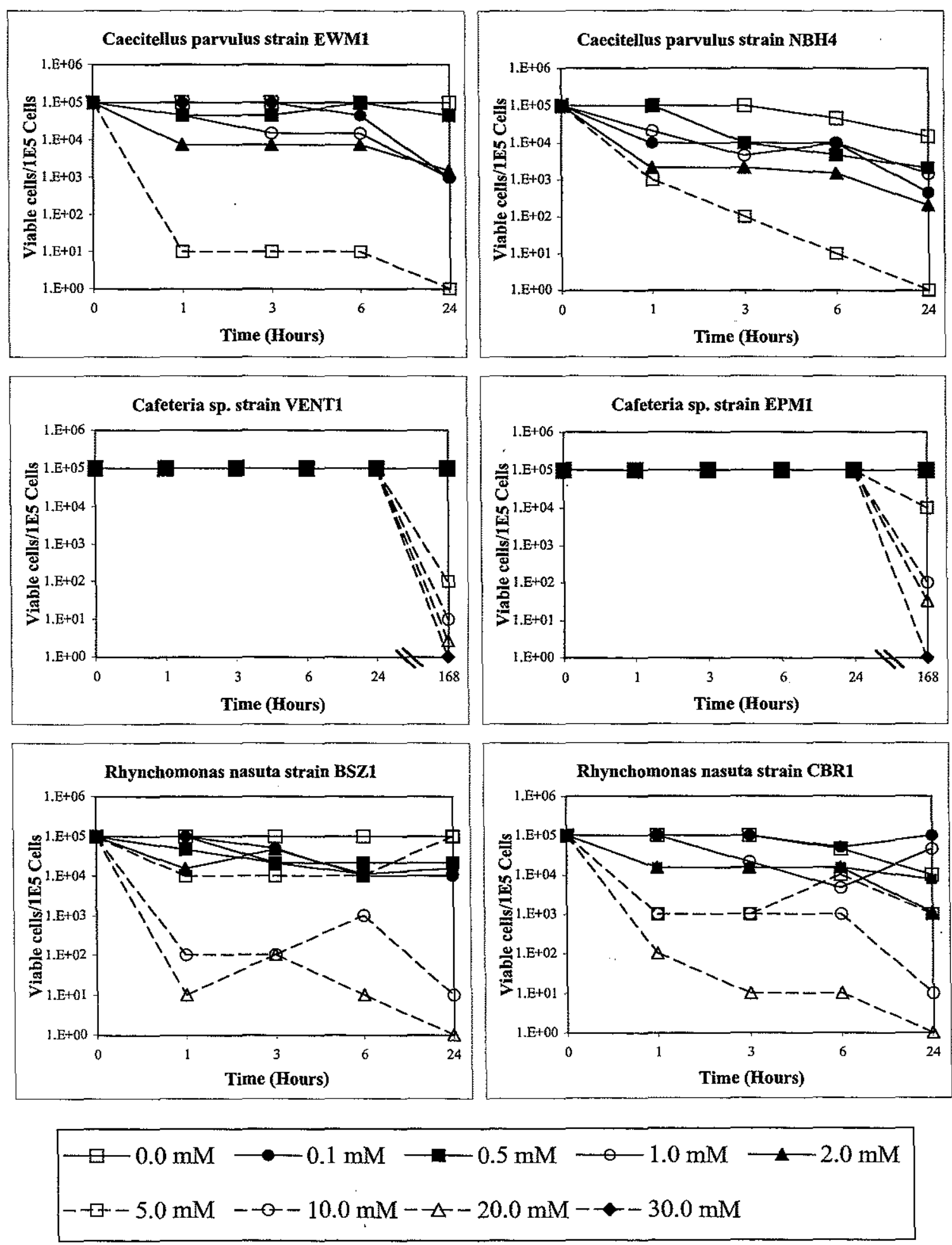
Comparison of literature and experimental metals concentrations: The important feature of Table 6.1 is to show that vent flagellates may encounter total metals (and sulfide) concentrations within the range tested in these experiments and that concentrations can reach or exceed those emitted in end-member fluids. Table 6.1 compares total metals concentrations from literature values in end-member fluids and AAS-measurements of vent samples from the exact microhabitats (shown as acronyms in parentheses) from which vent flagellates were isolated (see Atkins et al. in press). There is good agreement, within approximately an order of magnitude, between our measurements and literature values for $\mathrm{Cu}$ at all vents; for Fe at Juan de Fuca and for $\mathrm{Zn}$ at Juan de Fuca and Guaymas Basin. Endmember fluid and sediment-water interface metals concentrations are very similar for $\mathrm{Cu}$, $\mathrm{Mn}$ and $\mathrm{Zn}$ at Guaymas Basin. Generally, total metals concentrations were higher to much higher in sediments at Guaymas Basin than in end-member fluids or bottom water, suggesting accumulation and concentration of metal sulfide or other metal precipitates. Our measurements at $21^{\circ} \mathrm{N}$ were generally lower than literature values.

Tolerance to metal ions: Figure 6.3 shows the results of the metal toxicity survival experiments. In general, there was no difference in viability between strains or between species, with the possible exception of Caecitellus parvulus strain EWM1. The metals exhibited differing toxicities: ferric iron had the greatest effect on survival followed by copper and zinc; manganese produced little or no effect on survival (i.e., $\mathrm{Fe}>\mathrm{Cu}>\mathrm{Zn}>>\mathrm{Mn}$ ). Of iron, copper and zinc, only the $10^{-2}$ total metal concentration had an effect; lower concentrations were not significantly different and had little to no effect, in general. There seems to be a threshold response for these metals at $10^{-2}$ total metal concentration that is illustrated by a sharp decrease in species viability. 
Figure 6.3. Survival in metal toxicity experiments. Metals concentrations represent total metals as explained in the text. All metals concentrations shown in the figure legend were tested on each organism; overlaying of lines occurred at lower concentrations of all metals. Data for $R$. nasuta strain BSZ1 (vent strain) not shown due to contamination by other protist species during the experiments. 


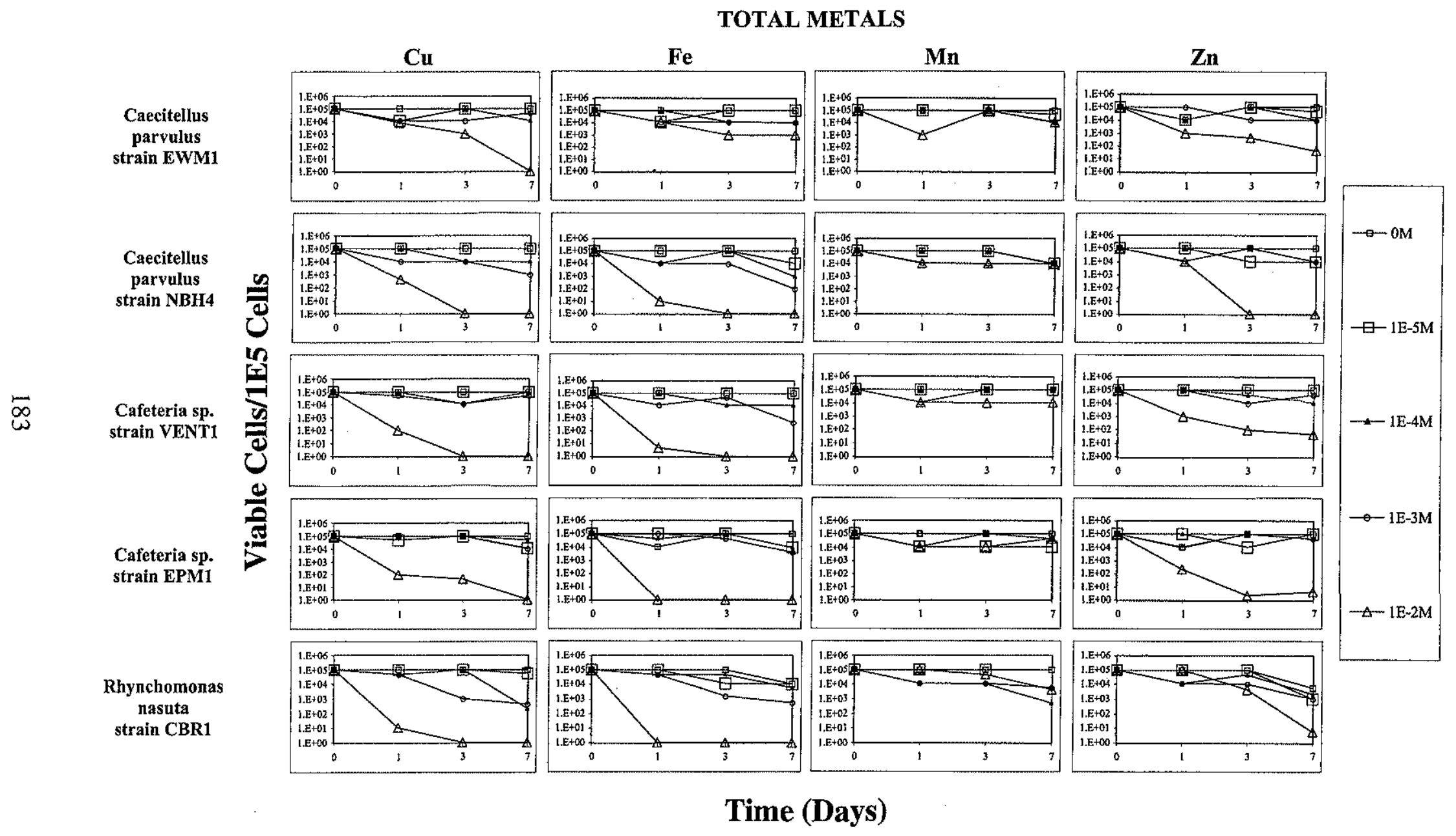


Caecitellus parvulus strain EWM1 had an increased tolerance to ferric iron relative to all other strains. After a $24 \mathrm{~h}$ exposure to $10^{-2}$ total Fe, other strains had ca. $0 \%$ viability; cultures of EWM1, on the other hand, showed $10 \%$ viability after $24 \mathrm{~h}$ and $1 \%$ viability to the end of the experiment. Compared with the results of the shallow-water strain NBH4 and the other flagellates, these results appear anomalous rather than exceptional. However, there still was a threshold response at $10^{-2}$ total metals concentrations for this strain.

Unlike in the sulfide experiment, strains of Cafeteria sp. did not show higher tolerance to metal exposure than the other species. This strengthens the hypothesis that Cafeteria $\mathrm{sp}$. are especially adapted to or tolerant of sulfidic conditions and indicates that metals act on flagellates via a generalized mechanism shared at least among a wide variety of flagellate taxa.

Experimental cultures of Rhynchomonas nasuta strain BSZ1 were contaminated by other protozoan species midway through the metals experiments, and so the data were not used. Preliminary results prior to the contamination event suggested that there was no difference in the responses to metals between vent and shallow-water strains of this species.

Calculated metal speciation under experimental conditions: Metal toxicity and bioavailability have been shown to correlate with the concentration of free metal ions rather than with the concentration of total metals in solution (Sunda 1989). Concentrations of free copper, iron, manganese, and zinc were calculated with respect to NTA buffering and solid precipitation in this experimental system and were plotted against total metal concentration (Figure 6.4). The results show that free ion concentrations are linear with total metal concentration until the NTA is close to being fully titrated with metal, at which point the slope increases as added metal is no longer bound by NTA. Lower pH generally results in higher free metal ion concentration relative to higher $\mathrm{pH}$ (Figure 6.4). Copper, iron, and zinc begin to precipitate as the free ion concentration exceeds the solubility product for the solid forms of metals included in our calculations (ferrihydrite, $\mathrm{Cu}(\mathrm{OH})_{2(\mathrm{~s})}, \mathrm{ZnCO}_{3} 1 \mathrm{H}_{2} \mathrm{O}_{(\mathrm{s})}$, and 
Figure 6.4. Calculations of metal speciation were made using MINEQL+ (Westall et al. 1976) with parameters adjusted for our culture conditions. Typical seawater concentrations of $\mathrm{Na}^{+}, \mathrm{Cl}^{-}, \mathrm{Mg}^{2+}, \mathrm{Ca}^{2+}$, and dissolved inorganic carbon were used in calculations to achieve correct ionic strength and free NTA concentrations. Solubility of the metals were determined relative to ferrihydrite, $\mathrm{Cu}(\mathrm{OH})_{2(s)}, \mathrm{ZnCO}_{3} \cdot 1 \mathrm{H}_{2} \mathrm{O}_{(\mathrm{s})}$, and $\mathrm{MnCl}_{2} \cdot 4 \mathrm{H}_{2} \mathrm{O}_{(\mathrm{s})}$ solids. Highly crystalline solids were ignored due to their inability to form at the low temperatures and short time scales of this experiment. $\mathrm{Fe}^{\prime}$ concentrations are plotted where $\mathrm{Fe}^{\prime}$ is the summation of the dominant inorganic iron species $\left(\mathrm{Fe}^{\prime}=\mathrm{Fe}^{3+}+\mathrm{FeOH}^{2+}+\mathrm{Fe}(\mathrm{OH})_{2}^{+}+\right.$ $\left.\mathrm{Fe}(\mathrm{OH})_{3(\mathrm{aq})}+\mathrm{Fe}(\mathrm{OH})_{4}^{-}\right) . \mathrm{Fe}^{\prime}$ is several orders of magnitude higher than the free $\mathrm{Fe}^{3+}$ ion alone. The stability constants and solubility products used by the computer program were verified against the Smith and Martell (1993) database. Total metal concentrations were calculated from dilutions of acidified stock solutions; background concentrations of metals in Vineyard Sound Water (VSW) were insignificant relative to the higher concentrations of metals added in the experiments. Circles indicate $\mathrm{pH}$ and free metal concentration at experimental (total) metal concentration. 

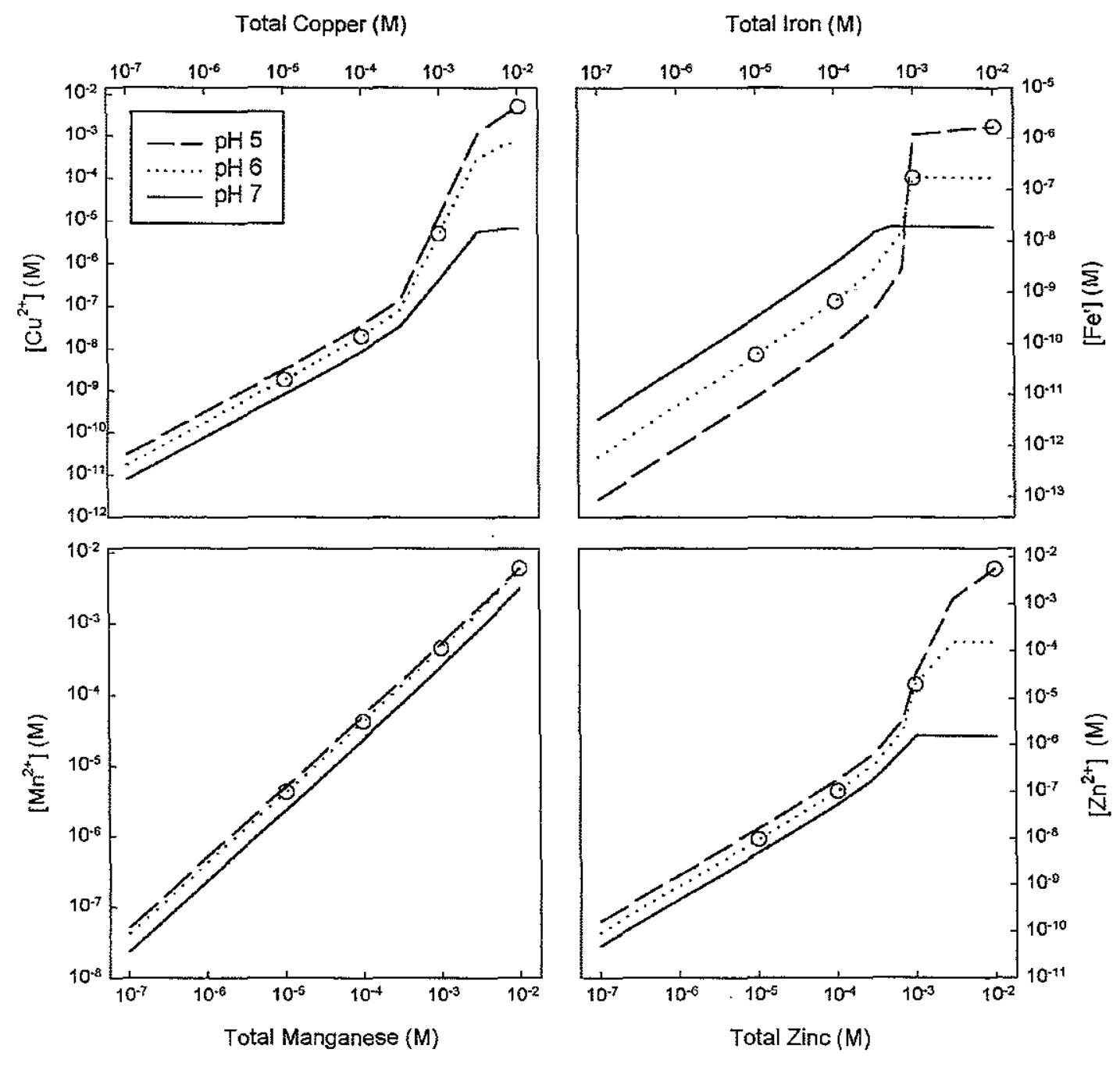
Pyrocroite and $\mathrm{MnCl}_{2} 4 \mathrm{H}_{2} \mathrm{O}_{(\mathrm{s})}$ ). While the thermodynamic constants for solubility suggest a metal will precipitate, this process either may not occur or may not go to completion due to slow kinetics of solid formation. Of these four metals, only manganese has a redox chemistry that could result in deviations from our calculated free ion activity. Manganese ( $\mathrm{Mn}$ ) exists in seawater primarily in the $\mathrm{Mn}(\mathrm{II})$ oxidation state as $\mathrm{Mn}^{2+}$. While thermodynamic predictions dictate that $\mathrm{Mn}$ should be oxidized to insoluble $\mathrm{Mn}(\mathrm{IV})$ oxides under typical oxic oceanic conditions, this reaction is kinetically slow on our experimental time scale. The oxidation of Mn(II) by microbial processes (Emerson and al 1982; Moffett and Ho 1996) and the reduction of manganese oxide solids $\left(\mathrm{Mn}(\mathrm{IV}) \mathrm{O}_{2(\mathrm{~s})}\right)$ by light and dissolved organic carbon (Sunda et al. 1983; Sunda and Huntsman 1988) have been shown to be important mechanisms influencing the chemistry of $\mathrm{Mn}$ in the surface ocean. However, other workers have observed little toxic effect of manganese on more sensitive marine organisms (Sunda and Huntsman 1998a), hence any inadvertent loss of $\mathrm{Mn}^{2+}$ by oxidation and subsequent precipitation may not change our results significantly. Under our oxic experimental condi-

tions, we would expect iron to remain primarily in its oxidized form as Fe(III). Anderson and Morel (1982) showed that Fe(III) uptake is controlled by the free-ion model in EDTA buffered media, with slight deviations possible when those cultures are exposed to light.

\section{Discussion}

The organisms used in this study were chosen because it was hypothesized that globallydistributed species, especially those occurring in both extreme and non-extreme environments, must be highly-tolerant or adaptable to a wide range of environmental conditions (Atkins et al. in press). The distribution of Caecitellus, Cafeteria and Rhynchomonas species is global (Fenchel and Patterson 1988; Patterson et al. 1993; Patterson and Simpson 1996; Ekelund and Patterson 1997), and they appear to be among a small group of the most 
commonly-occurring heterotrophic flagellates on Earth (Lee and Patterson 1998). Given this, they seemed the most promising eukaryotic organisms for studies of tolerance to very extreme environmental conditions. As deep-sea hydrothermal vents are among the most extreme environments found on Earth, we chose to examine two parameters of importance at vents to test extreme tolerance in our flagellates: exposure to sulfide and metals.

This study of extreme tolerance in eukaryotic organisms was conducted under simplified conditions that differ from conditions found at deep-sea vents. Variables were separated to make them experimentally more tractable. Vents are much more complex systems than laboratory experiments can simulate and the interactive effects of vent temperature, $\mathrm{pH}$, pressure and their complex chemistries cannot fully be explored in the more limited environment of the laboratory. Microniches inhabited by bacteria and nanoflagellates further complicate matters because physical and chemical parameters are not easily measured and replicated at this scale. These experiments began with the simplest question: how tolerant are these cosmopolitan species to individual parameters of the extreme chemistry they may encounter at deep-sea vents? The results suggest that these flagellates may be among the most tolerant eukaryotes studied (see Figure 6.5). Future studies can build on this baseline study by increasing in complexity to look at the interactive effects of multiple physical and chemical parameters.

Sulfide experiments: The results from sulfide experiments truly are remarkable from both ecological and evolutionary perspectives. That Cafeteria species showed no negative response to $30 \mathrm{mM}$ sulfide after $24 \mathrm{~h}$ and limited survival after one week at $20 \mathrm{mM}$ indicates that there is no sulfidic environment on Earth (except perhaps volcanic eruptions) where this organism cannot penetrate and survive for brief periods. Cafeteria spp. potentially could extend their range beyond the surficial vent field into the shallow subsurface biosphere below vents via a mechanism similar to that observed in groundwater protists (Novarino et al. 1999). It also is reasonable to assume that Cafeteria is capable of feeding 
on sulfur-oxidizing bacteria present at interfaces between $\mathrm{H}_{2} \mathrm{~S}$ and $\mathrm{O}_{2}$ (Taylor and Wirsen 1997), by swimming into the $\mathrm{H}_{2} \mathrm{~S}$ layer metabolized by their prey. This phenomenon was observed in hydrogen sulfide reactors prepared for chemoautotrophic sulfur-oxidizers (Taylor and Wirsen, pers. comm.).

Evolutionarily, Cafeteria may represent a seperate lineage among bicosoecids and their sister-taxa, which includes Caecitellus (Atkins et al. in press). Unlike Cafeteria, Caecitellus was unable to tolerate sulfide at concentrations up to $5 \mathrm{mM}$. This result suggests that high sulfide tolerance is not universal among members of this taxon, but rather a trait unique to a specialized few. Further study within this group is required to test this hypothesis. The results from Rhynchomonas bolster the conclusion that sulfide tolerance is variable, and perhaps even specialized, among the diversity of flagellates. Rhynchomonas showed relatively high tolerance to sulfide, yet it is a member of the Euglenozoa at the base of the eukaryotic $18 \mathrm{~S}$ tree, quite distant in its relationship to either Cafeteria or Caecitellus (Atkins et al. in press).

There was little or no difference in tolerance between vent and shallow-water strains of each species exposed to identical sulfide conditions. These results strengthen the conclusions of Atkins et. al. (in press), who suggested that microorganisms such as these are not affected by normal barriers contributing to speciation (e.g., large-scale geographical barriers such as continents or large oceanic distances). The results presented here illustrate that there is no significant evolutionary difference between the strains with respect to sulfide tolerance and results presented by Atkins et al. (in press) show there is no difference between $18 \mathrm{~S}$ rDNA sequences for vent and shallow strains of the same species isolated from distant geographical locations.

Metals experiments: Simulating the extreme environments of hydrothermal vent sites poses many unique challenges to the design of a metal toxicity study. Extremely high metal concentrations, and expansive proton $(\mathrm{pH})$ and redox $(\mathrm{Eh})$ concentration gradients 
within very small geographic regions are characteristic of vent environments. In order to tease out the toxic effects of individual metals on organism survival we used experimental systems with oxic seawater and no sulfide. This absence of sulfide in our experimental setup is an important simplification that allows for a tractable experimental design and straightforward calculations of free metal ion concentrations. The presence of sulfide would change the metal speciation and solubility through the formation of dissolved metal sulfide species and sulfide precipitates. Given that these organisms should be responding to the free metal ion toxicity rather than the total metal concentrations or metal sulfide chemical species, these toxicity results can be related to those of a system including sulfide if metal speciation data and/or sulfide concentrations from that environment are available for free metal ion calculations.

Metal toxicity studies at these high concentrations also pose unique challenges to the metal-ion buffered media used in the experimental system. We chose NTA as a buffer because it is weak enough to allow a relatively high free metal ion concentration relative to the concentration of total metal. Control studies determined that the maximum concentration of NTA we could use without the NTA itself becoming toxic was $10^{-3} \mathrm{M}$. We included a total metal concentration in excess of the NTA for the highest metal treatment in expectation of a high degree of metal tolerance. The changes in metal speciation were calculated, including the precipitation of metals at higher total concentrations once the NTA was titrated out. Free metal concentrations also increase once NTA has been completely titrated by a metal, and it is these higher free metal concentrations resulting in precipitation of solids which were observed experimentally in the $\mathrm{Cu}$ and $\mathrm{Fe}$ systems. 
Figure 6.5. Copper toxicity data for a variety of marine organisms is plotted. The planktonic ciliates Favella sp. and Balanion sp. were shown to be highly susceptible to copper as measured by reduction of growth rate (Stoecker et al. 1986). Data for the diatoms Thalassiosira oceanica and Rhizosolenia stolterfothii, the coccolithophore Umbilicosphaea hulburtiania, the dinoflagellate Thoracosphaera, and the oxygenic, photoautotrophic bacteria Synechococcus strain WH7803, were complied from Brand et al. (1986). The Prochlorococcus marinus data is from Mann et al. (2000). Our data for 50\% decreases in survival for the flagellated protists Caecitellus parvulus, Cafeteria spp. and Rhynchomonas nasuta include both vent and surface strains, with free cupric ion concentrations calculated with respect to NTA concentration, $\mathrm{pH}$, and copper solubility. It is important to note that data on species marked with an asterisk were taken from studies that measured toxicity by decreases in growth rate, while our study measured toxicity by decreases in survival in the absence of growth. 
Toxicity Threshold of Free Copper (M)

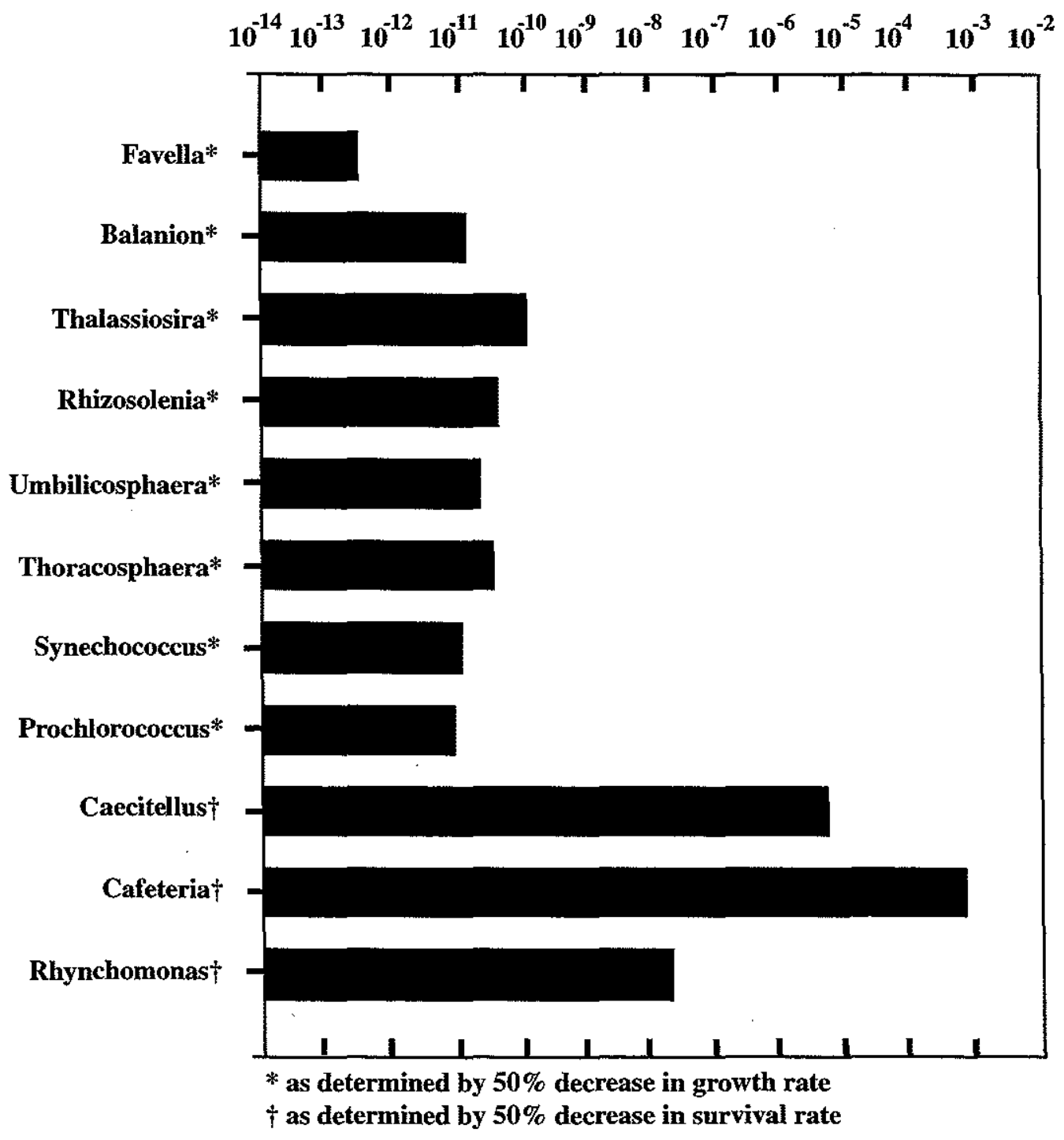


The results presented here are compared with copper toxicity results with other organisms (Figure 6.5). Copper is generally considered one of the most toxic metals in marine environments: toxicity has been observed at picomolar to nanomolar concentrations of free copper. The other studies shown in Figure 6.5 measured toxicity by decreases in growth rate, while our study measured survival after exposure to metal concentrations in the absence of growth. While both types of studies are ultimately measuring mortality caused by metal toxicity, readers should note the differences in methodology. The oxygenic photosynthetic cyanobacteria are generally thought to be among the most copper sensitive organisms with 50\% decreases in growth rate occurring at free cupric ion concentrations between $10^{-12}$ and $10^{-10} \mathrm{M}$ for Synechococcus sp. strain WH7803 (Brand et al. 1986) and several Prochlorococcus marinus strains (Mann et al. 2000). The eukaryotic phytoplankton Thalassiosira oceanica, Rhizosolenia stolterfothii, Umbilicosphaea hulburtiania, and Thoracosphaera heimii show more resistance to free cupric ions with 50\% decreases in growth rate occurring at $10^{-9.88}, 10^{-10.31}, 10^{-10.62}$, and $10^{-10.40} \mathrm{M}$, respectively (Brand et al. 1986). A study of copper toxicity to ciliates in similar growth media conditions showed that Favella sp. and Balanion were more sensitive than the eukaryotic phytoplankton in Brand et al's (1986) study, with $50 \%$ inhibition of growth rate at $10^{-12.5} \mathrm{M}$ and $10^{-10.9} \mathrm{M}$ free cupric ion concentrations (Stoecker et al. 1986). These ciliates were observed to be significantly less sensitive to copper in the presence of higher zinc concentrations, with $50 \%$ inhibition of growth rate occurring at one and two orders of magnitude higher copper concentrations for Favella and Balanion respectively, when zinc ion activities were increased by two to three orders of magnitude. Nevertheless, these deleterious effects of copper on photosynthetic cyanobacteria, eukaryotic phytoplankton, and planktonic ciliates occur at copper concentrations that are three orders of magnitude lower than where Caecitellus, Cafeteria, and Rhynchomonas showed 50\% survival after exposure to copper. This large difference between these cosmopolitan flagellates and the organisms from other studies would not change ap- 
preciably if the data were presented as $0 \%$ survival in the flagellate studies and $100 \%$ inhibition of growth (also described as death by Brand et al, 1986) in the other studies. One possible explanation for the large difference between organisms shown in Figure 6.5 is that the flagellates used in this study are benthic or surface associated organisms whose exposure to high concentrations of particulate (and dissolved) metals may be higher than the other organisms which may be considered more pelagic in nature.

Future work could incorporate sulfide chemistry into the metal toxicity studies. While hydrogen sulfide is rapidly oxidized seawater, it is thought that it may be stabilized by complexation to metal ions (as cited in Rozan et al. 1999). Metal sulfide complexes were shown to have environmentally relevant half-lives in river waters, with $\mathrm{Zn}$ and $\mathrm{Cu}$ sulfide having $16.7 \mathrm{~d}$ and $21.9 \mathrm{~d}$ half lives respectively (Rozan et al. 1999). Extrapolation of our toxicity results to the temperature, pressure, and chemical conditions of hydrothermal vent communities is difficult without metal speciation data. To our knowledge, no studies of electrochemical speciation have been conducted in these extreme environments. However, we can speculate that given the high concentrations of sulfide at vent communities and its relatively slow degradation half-life, metal bioavailability is likely to be significantly less than the total dissolved metal concentrations.

In both cases, sulfide and metals damage organisms on a subcellular level. For unicellular organisms, the result is death of individuals and decreased viability or survival for the population. The mechanism of sulfide toxicity is disruption of the electron transport chain in mitochondria, resulting in intracellular hypoxia. Detoxification of sulfide in eukaryotes is accomplished by sulfide-binding proteins or enzymatic and non-enzymatic oxidation of sulfide compounds to nontoxic or less toxic compounds, such as thiosulfate $\left(\mathrm{S}_{2} \mathrm{O}_{3}{ }^{2-}\right)$ (Grieshaber and Völkel 1998). Metal ions, such as copper and iron, are thought to catalyze the conversion of hydrogen peroxide $\left(\mathrm{H}_{2} \mathrm{O}_{2}\right)$ to a hydroxyl radical $\left(\mathrm{OH}{ }^{*}\right)$, a powerful oxidant with the ability to damage cellular components (Fridovich 1978; Fridovich 
1983). Alternatively, heavy metals such as $\mathrm{Cd}, \mathrm{Cu}, \mathrm{Pb}$ and $\mathrm{Zn}$ replace functional metals inside cells by inappropriate binding to nitrogen, oxygen and sulfur ligands in biomolecules, thereby inactivating enzymes and disrupting cellular function (Gadd and Griffiths 1978; Karlström and Levine 1991). It has been demonstrated in yeasts that there is vacuolar involvement in detoxification of $\mathrm{Co}, \mathrm{Mn}, \mathrm{Ni}$, and $\mathrm{Zn}$ (Ramsay and Gadd 1997), whereas detoxification of $\mathrm{Cu}$ and $\mathrm{Cd}$ appears to be cytosolic, with metal-binding proteins and even sulfide playing a large role (e.g., metallothionein for $\mathrm{Cu}$ and phytochelatins for $\mathrm{Cd}$ ) (Mehra and Winge 1991; Gadd 1993; Wu et al. 1995).

An intriguing question is raised by the results in Figure 6.3: Are we observing metal toxicity due to colloidal or particulate metal formation? The data in Figures 6.3 and 6.4 suggest this possibility since copper, iron, and zinc precipitation is predicted to occur in the treatments where significant toxicity is observed. At total metal concentrations between $10^{-3}$ $\mathrm{M}$ and $10^{-2} \mathrm{M}$ where a threshold response is observed in flagellate populations, there is a rapid increase in free-metal ions due to an excess of metal over NTA concentration and the formation of metal precipitates (data points in Figure 6.4). At this threshold, all flagellate populations have a survival rate effectively of zero. While toxicity due to exposure to high concentrations of free metal ions has been well documented (Gledhill et al. 1997), it is possible that exposure to particulate and colloidal metals could also result in a toxic response. Barbeau showed that Cafeteria and other species of protists can ingest colloidal iron at a fairly fast and efficient rate, and that colloidal iron is remineralized during passage through the cells (Barbeau et al. 1996; Barbeau 1998). Toxicity may occur due to internal poisoning via nonselective ingestion of metal colloids and other particles during feeding. This ingestion and remineralization of colloids could potentially deliver a much larger dose of toxicants to the cytosol relative to diffusion and transported uptake of dissolved metals from outside the cell. In this way, metal colloid ingestion could be faster and more lethal than cell surface uptake alone. Further study is necessary to explore this mechanism of toxicity. 
A final point of inquiry remains, namely what of remediation from toxicity under conditions at deep-sea vents. Holmes et al. (1997) have shown that production of sulfide and other sulfide compounds by microorganisms may actually increase resistance to metal toxicity through the formation of intracellular metal-sulfide precipitates eliminated as waste. High external concentrations of sulfide may also reduce metal toxicity through removal of toxic metals via metal-sulfide precipitation from the surrounding environment (White and Gadd 1998), before flagellates encounter them, although metal sulfide oxidation could replace at least some of this loss through dissolution (Eberhard et al. 1995). While the precise chemistry of vent microniches remains somewhat elusive, these findings suggest that some vent-specific conditions could ameliorate toxicity of at least metals if not other compounds. Future work should examine interactive effects between sulfide and metals, as well as including physical parameters unique to vent environments.

The results of these experiments indicate that Caecitellus parvulus, Cafeteria sp. and Rhynchomonas nasuta have the ability to survive very high concentrations of sulfide and the metals $\mathrm{Cu}, \mathrm{Fe}, \mathrm{Mn}$ and $\mathrm{Zn}$ potentially encountered in deep-sea hydrothermal vent environments. The evidence presented here coupled with (1) evidence of their presence at vents through isolation and culturing of flagellates from vent samples (Atkins et al. in press), (2) evidence of their presence at vents through molecular analysis of uncultured vent samples (Atkins unpub. data), and (3) their ability to be metabolically active under deep-sea pressures (Atkins et al. 1998), shows that these flagellate species are able to tolerate extreme vent conditions and have the potential to be active members of the microbial food webs at deep-sea vents. 


\section{Acknowledgments}

We would like to thank Dr. Harold Hemond for his suggestions regarding the experimental design and his help using the atomic absorption spectrophotometer and Dr. James Moffett for his advice in the design of the metals experiments. This work was supported by a National Science Foundation grant number IBN96-30054 to CDT and COW. Sampling at the $9{ }^{\circ} \mathrm{N}$ EPR vents was made possible by NSF grant OCE-9019575 to Dr. Lauren S. Mullineaux. This is Woods Hole Oceanographic Institution contribution number 0000. 


\section{References}

Anderson, M. A. and F. M. M. Morel. 1982. The influence of aqueous iron chemistry on the uptake of iron by the coastal diatom Thalassiosira weissflogii. Limnol. Oceanogr. 27(5):789-813.

Atkins, M. S., O. R. Anderson and C. O. Wirsen. 1998. Effect of hydrostatic pressure on the growth rates and encystment of flagellated protozoa isolated from a deep-sea hydrothermal vent and a deep shelf region. Mar. Ecol. Prog. Ser. 171:85-95.

Atkins, M. S., A. P. Teske and O. R. Anderson. 2000. A Survey of Flagellate Diversity at Four Deep-Sea Hydrothermal Vents in the Eastern Pacific Ocean Using Structural and Molecular Approaches. J. Euk. Microbiol., 47(4): In Press.

Bak, R. P. M., F. C. van Duyl and G. Nieuwland. 1995. Organic sedimentation and macrofauna as forcing factors in marine benthic nanoflagellate communities. Microb. Ecol. 29(2):173-182.

Barbeau, K. 1998. Influence of Protozoan Grazing on the Marine Geochemistry of Particle Reactive Trace Metals. PhD, Massachusetts Institute of Technology/Woods Hole Oceanographic Institution, Woods Hole, MA.

Barbeau, K., J. W. Moffett, D. A. Caron, P. L. Croot and D. L. Erdner. 1996. Role of protozoan grazing in relieving iron limitation of phytoplankton. Nature. 380:61-64.

Bick, H. and S. Kunze. 1971. A review of autecological and saprobiological data on freshwater ciliates. Int. Rev. Gesamt. Hydrobiol. 56(3):337-384.

Brand, L. E., W. G. Sunda and R. R. L. Guillard. 1986. Reduction of marine phytoplankton reproduction rates by copper and cadmium. J. Exp. Mar. Biol. Ecol. 96:225-250.

Brown, L., J. F. Downhower and R. B. Jonas. 1994. Ecological Research Activities: Andros Island Studies 1993-1994.

Burnett, B. R. 1977. Quantitative sampling of microbiota of the deep-sea benthos - I. Sampling techniques and some data from the abyssal central North Pacific. Deep-Sea Res. 24:781-789.

Butterfield, D. A., R. E. McDuff, M. J. Mottl, M. D. Lilley, J. E. Lupton and G. J. Massoth. 1994. Gradients in the composition of hydrothermal fluids from the Endeavor Segment Vent Field: Phase separation and brine loss. J. Geophys. Res. 99:9561.

Campbell, A. C., T. S. Bowers, C. I. Measures, K. K. Falkner, M. Khadem and J. M. Edmond. 1988. A time-series of vent fluid compositions from $21^{\circ} \mathrm{N}$, East Pacific Rise 
$(1979,1981,1985)$ and the Guaymas Basin, Gulf of California $(1982,1985)$. J. Geophys. Res. 93:4537-4549.

Caron, D. A. 1991. Heterotrophic flagellates associated with sedimenting detritus, pp. 7792. In D. J. Patterson and J. Larsen [ed.], The Biology of Free-Living Heterotrophic Flagellates. Clarendon Press.

Cline, J. D. 1969. Spectrophotometric determination of hydrogen sulfide in natural waters. Limnol. Oceanogr. 14:454-458.

Delaney, J. R., D. S. Kelley, M. D. Lilley, D. A. Butterfield, J. A. Baross, W. S. D. Wilcock, R. W. Embley and M. Summit. 1998. The Quantum Event of Oceanic Crustal Accretion: Impacts of Diking at Mid-Ocean Ridges. Science. 281(5374):222-30.

Deming, J. W. 1986. Ecological strategies of barophilic bacteria in the deep ocean. Microbiol. Sci. 3(7):205-11.

Duffaud, G. D., O. B. d'Hennezel, A. S. Peek, A. L. Reysenbach and R. M. Kelly. 1998. Isolation and characterization of Thermococcus barossii, sp. nov., a hyperthermophilic archaeon isolated from a hydrothermal vent flange formation. Syst Appl Microbiol. 21(1):40-9.

Eberhard, C., C. O. Wirsen and H. W. Jannasch. 1995. Oxidation of polymetal sulfides by chemolithoautotrophic bacteria from deep-sea hydrothermal vents. Geomicrobiol. J. 13:145-164.

Ekelund, F. and D. J. Patterson. 1997. Some heterotrophic flagellates from a cultivated garden soil in Australia. Arch. Protistenkd. 148:461-478.

Emerson, S. and e. al. 1982. Environmental oxidation rate of manganese(II): bacterial catalysis. Geochim. Cosmochim. Acta. 46:1073-1079.

Fenchel, T. and D. J. Patterson. 1988. Cafeteria roenbergensis nov. gen., nov. sp., a heterotrophic microflagellate from marine plankton. Mar. Microb. Food Webs. 3:9-19.

Fridovich, I. 1978. The biology of oxygen radicals. Science. 201:875-879.

Fridovich, I. 1983. Superoxide radical: an endogenous toxicant. Ann. Rev. Pharmacol. Toxicol. 23:239-257.

Gadd, G. M. 1993. Interactions of fungi with toxic metals. New Phytol. 124:25-60.

Gadd, G. M. and A. J. Griffiths. 1978. Microorganisms and heavy metal toxicity. Microbiol. Ecol. 4:303-317.

Gledhill, M., M. Nimmo, S. J. Hill and M. T. Brown. 1997. The toxicity of copper(II) species to marine algae with particular reference to macroalgae. J. Phycol. 33:2-11. 
Godfroy, A., J. R. Meunier, J. Guezennec, F. Lesongeur, G. Raguenes, A. Rimbault and G. Barbier. 1996. Thermococcus fumicolans sp. nov., a new hyperthermophilic archaeon isolated from a deep-sea hydrothermal vent in the north Fiji Basin. Int $\mathbf{J}$ Syst Bacteriol. 46(4):1113-9.

Gonzalez, J. M., D. Sheckells, M. Viebahn, D. Krupatkina, K. M. Borges and F. T. Robb. 1999. Thermococcus waiotapuensis sp. nov., an extremely thermophilic archaeon isolated from a freshwater hot spring. Arch. Microbiol. 172(2):95-101.

Grieshaber, M. K. and S. Völkel. 1998. Animal adaptations for tolerance and exploitation of poisonous sulfide. Ann. Rev. Physiol. 60:33-53.

Haymon, R. M., D. J. Fornari, K. L. Von Damm, M. D. Lilley, M. R. Perfit, J. M. Edmond, W. C. I. Shanks, R. A. Lutz, J. M. Grebmeier, S. Carbotte, W. D., E. McLaughlin, M. Smith, N. Beedle and E. Olson. 1993. Volcanic eruption of the mid-ocean ridge along the East Pacific Rise crest at $9^{\circ} 45-52 ' N$ : Direct submersible observations of seafloor phenomena associated with an eruption event in April 1991. Earth Planet. Sci. Lett. 119:85-101.

Holmes, J. D., D. J. Richardson, S. Shaheen, R. Evans-Gowing, D. A. Russell and J. R. Sodeau. 1997. Cadmium-specific formation of metal sulfide 'Q-particles' by Klebsiella pneumoniae. Microbiology. 143:2521-2530.

Jannasch, H. W., C. O. Wirsen, S. J. Molyneaux and T. A. Langworthy. 1992. Comparative physiological studies on hyperthermophilic archaea isolated from deep-sea hot vents with emphasis on Pyrococcus strain GB-D. Appl. Environ. Microbiol. 58(11):34723481.

Jonas, R. B. and J. H. Tuttle. 1996. Comparative microbial diversity and ecophysiology in Bahamian Blue Holes of differing sulfidic regimes. 95th Meeting of the American Society of Microbiology, New Orleans, LA,

Karlström, A. R. and R. L. Levine. 1991. Copper inhibits the protease from human immunodeficiency virus 1 by both cysteine-dependent and cysteine-independent mechanisms. Proc. Natl. Acad. Sci. USA. 88:5552-5556.

Lee, W. J. and D. J. Patterson. 1998. Diversity and geographic distribution of free-living heterotrophic flagellates - analysis by PRIMER. Protist. 149:229-244.

Lilley, M. D., D. A. Butterfield, E. J. Olson, J. E. Lupton, S. A. Macko and R. E. McDuff. 1993. Anomalous $\mathrm{CH}_{4}$ and $\mathrm{NH}_{4}$ concentrations at an unsedimented mid-ocean ridge hydrothermal system. Nature. 364:45. 
Mann, E. L., P. Lam, H. Hsu, S. W. Chisholm and J. W. Moffett. 2000. Does Copper Influence the Distribution of Prochlorococcus in the Sargasso Sea? AGU Ocean Sciences Meeting, San Antonio, TX,

Martell, A. E. and R. M. Smith. 1993. NIST Critical Stability Constants of Metal Complexes Database.

Matsuyama, M. and S.-W. Moon. 1997. Feeding of a hypotrichous ciliate swimming in the $\mathrm{H}_{2} \mathrm{~S}$ layer of Lake Kaiike on Chromatium sp. Japan. J. Limnol. 58(1):61-67.

Mehra, R. K. and D. R. Winge. 1991. Metal ion resistance in fungi: molecular mechanisms and their related expression. J. Cell. Biochem. 45:30-40.

Moffett, J. W. and J. Ho. 1996. Oxidation of cobalt and manganese in seawater via a common microbially catalyzed pathway. Geochim. Cosmochim. Acta. 60(18):34153424.

Nelson, D. C. and C. R. Fisher. 1995. Chemoautotrophic and methanotrophic endosymbiotic bacteria at deep-sea vents and seeps, pp. 125-168. In D. M. Karl [ed.], The Microbiology of Deep-Sea Hydrothermal Vents. CRC Press.

Novarino, G., A. Warren and N. E. Kinner. 1999. Diversity of groundwater protists in relation to environmental pollution. 4th International Symposium on Subsurface Microbiology, Vail, Colorado.

Paerl, H. W., J. L. Pinckney and T. F. Steppe. 2000. Cyanobacterial-bacterial mat consortia: examining the functional unit of microbial survival and growth in extreme environments. Environ. Microbiol. 2:11-26.

Patterson, D. J. and T. Fenchel. 1990. Massisteria marina Larsen \& Patterson 1990, a widespread and abundant bacterivorous protist associated with marine detritus. Mar. Ecol. Prog. Ser. 62:11-19.

Patterson, D. J., K. Nygaard, G. Steinberg and C. M. Turley. 1993. Heterotrophic flagellates and other protists associated with oceanic detritus throughout the water column in the mid North Atlantic. J. Mar. Biol. Assoc. U.K. 73:67-95.

Patterson, D. J. and A. G. B. Simpson. 1996. Heterotrophic flagellates from coastal marine and hypersaline sediments in Western Australia. Europ. J. Protistol. 32:423-448.

Prescott, L. M., M. K. Kubovec and D. Tryggestad. 1977. The effects of pesticides, polychlorinated biphenyls and metals on the growth and reproduction of Acanthamoeba castellanii. Bull. Env. Contam. Toxicol. 18(1):29-34. 
Ramsay, L. M. and G. M. Gadd. 1997. Mutants of Saccharomyces cerevisiae defective in vacuolar function confirm a role for the vacuole in toxic metal ion detoxification. FEMS Microbiol. Lett. 152:293-298.

Rijstenbil, J. W., A. Sandee, J. Van Drie and J. A. Wijnholds. 1994. Interaction of toxic trace metals and mechanisms of detoxification in the planktonic diatoms Ditylum brightwellii and Thalassiosira pseudonana. FEMS Microbiol. Rev. 14:387-396.

Rozan, T. F., G. Benoit and G. W. I. Luther. 1999. Measuring Metal Sulfide Complexes in Oxic River Waters with Square Wave Voltammetry. Environ. Sci. Technol. 33:3021-3026.

Seyfried, W. E., Jr. and M. J. Mottl. 1995. Geological Setting and Chemistry of Deep-Sea Hydrothermal Vents, pp. 1-34. In D. M. Karl [ed.], The Microbiology of Deep-Sea Hydrothermal Vents. CRC Press.

Silver, M. W. and A. L. Alldredge. 1981. Bathypelagic marine snow: deep-sea algal and detrital community. J. Mar. Res. 39:501-530.

Silver, M. W., M. M. Gowing, D. C. Brownlee and J. O. Corliss. 1984. Ciliated protozoa associated with oceanic sinking detritus. Nature. 309:246-248.

Small, E. B. and M. E. Gross. 1985. Preliminary observations of protistan organisms, especially ciliates, from the $21^{\circ} \mathrm{N}$ hydrothermal vent site. Biol. Soc. Wash. Bull. 6:401410.

Stetter, K. O., R. Huber, E. Blöchi, M. Kurr, R. D. Eden, M. Felder, H. Cash and I. Vance. 1993. Hyperthermophilic archaea are thriving in deep North Sea and Alaskan oil reservoirs. Nature. 365:743-745.

Stoecker, D. K., W. G. Sunda and L. H. Davis. 1986. Effects of copper and zinc on two planktonic ciliates. Mar. Biol. 92:21-29.

Sunda, W. G. 1989. Trace metal interactions with marine phytoplankton. Biol. Oceanogr. 6:411-442.

Sunda, W. G. and S. A. Huntsman. 1988. Effect of sunlight on redox cycles of manganese in the southwestern Sargasso Sea. Deep-Sea Res. 35(8):1297-1317.

Sunda, W. G. and S. A. Huntsman. 1996. Antagonisms between cadmium and zinc toxicity and manganese limitation in a coastal diatom. Limnol. Oceanogr. 41(3):373-387.

Sunda, W. G. and S. A. Huntsman. 1998a. Interactive effects of external manganese, the toxic metals copper and zinc, and light in controlling cellular manganese and growth in a coastal diatom. Limnol. Oceanogr. 43(7):1467-1475. 
Sunda, W. G. and S. A. Huntsman. 1998b. Processes regulating cellular metal accumulation and physiological effects: Phytoplankton as model systems. Science of the Total Environment. 219(2-3):165-181.

Sunda, W. G., S. A. Huntsman and G. R. Harvey. 1983. Photoreduction of manganese oxides in seawater and its geochemical and biological implications. Nature. 301:234236.

Taylor, C. D: and C. O. Wirsen. 1997. Microbiology and ecology of filamentous sulfur formation. Science. 277:1483-1485.

Taylor, C. D., C. O. Wirsen and F. Gaill. 1999. Rapid microbial production of filamentous sulfur mats at hydrothermal vents. Appl. Environ. Microbiol. 65(5):2253-2255.

Turley, C. M., K. Lochte and D. J. Patterson. 1988. A barophilic flagellate isolated from $4500 \mathrm{~m}$ in the mid-North Atlantic. Deep-Sea Res. 35(7):1079-1092.

Von Damm, K. L. 1990. Seafloor hydrothermal activity: black smoker chemistry and chimneys. Annu. Rev. Earth Planet. Sci. 18:173-204.

Von Damm, K. L., J. M. Edmond, B. Grant, C. I. Measures, B. Walden and R. F. Weiss. 1985a. Chemistry of submarine hydrothermal solutions at $21^{\circ} \mathrm{N}$, East Pacific Rise. Geochim Cosmochim Acta. 49:2197.

Von Damm, K. L., J. M. Edmond, C. I. Measures and B. Grant. 1985b. Chemistry of submarine hydrothermal solutions at Guaymas Basin, Gulf of California. Geochimica et Cosmochimica Acta. 49:2221-2237.

Von Damm, K. L., S. E. Oosting, R. Kozlowski, L. G. Buttermore, D. C. Colodner, H. N. Edmonds, J. M. Edmond and J. M. Grebmeier. 1995. Evolution of East Pacific Rise hydrothermal vent fluids following a volcanic eruption. Nature. 375:47-50.

Welhan, J. A. and H. Craig. 1983. Methane and hydrogen and helium in hydrothermal fluids of $21^{\circ} \mathrm{N}$ on the East Pacific Rise, pp. 391-409. In P. A. Rona, K. Bostrom, L. Laubier and K. L. J. Smith [ed.], Hydrothermal Processes at Seafloor Spreading Centers. Plenum Press.

Westall, J. C., J. L. Zachery and F. M. M. Morel. 1976. MINEQL, A computer program for the calculation of Chemical Equilibrium Composition of Aqueous Systems. Civil Engineering Dept. (MTT), Cambridge, MA.

White, C. and G. M. Gadd. 1998. Reduction of metal cations and oxyanions by anaerobic and metal-resistant microorganisms: chemistry, physiology, and the potential for the control and bioremediation of toxic metal pollution, pp. 233-254. In K. Horikoshi and 
W. D. Grant [ed.], Extremophiles: Microbial Life in Extreme Environments. WileyLiss.

Wong, S. L., J. F. Wainright and J. Pimenta. 1995. Quantification of total and metal toxicity in wastewater using algal bioassays. Aq. Toxicol. 31:57-75.

Wu, J. S., H. Y. Sung and R. H. Juang. 1995. Transformation of cadmium-binding complexes during cadmium sequestration in fission yeast. Biochem. Mol. Biol. Int. 36:1169-1175. 


\section{Chapter 7}

\section{General Conclusions}


Culturing and Molecular Analysis. When the concept for this study was developing, I had the idea that vent environments must harbor novel species of flagellates unknown to science. I especially wanted to find and isolate thermophilic protists whose thermal-stable DNA replication systems would have much higher fidelity in PCR biotechnologies than do the currently-used prokaryotic polymerases. Such flights of fancy were dashed when the results of culturing the first vent samples became apparent. Instead of finding novel flagellates that would make my fortune, I cultured and isolated only very well-known, well-described species. Disappointment soon gave way to a more realistic assessment of the situation at hand: while the sampling and culturing methods used in this work certainly had selected for the species isolated it appeared that cosmopolitan species were present at, and perhaps significant members of, vent ecosystems. This evolving realization played a very large role in the later development of the sulfide and metals experiments, which were designed for the most common species, rather than unique or less common ones. A new hypothesis has been advanced, which suggests that ubiquity in occurrence patterns implies high tolerance or adaptability to a wide range of environmental conditions. In other words, the most common species are common because they are able to tolerate and adapt to whatever conditions they encounter in nature. This hypothesis was born out of the results of culturing, molecular analysis and the physiological experiments presented here.

The combined use of culturing and denaturing gradient gel electrophoresis was successful because the results of one supported the results of the other, thereby strengthening the results of both. The power of DGGE became apparent as this is the first time all cultured species from an environmental sample have been selectively retrieved by an independent molecular method. DGGE was also able to resolve distribution patterns better than culturing, as shown in Table 4.2. Although time and sample intensive, DGGE was a very useful tool for discerning ecologically-relevant questions concerning the complex and remote environments of deep-sea hydrothermal vents. 
Another testament to the power of the combined approach was the tangential discovery of the phylogenetic importance of Ancyromonas. Culturing alone would have revealed its presence at vents and the ultrastructural work of others had hinted at its potential importance (Cavalier-Smith 1998), but it took the molecular analysis of cultured isolates in Chapters $2 \& 3$ to fit the piece into the puzzle. However, the fit remains tenuous, as the resolving power of $18 \mathrm{~S}$ ssrDNA phylogenies comes into question. Yet the work here has laid the foundation for future molecular analysis of this very important area in eukaryote phylogeny.

Physiological Experiments. The results of the pressure experiments in Chapter 5 indicated that barotolerance and/or reversible encystment at high pressures are mechanisms by which sinking flagellates could reseed upper water-column populations if advection processes could transport cells and cysts up and away from inhibitory pressures. If this process does occur, the implications are significant for benthic/pelagic coupling in the open ocean. For one, there would be a continuous supply of flagellates for reseeding depleted pelagic populations following seasonal or catastrophic events (ENSO?). Population flow does not have to be unidirectional, a suggestion supported by the results of phylogenetic analysis of ssrDNA and physiological responses to extreme chemical conditions, both of which show that there is no difference between vent and shallow-water strains of the same species (an exception to this suggestion may be pressure adaptation in vent strains shown in Chapter 5). And finally, the whole process from sinking to tolerance and adaptation at vents to redelivery and reseeding in surface waters would selectively amplify tolerant species over less tolerant ones, resulting in cosmopolitanism of tolerant species.

The results in Chapter 6 , show the degree of tolerance in these cosmopolitan species. Figure 6.5 clearly illustrates that the three species tested are among the most tolerant eukaryotes studied. One of the most important results of these experiments is the evidence in support of these species ability to be active members of vent communities. Taken together with evidence provided in Chapters $2 \& 4$ of their presence at vents, the evidence in 
Chapter 6 indicates that they can be both present and active under vent conditions. Finally, the results in Chapter 6 offer additional support in favor of the hypothesis that ubiquity in occurrence patterns implies high tolerance or adaptability to a wide range of environmental conditions.

Summary. Figure 7.1 summarizes the results and implications of this thesis. Heterotrophic, bacterivorous flagellates are integral members of the microbial food webs found in most of the habitable environments on Earth (Azam and Ammerman 1984; Azam et al. 1983; Caron et al. 1982; Fenchel 1982). Many of the species cultured and isolated from deep-sea vents are ubiquitous species belonging to a small but commonly-occurring group with global distribution (Lee and Patterson 1998). They have been described in environments as diverse as terrestrial garden soils (Ekelund and Patterson 1997), hypersaline sediments (Patterson and Simpson 1996), freshwater lakes and streams (Lee and Patterson 1998; Patterson and Hedley 1992), the marine water column (Caron 1991; Patterson et al. 1993; Silver and Alldredge 1981), the deep-sea benthos (Atkins et al. 1998; Turley et al. 1988), and now deep-sea hydrothermal vents (Atkins et al. in press). Heterotrophic flagellates have been shown to be associated with sinking particulate matter (Caron 1991; Silver and Alldredge 1981; Silver et al. 1984; Silver et al. 1978) that has the potential to deliver cells to deep-sea vents. Once there, heterotrophic flagellates can survive extreme vent conditions such as pressure (Atkins et al. 1998), acidic $\mathrm{pH}$, and high concentrations of toxic metals and sulfide (Atkins et al. submitted). Advective processes such as entrainment in plume waters and diffusive, vertical transport have the potential to deliver cells and cysts well above the vent field, where reseeding of flagellate populations may occur (Atkins et al. 1998). Taken together, these processes could contribute to the phenomenon of cosmopolitanism as observed in this research and by others. 
Figure 7.1. A diagram summarizing the results of this thesis, which support the hypothesis that ubiquity in occurrence patterns among heterotrophic flagellates implies high tolerance and/or adaptability to a wide range of environmental conditions. 


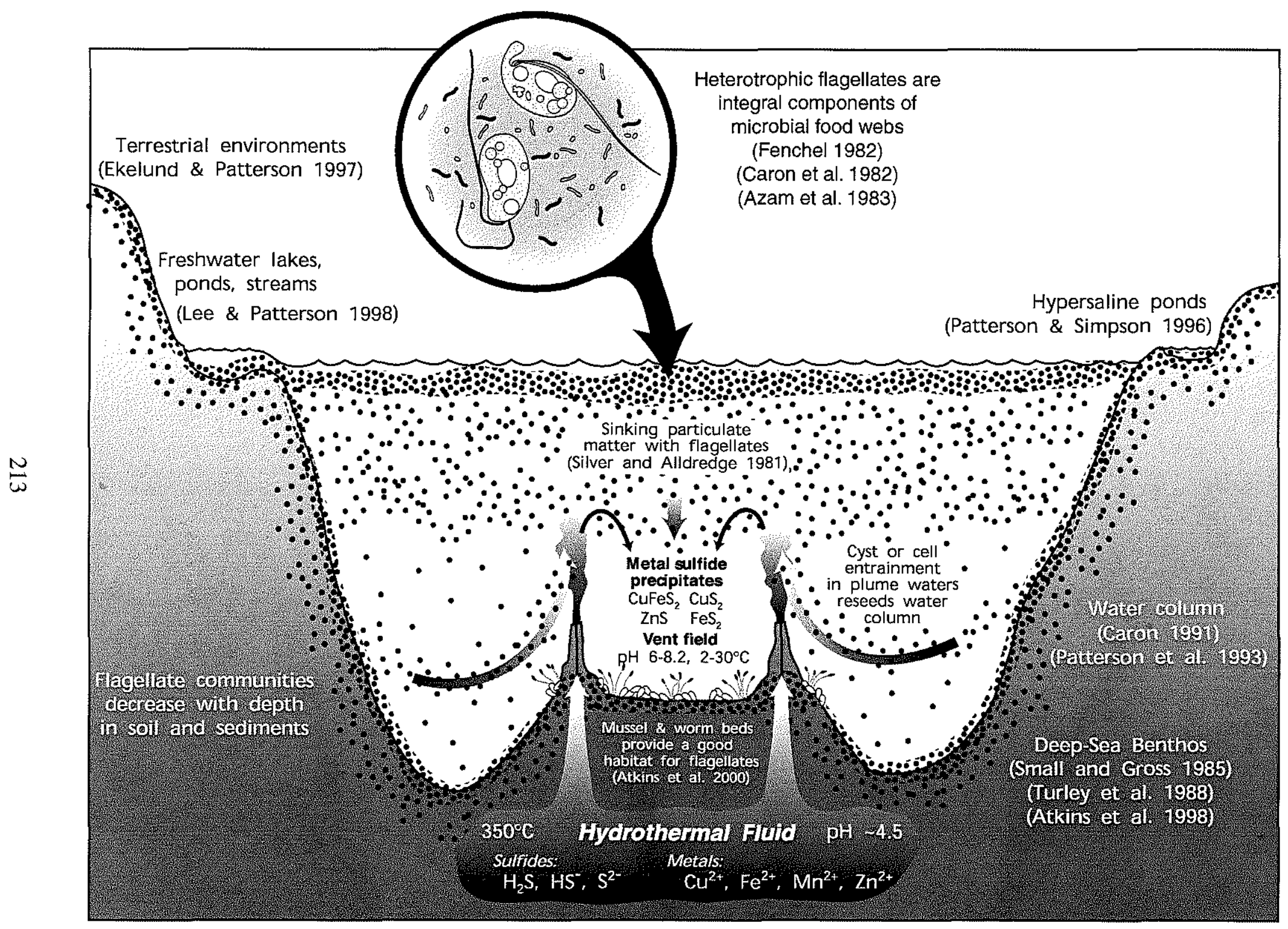




\section{References}

Atkins, M. S., O. R. Anderson, and C. O. Wirsen. 1998. Effect of hydrostatic pressure on the growth rates and encystment of flagellated protozoa isolated from a deep-sea hydrothermal vent and a deep shelf region. Mar. Ecol. Prog. Ser., 171:85-95.

Atkins, M. S., M. A. Hanna, E. A. Kupetsky, M. A. Saito, C. D. Taylor, and C. O. Wirsen. submitted. Tolerance of flagellated protozoa to extreme environmental conditions potentially encountered at deep-sea hydrothermal vents: I. High sulfide; II. High concentrations of $\mathrm{Cu}, \mathrm{Fe}, \mathrm{Mn}$ and $\mathrm{Zn}$. Limnol. Oceanogr.

Atkins, M. S., A. P. Teske, and O. R. Anderson. 2000. A Survey of Flagellate Diversity at Four Deep-Sea Hydrothermal Vents in the Eastern Pacific Ocean Using Structural and Molecular Approaches. J. Euk. Microbiol., 47(4): In Press.

Azam, F., and J. W. Ammerman. 1984. Cycling of organic matter by bacterioplankton in pelagic marine ecosystems: microenvironmental considerations. In: Fasham, M. J. R. (ed.), Flows of energy and materials in marine ecosystems, Plenum Publishing Corp., New York. pp. 345-360.

Azam, F., T. Fenchel, J. G. Field, J. S. Gray, L. A. Meyer-Reil, and F. Thingstad. 1983. The ecological role of water-column microbes in the sea. Mar. Ecol. Prog. Ser., 10:257-263.

Caron, D. A. 1991. Heterotrophic flagellates associated with sedimenting detritus. In: Patterson, D. J. and J. Larsen (ed.), The Biology of Free-Living Heterotrophic Flagellates, Special Volume 45. Clarendon Press, Oxford. pp. 77-92.

Caron, D. A., P. G. Davis, L. P. Madin, and J. M. Sieburth. 1982. Heterotrophic bacteria and bacterivorous protozoa in oceanic macroaggregates. Science, 218:795-797.

Cavalier-Smith, T. 1998. Neomonadida and the origin of animals and fungi. In: Coombs, G. H., K. Vickerman, M. A. Sleigh, and A. Warren (ed.), Evolutionary Relationships Among Protozoa, Klewer Academic Publishers, London. pp. 375-407.

Ekelund, F., and D. J. Patterson. 1997. Some heterotrophic flagellates from a cultivated garden soil in Australia. Arch. Protistenkd., 148:461-478.

Fenchel, T. 1982. Ecology of heterotrophic microflagellates. III. Adaptations to heterogeneous environments. Mar. Ecol. Prog. Ser., 9:25-33.

Lee, W. J., and D. J. Patterson. 1998. Diversity and geographic distribution of free-living heterotrophic flagellates - analysis by PRIMER. Protist, 149:229-244.

Patterson, D. J., and S. Hedley. 1992. Free-Living Freshwater Protozoa: A Color Guide, CRC Press, Boca Raton. 
Patterson, D. J., K. Nygaard, G. Steinberg, and C. M. Turley. 1993. Heterotrophic flagellates and other protists associated with oceanic detritus throughout the water column in the mid North Atlantic. J. Mar. Biol. Assoc. U.K., 73:67-95.

Patterson, D. J., and A. G. B. Simpson. 1996. Heterotrophic flagellates from coastal marine and hypersaline sediments in Western Australia. Europ. J. Protistol., 32:423-448.

Silver, M. W., and A. L. Alldredge. 1981. Bathypelagic marine snow: deep-sea algal and detrital community. J. Mar. Res., 39:501-530.

Silver, M. W., M. M. Gowing, D. C. Brownlee, and J. O. Corliss. 1984. Ciliated protozoa associated with oceanic sinking detritus. Nature, 309:246-248.

Silver, M. W., A. L. Shanks, and J. D. Trent. 1978. Marine snow: microplankton habitat and source of small-scale patchiness in pelagic populations. Science, 201:371-373.

Turley, C. M., K. Lochte, and D. J. Patterson. 1988. A barophilic flagellate isolated from $4500 \mathrm{~m}$ in the mid-North Atlantic. Deep-Sea Res., 35(7):1079-1092. 


\section{Abbreviations and Acronyms}

A

ATCC

atm

bp

BRM

BSZ

C

${ }^{\circ} \mathrm{C}$

ca.

CAS

CBR

d

DFS

DGGE

DNA

ed.

eds.

EDTA

e.g.

EPM

et

et al.

EWM

F

$\mathrm{g}$

G

GBB

gen

h

i.e.

JDF

$\mathrm{k}$ adenine

American Type Culture Collection

atmospheres

base pairs

Biovent Riftia and Mussels ( $9^{\circ} \mathrm{N}$ vent station)

Biovent Serpulid Zone ( $9^{\circ} \mathrm{N}$ vent station)

cytosine

degree Celsius

circa (around)

Clam Acres Spire ( $21^{\circ} \mathrm{N}$ vent station)

Chesapeake Bay (MD) Rhynchomonas

day

Dante Flange Substrates (JDF vent sample)

denaturing gradient gel electrophoresis

deoxyribonucleic acid

editor

editors

ethylene diamine tetraacetic acid

exempli gratia (for example)

Eel Pond Marsh (Woods Hole, MA)

and

et alia (and others)

East Wall Mussels ( $9^{\circ} \mathrm{N}$ vent station)

forward

gram

guanine

Guaymas Basin Beggiatoa (Guaymas vent sample)

genus or genera

hour

id est (that is)

Juan De Fuca (vent site)

kilo- $\left(10^{3}\right)$ 


\begin{tabular}{|c|c|}
\hline $\mathrm{K}$ & $\mathrm{G}$ or $\mathrm{T}$ \\
\hline $\mathrm{kbp}$ & kilobase pairs \\
\hline 1 & liter \\
\hline LFS & Lobo Flange Substrates (JDF vent sample) \\
\hline LRT & likelihood ratio test \\
\hline$\mu$ & micro- $\left(10^{-6}\right)$ \\
\hline$\mu \mathrm{m}$ & micrometer \\
\hline $\mathrm{m}$ & milli- $\left(10^{-3}\right)$ or meter \\
\hline $\mathrm{ml}$ & milliliter \\
\hline $\mathrm{mm}$ & millimeter \\
\hline $\mathbf{M}$ & molar or Mega $\left(10^{6}\right)$ \\
\hline $\mathrm{M}$ & $\mathrm{C}$ or $\mathrm{A}$ \\
\hline $\mathrm{ME}$ & minimum evolution \\
\hline $\min$ & minute \\
\hline ML & maximum likelihood \\
\hline MP & maximum parsimony \\
\hline MPN & most-probable-number \\
\hline $\mathrm{n}$ & number \\
\hline $\mathrm{NBH}$ & New Bedford Harbor, MA \\
\hline nov. & novum (new) \\
\hline NTA & nitrilotriacetic acid \\
\hline PAUP & phylogenetic analysis using parsimony \\
\hline PCR & polymerase chain reaction \\
\hline pers. comm. & personal communication \\
\hline $\mathrm{R}$ & A or $\mathrm{G}$ \\
\hline $\mathrm{R}$ & reverse \\
\hline rDNA & rRNA encoding gene \\
\hline RDP & Ribosomal Database Project \\
\hline rRNA & ribosomal ribonucleic acid \\
\hline$S$ & $\mathrm{C}$ or $\mathrm{G}$ \\
\hline SD & standard deviation \\
\hline SDS & sodium dodecyl sulfate \\
\hline $\sec$ & second \\
\hline SEM & scanning electron microscopy \\
\hline
\end{tabular}


sp.

spp.

ssrDNA

ssrRNA

$\mathrm{T}$

TAE

TBR

TEM

TPC

$\mathrm{V}$

VENT

VSW

W

(w/v)

Y

yr species (singular)

species (plural)

small subunit ribosomal DNA

small subunit ribosomal RNA

thymine

Tris-Acetate-EDTA

tree-bisection-reconnection

transmission electron microscopy

Twin Peaks Chimney ( $21^{\circ} \mathrm{N}$ vent station)

voltage

$9^{\circ} \mathrm{N}$ vent water sample

Vineyard Sound Water

A or $\mathrm{T}$

weight per volume

$\mathrm{C}$ or $\mathrm{T}$

year 
Contributions to publications presented in this dissertation:

\section{Part I}

Chapter 2. A survey of flagellate diversity at four deep-sea hydrothermal vents in the Eastern Pacific Ocean using structural and molecular approaches.

By M. S. Atkins, A. P. Teske and O. R. Anderson.

Concept by M. S. Atkins, A. P. Teske and O. R. Anderson.

Preparation of samples for sequencing by M. S. Atkins.

Phylogenetic analysis performed by M. S. Atkins and A. P. Teske.

Electron microscopy and images done by O. R. Anderson.

Manuscript written by M. S. Atkins.

Edited by A. P. Teske and O. R. Anderson.

Chapter 3. Ancyromonadida: a new phylogenetic lineage among the protozoa closely related to the common ancestor of Metazoans, Fungi, and Choanoflagellates (Opisthokonta).

By M. S. Atkins, A. G. McArthur and A. P. Teske.

Concept by M. S. Atkins and A. P. Teske

Analysis and manuscript preparation by all co-authors.

Chapter 4. Detection and distribution patterns of kinetoplastid flagellates at deep-sea hydrothermal vents as determined by culturing and denaturing gradient gel electrophoresis.

By M. S. Atkins and A. P. Teske.

Concept by M. S. Atkins and A. P. Teske.

Experiments performed by M. S. Atkins.

Manuscript written by M. S. Atkins and edited by A. P. Teske.

\section{Part II}

Chapter 5. Effect of hydrostatic pressure on the growth rates and encystment of flagellated protozoa isolated from a deep-sea hydrothermal vent and a deep shelf region.

By M. S. Atkins, O. R. Anderson and C. O. Wirsen.

Concept by M. S. Atkins, C. O. Wirsen, and D. A. Caron.

All experiments performed by M. S. Atkins.

Manuscript written by M. S. Atkins.

Edited by O. R. Anderson and C. O. Wirsen.

Chapter 6. Tolerance of flagellated protozoa to extreme environmental conditions potentially encountered at deep-sea hydrothermal vents: $I$. High sulfide; II. High concentrations of $\mathrm{Cu}, \mathrm{Fe}, \mathrm{Mn}$, and $\mathrm{Zn}$.

By M. S. Atkins, M. A. Hanna, E. A. Kupetsky, M. A. Saito, C. D. Taylor and C. O. Wirsen.

Concept by M. S. Atkins, C. O. Wirsen, C. D. Taylor, J. Moffett, M. Saito.

Experiments performed by M. S. Atkins, M. A. Hanna and E. A. Kupetsky. Manuscript written by all co-authors. 


\section{Acknowledgements}

I would like to thank the following people and funding agencies for their help and support:

Atkins Family: Mom, Dad, David, Brandt, Douglas, Philip, and Scot

Friends: Larry Newsome, Eliza Garfield, Mike Gerzewitz

Bill Shaw, Lihini, Joe Warren, Regina, Brian Arbic, Doc Reddy, Amos, Ross, Danny and Ellen S., Craig, Peter, and other WHOI housing "housemates" Sean Callahan and Matt Sullivan for squash at MIT and other diversions BLee Williams, Matt Heinz, Dave Olds and Pat Hickey for fun on and offshore Anne Sell, Heather Hunt, Anne Metaxas, Barbara Neihoff and Aleka Andrew McArthur, Jeff Silberman and others from MBL Steve Molyneaux, Dave Kulis and Mark Dennett for all their help over the years The California crew: Gary Gaje, Amanda Aymar, Margaret Hinebaugh and Mindy WHOI 94's and others: Ee Lin, Gaspar, Gorka, Susan A., Pulcherie, Celine, Brenda and Eric, Patrick Miller, Eli, Yale, Omak, Akiko, Karin and Dag, Graziella, Carolina, Magda Hanna, Erine Kupetsky, Kirsten, Jen Mixsis, Yvonne Campbell,

\section{AND}

\section{Nicole}

Mark and Deb Albert and family, Ken and Vicky Page, and many others for helping me feel like part of a larger community than just the one here in Woods Hole.

$$
\text { and many, many others! }
$$

Committee Members: Carl Wirsen, Lauren Mullineaux, Roger Anderson, and Harry Hemond and a special thanks to Ken Halanych

Advisors: Craig Taylor and Andreas Teske

Funding Sources:

The WHOI Education Office (and people: Julia, Stella, Marcie, Judy and John) The National Science Foundation The Rhinehart Coastal Research Center The PADI Foundation 